UNIVERSIDAD NACIONAL DE LA PLATA FACULTAD DE CIENCIAS JURÍDICAS Y SOCIALES

INSTITUTO DE DERECHOS HUMANOS MAESTRÍA EN DERECHOS HUMANOS

\title{
LA REPRESION SELECTIVA DEL ESTADO SOBRE AGRUPAMIENTOS SINDICALES NO LEGITIMADOS
}

Tesis presentada como requisito para la obtención del título de Magíster en Derechos Humanos por la Universidad Nacional de La Plata

Maestrando: Darío Alejandro Cocetta

Co-Directores de tesis: Dr. Fabián Quintero y Dr. Rodolfo E. Capón Filas 


\section{INTRODUCCION.}

El primer llamado de atención sobre represión policial selectiva, desatada sobre grupos organizados de trabajadores y trabajadoras que no respondían al oficialismo de sus sindicatos -que es el interés primario que motivó este estudio-, se presentó a mediados de 2008, en momentos en que por razones laborales tenía contacto asiduo con personas que vivían y trabajaban en el conurbano bonaerense. Con mecánica persistencia, se detectaban en todo ese territorio, conflictos acotados a un establecimiento o empresa, protagonizados por los trabajadores y trabajadoras, $y$ desmedidamente reprimidos por las fuerzas de seguridad (provinciales o nacionales) o por "grupos de choque" que actuaban aparentemente con zonas liberadas.

Con Ilamativa coincidencia, sobre el pequeño universo de casos que podía advertir -y en una primer mirada-, los conflictos en los lugares de trabajo que eran liderados por conducciones no alineadas al oficialismo del sindicato representativo respectivo, se desactivaban a partir de una fuerte intervención de las fuerzas de seguridad. Paradójicamente, otros muchos conflictos, incluso algunos de trascendencia pública, no llegaban a ningún grado de hostigamiento represivo.

Además llamaba la atención, la coordinación -o aparente complicidad- de todo el sistema institucional estatal ante la acción represiva que llevaba adelante el mismo estado. Una acción represiva, ejercida sobre actos lícitos y reconocidos expresamente por el propio ordenamiento. Todo ello, en el medio del más llamativo de los silencios de los despachos oficiales.

Un estudio complementario a esta investigación -me aventurodemostraría, que casi en su totalidad, las represiones dispuestas en el período estudiado se llevaron adelante sin que mediara orden judicial alguna que les brindara fundamento.

Una complicidad de dimensiones, que llega al paroxismo cuando un Secretario de Seguridad de la Provincia de Buenos Aires, frente a las requisitorias formales de organizaciones de la sociedad civil, representantes obreros y legisladores provinciales que reclamaban explicaciones de la 
inusitada ola de represión que era evidente en vastos sectores del conurbano, desconocía - sin inmutarse- la movilización de trescientos (300) efectivos de su propia fuerza que se encontraban ocupando -en ese momento- un establecimiento fabril ubicado en la misma zona norte del Gran Bs As. ${ }^{1}$ Obviamente, nadie puede creer que puedan movilizarse en un procedimiento trescientos efectivos en una regional o departamental de la policía bonaerense, y sus principales responsables políticos no tengan conocimiento de ello. Se pudo corroborar con posterioridad, que los efectivos movilizados carecían de orden judicial que dispusiera la militarización de la planta. ${ }^{2}$ Allí estaba en parte, la respuesta al por qué del silencio del funcionario.

Habiendo comenzado a prestar atención a los conflictos, y pasaba algo particularmente significativo en aquellos que se desarrollaban en los establecimiento, pero no siempre. Era muy llamativo que cuando aparecían liderando agrupamientos sindicales disidentes de las conducciones oficiales de sus sindicatos, se configuraba una situación de tensión creciente que solo se detenía cuando se desataba la represión para desactivar el conflicto. En la mayoría de los casos de que se tenía conocimiento, esa violencia la llevaban adelante las fuerzas de seguridad.

Era posible, que detrás de esas aparentes coincidencias, hubiese una conducta institucional oculta y contraria a derecho; y que también pudiese encontrarse un algoritmo que desnudara los hechos que los conforman y las condiciones en que se desata. Demostrando ello, quedaría a la luz del días los posibles intereses que los impulsan, los derechos que esa sistematicidad violentan; y en definitiva, proponer respuestas jurídicas de conformidad a las mandas que exige nuestra constitución.

Motivado por estas primeras reflexiones producto de la observación, comencé a desarrollar la idea de encontrar una forma de contrastar una hipótesis que me surgía claramente, y que consistía en que "Cuando agrupamientos de trabajadores no legitimados lideran acciones colectivas

${ }^{1}$ http://ptszonanorte.blogspot.com.ar/2009/09/legisladora-plantea-retiroinmediato-de.html

${ }^{2}$ http://ptszonanorte.blogspot.com.ar/2009/09/legisladora-plantea-retiroinmediato-de.html 
de altísima intensidad en sus lugares de trabajo, en momentos de disputa con otros grupos sindicales legitimados, el estado recurre en forma selectiva al uso de la fuerza para evitar (impidiendo) el surgimiento deestos nuevos grupos sindicales no legitimados". 


\section{ESCENARIO ECONOMICO $Y$ CONFLICTIVIDAD LABORAL EN EL PERIODO 2007-2013.}

\section{La economía durante el período 2007-2013.}

Nuestro estudio se realiza en un tiempo que va de enero de 2007 a diciembre de 2013, y en un espacio concreto, diez (10) distritos de la zona norte de Gran Bs. As. Los municipios que corresponden a la competencia de los Departamentos Judiciales provinciales de San Isidro y San Martín. La conflictividad laboral y la respuesta estatal represiva, deben ser observadas en un contexto económico y de conflictividad general determinado.

En primer término podríamos señalar, que este período comienza a transcurrir coincidentemente con el segundo lustro de la administración Kirchner - Fernández de Kirchner,y se caracterizará por el desmejoramiento macroeconómico de nuestra economía. El nivel de actividad económica desde el inicio de su gobierno en mayo 2003 (en realidad hay coincidencias en observar esta tendencia desde el año 2002) hasta fines de 2007 tiene una trayectoria creciente y sostenida. A partir de esta última fecha, se vuelve sinuosa, con claros momentos de declinación (en 2009 y 2012), y "una tendencia general todavía positiva pero de mucho menor dinamismo que en la fase precedente" (Frenkel , R. y Damill , M. : 2013, pág.2). Con idéntica mirada el centro de estudios CENDA -afín a la administración del gobierno- calificaba a este período como "La etapa rosa" (CENDA: 2010, pág. 40).

La etapa virtuosa que comienza a abandonarse en 2007, había iniciado con medidas económicas que promovían la producción nacional y el empleo (abandono de la paridad 1 a 1 con el dólar, y con la fuerte depreciación de nuestra moneda se producía la modificación favorable de nuestros precios relativos, y el aumento de nuestra competitividad). La misma venía a romper los cánones de la década pasada (Frenkel, R. y Damill , M. : 2013, pág.3)³. Sostienen, la misma afirmación núcleos

3"Estrangulada por la apreciación cambiaria, el aumento exponencial del
endeudamiento externo, y las limitaciones que imponía a la política 
intelectuales que nutrieron de cuerpos técnicos a la administración (CENDA: 2010, pág.37). Esa reactivación económica tuvo un rápido reflejo positivo en los incrementos en la ocupación laboral y en los salarios. El escenario económico del país durante el quinquenio 2003-2007 que se abandonaba, resultó claramente favorable ${ }^{4}$.

En el año 2007, las crisis internacionales y el viraje en el rumbo económico señalan el cambio en esta tendencia. En relación a las reiteradas crisis cíclicas del sistema internacional, se debe dejar aclarado que si bien incidirán desfavorablemente en el cambio el escenario, su influencia externa no tuvo -como en similares oportunidades de nuestra historia política y económica- la severidad que habitualmente provocaba, afectando centralmente las variables de ocupación y el salario.

Durante este período (2007-2013) concordante con nuestro estudio, aparecerá un proceso de fuerte apreciación de nuestra moneda, que sumado a un contexto externo negativo para la colocación de nuestros productos, incidirá en el registro de una fuerte caída del PIB (caída que se atenuará a través de políticas expansivas fiscales y monetarias).

Las razones que explicitarían para algunos autores esta caída, están directamente vinculadas al cambio en el rumbo de política macroeconómica, y en segundo término por el proceso inflacionario que se desata y acompañará a la gestión hasta 2015. "Como se señalara más arriba, desde inicios de 2007, la orientación de la política macroeconómica abandonó de hecho el principal pilar del esquema establecido en 2002-2003: la preservación de un tipo de cambio real competitivo y estable. Hemos señalado que la aceleración de la inflación y el hecho de que las autoridades no la reconocieran fueron probablemente los principales factores por detrás

macroeconómica el rígido esquema de la convertibilidad, la actividad económica venía siguiendo una tendencia contractiva desde 1998. La prolongada recesión se había acentuado notoriamente desde mediados de 2001" (Frenkel , R. y Damill , M. : 2013, pág.3).

$4 "(U) n$ muy buen desempeño macroeconómico, con un crecimiento promedio del PIB próximo al $9 \%$ anual. La inversión fija repuntó fuertemente y la inflación se mantuvo relativamente baja en el mismo lapso, aunque en paulatino ascenso desde el mínimo posterior a la devaluación, registrado en 2003, que fue de 3,7\% anual . A lo largo del quinquenio se mantuvieron los superávits fiscal y externo, los salarios reales y la ocupación subieron marcadamente, y la distribución del ingreso mejoró de manera apreciable" (Frenkel, R. y Damill, M. : 2013, pág.11) 
de ese cambio" (Frenkel, R. y Damill , M. : 2013, pág..23). Desde el gobierno, el obstáculo central no estaba marcado por la política cambiaria y la apreciación monetaria; sino en el proceso inflacionario al que denominará el talón de Aquiles del esquema de post-convertibilidad (CENDA: 2010, pág.54).

Tengan razón Tirios o Troyanos, caracterizará el período que transita el estudio, la senda del menor dinamismo económico y el crecimiento de la desocupación (CENDA: 2010, pág.181) . Como dato pertinente se destaca, que la fuerte ocupación (tasa de ocupación de tiempo completo en el sector privado) que se pudo observar desde 2002 se frenó abruptamente hacia 2008, manteniéndose en idénticos índices a fines de 2012 (Frenkel , R. y Damill , M. : 2013, pág.22). En modo concordante, los salarios reales que crecieron durante el lustro que precede al año 2007, se estabilizan (20072009) y tendieron a incrementarse pero a un ritmo mucho menor que en el primer quinquenio. Todo en medio de un indetenible proceso inflacionario (una media de 22\% anual en 2008-2012 (Frenkel, R. y Damill , M. : 2013, pág.21).

Ese esquema político de desmejoramiento de precios relativos no varió (ni aún con la victoria electoral de 2011). Que, en lugar de corregir, intentó acotar sus efectos negativos restringiendo las transacciones de los diferentes agentes que intervienen en los distintos mercados; lo que de hecho significó acentuar ese desmejoramiento progresivamente. Estas medidas, sin embargo, no lograron revertir las principales tendencias macroeconómicas problemáticas; entre ellas, el relativo estancamiento productivo y del empleo privado, que es el escenario real en el que se desenvuelven la conflictividad laboral (Frenkel, R. y Damill, M. : 2013, pág.29).

\section{La conflictividad laboral durante el período (2007-2013).}

El escenario de recomposición económica y social que acompañó al primer quinqueniode la administración Kirchner, tuvo como correlato la recomposición del poder sindical (Spaltenberg, R. : 2012, pág. 95). 
En el año 2007, la administración dirigía sus esfuerzos para institucionalizar la conflictividad obrera ${ }^{5}$. Esa institucionalización, se reconoce a través de dos elementos: por el sistemático crecimiento de la negociación colectiva (desde fines del año 2005), constituyéndose en el principal mecanismo de regulación de las relaciones entre trabajadores y trabajadoras y empresarios, articulado desde el Estado (Palomino, H. : 2011, pág.68); y la reunificación de la CGTRA, consolidando la relación entre la administración y las organizaciones sindicales (Etchemendy, S.: 2011, pág.5).

En cuanto a la conflictividad laboral en esta etapa -sin desagregar las causas que las motivan-, en el sector privado (que es el ámbito de observación) los conflictos se extendieron de los servicios a la industria. Particularmente se señala como una caracterización del sub-período 20082009 que "estos conflictos se desarrollarían con una particularidad, la mayoría fueron reprimidos, judicializados, y finalmente aislados finalizando con derrotas para los trabajadores" (Longo, J. : 2011, pág.5).

Desde la crisis del campo y las crisis internacionales (2008-2009) se profundizó la tendencia hacia la descentralización de los conflictos laborales, es decir el crecimiento de los conflictos localizados (que se desarrollan en el nivel de empresa), -que son objeto de nuestro trabajo- con la intervención de sindicatos y seccionales de base.

Un dato destacado para nuestra investigación -en razón a que se manifiesta por los propios funcionarios del MTESS- es señalar que el comportamiento de los conflictos localizados "evidenciaría un implante creciente de las representaciones sindicales en los lugares de trabajo",lo que desde concepciones teóricas del mundo de la sociología reconocen como "movilización de recursos" (Spaltemberg, R.: 2012, pág.96). Quizás el temblor bajo la tierra, que señala el advenimiento de nuevos actores.

Este incremento de la representatividad sindical en los lugares de trabajo, debe tenerse presente cuando se analice la trascendencia que tiene en la construcción de un poder autónomo dentro de las organizaciones sindicales. Y como bien indican los autores, ese incremento acompaña la

${ }^{5}$ Desde su acceso al poder y hasta el año 2006, suele reconocerse el liderazgo de esa conflictividad compartida con otros actores sociales (como desocupados, y otros colectivos ), conforme afirma Marianela Svampa (Svampa, M. :2007, pág. 5). 
ubicación del crecimiento de conflictividad que registran en el propio MTESS. "La evolución de la cantidad de conflictos localizados ${ }^{6}$, muestra un incremento sostenido desde 2007 hasta 2010; tras un leve descenso registrado en el año 2011, vuelven a aumentar de manera significativa en 2012 (28\%). Entre 2007 y 2012 la cantidad de conflictos se acrecentó en un $72 \%$. En estos años los conflictos de este nivel aportaron en promedio el $80 \%$ al total de conflictos del ámbito privado. Lo sucedido en este nivel arroja luz sobre la evolución del número total de conflictos en el ámbito privado" (Spaltemberg, R. : 2012, pág.104).

Desmitificando algunas preconceptos que atribuyen liderazgos a otros agrupaciones extra sindicales o actores sociales no institucionalizados, se constata que la mayoría de los conflictos localizados fueron conducidos por instancias de base de grandes sindicatos de rama de actividad con personería gremial (Spaltemberg, R. : 2012, pág.105); siendo una observación sobre un recorte parcial de ese período). No obstante esta corroboración casi excluyente de esos liderazgos, se debe observar por tener particular interés en este estudio, que "una parte de los conflictos localizados en el lugar de trabajo estuvieron atravesados por tensiones en el interior de las organizaciones sindicales: en $7 \%$ de los casos en que el conflicto laboral es dirigido por alguna instancia sindical, se trató de delegados, cuerpos de delegados o seccionales de listas opositoras a la conducción del sindicato" (Spaltemberg, R. : 2012, pág.106).

Es interesante señalar una observación coincidente con el interés de este estudio. Al desagregar los motivos que originan los conflictos, se advierte un incremento en el número de despidos que se motivan "(...) en represalias por algún reclamo o acción colectiva previa llevada adelante por los trabajadores, lo que podría expresar la resistencia por parte de empleadores a los avances del implante de las organizaciones sindicales en los lugares de trabajo y del ejercicio de su papel de representación de los trabajadores"(Spaltemberg, R. : 2012, pág.107).Como bien señala el autor, estos datos conformarían por sí mismos, una hipótesis para futuras

${ }^{6}$ Conflictos localizados, son aquellos conflictos que se desenvuelven en espacios de interacción acotados a los lugares de trabajo. 
investigaciones sobre la representación sindical en los lugares de trabajo, lo que intentaremos en este estudio. 


\section{PLAN DE TRABAJO}

El Plan de Trabajo de esta tesis, se divide en tres (3) partes; a su vez divididas en diecisiete (17) capítulos. Acompañan al mismo como Anexo, dos (2) planillas excels que plasman el entrecruzamiento de datos observados, ciento sesenta y cuatro (164) archivos word que detallan las características de cada conflicto analizado; y dieciocho (18) archivos Word que contiene cada uno de ellos los numerosos link que registran la segunda fuente del registración de datos.-

La primer parte, consta de un (1) capítulo en el que se señala el marco teórico desde el que se efectúa el trabajo; y ocho (8) capítulos restantes en los que se conceptualizan los distintos elementos de la realidad que serán analizados, destacando el interés que cada uno de ellos tienen para el estudio.-

En el capítulo IV., presentaremos el marco conceptual adoptado. Allí, explicitamos las razones que llevan a adoptar a la teoría de la movilización de recursos, como sostén teórico del trabajo. Su valor para la observación, estudio y comprensión de la emersión de nuevos actores sociales; y también, su llamativa adecuación para reflejar la influencia negativa que tiene el contexto refractario del estado frente a la aparición de nuevos grupos. En una de las expresiones de esta escuela (Della Porta, D: 1996), nos apoyaremos para registrar a partir de la represión policial que se releven, las posibilidades de integración o exclusión de los agrupamientos aún no legitimados.

En el capítulo V., describiremos a la representatividad sindical. Se destaca la importancia que lo señala como recurso vital para todo agrupamiento de trabajadores y trabajadoras (sean estos reconocidos o no, por parte del estado). Se conceptualizará como una noción perteneciente al mundo de la sociología, y su diferenciación de otras formas de representación que nacen en el reconocimiento estatal. La representatividad sindical, que nace exclusivamente del reconocimiento de sus pares, se razona y muestra el por qué resulta ser este un recurso indispensable para todo agrupamiento de trabajadores y trabajadoras insurgente, para poder llegar a incidir en su universo gremial y en la sociedad en la que viven. 
En el capítulo VI, describiremos a la representación sindical en los establecimientos de trabajo. En este capítulo se destaca la trascendencia que tiene esta representación como actor potencial de la transformación de la organización sindical a la que pertenece. Se explicará la particularidades de la representación sindical que se constituye en los lugares de trabajo (delegados y comisiones internas). Se analiza las diferentes funciones que puede tener este tipo de representación, y la aparición de una nota característica - de existencia periódica- que responde a la pretensión de construir poder sindical autónomo de las conducciones de sus propias organizaciones. Se exteriorizará la tensión antagónica de las conducciones de las organizaciones sindicales frente a las representaciones sindicales en las empresas.

En el capítulo VII, se describe la importancia que tiene el lugar de trabajo en una disputa sindical. Se lo analiza como una construcción social, y su carácter político. Se relaciona al lugar de trabajo con la posibilidad que tienen los agrupamientos de trabajadores y trabajadoras que laboran allí, de poder darle un sentido propio (un espacio de resistencia). En este capítulo se muestra un elemento que justifica el por qué, de donde se realiza la observación del trabajo: el establecimiento o la empresa es el único sitio donde un agrupamiento sindical disidente, puede llegar a disputar con algo de suerte la representatividad con las conducciones de las organizaciones sindicales a las que pertenecen.

También se señalará en este capítulo, las razones por las que un establecimiento es un lugar donde se producen crisis en el sistema capitalista, y por las que el estado prestará particular atención para conservar el "statu quo" imperante.

En el capítulo VIII, se presenta una tipología de conflictos laborales, y de ella se selecciona un tipo especial de ellos, el conflicto localizado. Serán aquellos que se desenvuelven en el limitado espacio de los lugares de trabajo. Se precisa su importancia, y razones por las que se los analiza en este trabajo.

En los capítulos IX,X y XI, se destacan nociones vinculadas a las acciones conflictivas que llevan adelante los trabajadores y trabajadoras (lo que bajo cualquier modalidad denominamos huelga), y su importancia con el trabajo. 
En el capítulo IX, se destaca el elemento sociológico inexorable que nace del estado de hiposuficiencia en que se encuentran los trabajadores y trabajadoras (como grupo en condiciones de vulnerabilidad), y que en su reacción tiene como respuesta colectiva el organizarse para luchar (ejercer el derecho de huelga). Mostrando la trascendencia que ésta tiene para trabajadores y trabajadoras.-

En el capítulo $\mathbf{X}$, se destaca el reconocimiento del derecho de huelga en el derecho positivo, su consagración en el orden internacional, particularmente como derecho humano en el sistema regional y universal

En el capítulo XI, se precisa al conflicto laboral como concepto en el marco teórico que se propone, reconociéndose como recurso que utilizan los agrupamientos de trabajadores y trabajadoras para acopiar o mantener otros recursos, en pos de sus objetivos.

En el capítulo XII, se conecta a la acción represiva del estado con factor impeditivo de la emersión de un nuevo agrupamiento en la sociedad. Se explica la noción de represión. Se la caracteriza en el marco de las ideas predominantes del mundo de la sociología, como incentivo selectivo negativo para un grupo. Constituyéndose en parte del contexto externo desfavorable, ineludible y constitutivo de la decisión de un grupo de movilizar sus recursos para incidir en la sociedad que habita.

La segunda parte, se divide en tres (3) capítulos en donde se desarrollan los aspectos metodológicos y técnicos de la tesis, que básicamente consiste en un enfoque mixto (Sampieri, H. : 2014). En el capítulo XIII, se explica que metodología utilizamos para poder llevar a delante la investigación. Se explica cómo se realiza la construcción de la base de datos para ser utilizados. Se explicita la existencia de las dos (2) fuentes diferentes para el acopio de información; y la construcción de una matriz común para su volcado.

En el capítulo XIV, se enumeran y desarrollan los resultados que produce el análisis cualitativo sobre el volcado de datos y el entrecruzamiento de los mismos. Se describirán los datos duros. Aquí aparece desde un punto de vista cualitativo la constatación, en ambas fuentes, de la hipótesis inicial del trabajo. 
En el capítulo XV, se aplicará sobre la base de datos seleccionada, un análisis estadístico. Se explicará la metodología utilizada, y los resultados a que se arriban desde este análisis.-

La tercera y última parte, se divide en cuatro (4) capítulos. Aquí se desarrollan algunas implicancias que entendemos se derivan del planteo original, pero sobre todo las que derivan de los resultados obtenidos.

En el capítulo XVI, se desarrollan conclusiones de naturaleza sociológica. Aquí se analizará la forma que se releva en la represión registrada en el estudio, confrontándola a la luz de una tipología adecuada al marco teórico del trabajo. De los rasgos que se destacan, se podrá observar un carácter refractario a la integración social de los grupos que la sufren. Señalándose, la existencia de una tendencia a reprimir a estos agrupamientos sindicales, en lo que algunos autores describen como una "estrategia predominante" del estado destinada a los agrupamientos desafiantes del orden que preservan.

En el capítulo XVII, se desarrollan conclusiones de naturaleza jurídica. Aquí, confrontando los datos relevados y las obligaciones que tiene un estado, se constatará y se precisarán cuáles son los incumplimientos del estado argentino en el caso concreto que se estudia.

En el capítulo XVIII , se analiza el conflicto postal y lo resuelto por la CSJN en el caso Orellano. La pertinencia de su análisis, se motiva en la trascendencia del actor institucional, y las proyeccionesque tendrá sobre el mundo sindical y particularmente sobre el tema de tesis. Aquí se investigará su correspondencia con la hipótesis ; y en segundo lugar se analizará su funcionalidad dentro del sistema represivo del estado que propone el trabajo.

En el capítulo XIX, se intenta señalar aquellos autores que brindan un sendero teórico para receptar favorablemente las interpretaciones y conclusiones a las que se arriban en este trabajo.

Siendo un trabajo que pertenece al mundo de lo jurídico, en el capítulo $\mathbf{X X}$ se realiza una propuesta transformadora para adecuar la práctica institucional del estado al orden interno (que ya lo ordena) y al sistema internacional de derechos humanos (que también lo ordena, e integra). 


\section{MARCO TEÓRICO. CARACTERISTICAS DEL ENFOQUE ADOPTADO}

1. Objeto de la investigación. Este trabajo investiga la conducta represiva del estado dirigida selectivamente hacia grupos en condiciones de vulnerabilidad. Al entenderla como violatoria de derechos humanos (DDHH), su objeto es analizar si existe esa conducta; y en ese caso, si podemos detectar una sistematicidad, determinando en qué circunstancias se manifiesta.

Se postula en la presente tesis que los grupos afectados por la acción estatal, son aquellos agrupamientos sindicales aún no legitimados o agrupamientos sindicales disidentes (ASD). Estos necesariamente deben movilizar sus esfuerzos para poder obtener la representatividadante sus pares. Estos agrupamientos, tienen pocos recursos a movilizar, y escasísimas oportunidades para obtenerla. Será entonces en un muy acotado contexto y tiempo, de condiciones externas casi siempre adversas, en el que estos agrupamientos puedan disputar con algo de suerte el liderazgo grupal. Es en ese contexto y tiempo en que el ASD comienza a ser reconocido, $y$ en el que se estudia la conducta represiva del estado, frente a estos intentos.

La conducta estatal es observada en ese breve momento venturoso, y de inmensa volatilidad para el surgimiento de un nuevo liderazgo sindical. Este trabajo indaga sobre una posible acción represiva del estado, que se active de forma selectiva y sistemática, acompañando el "parpadeante" tiempo de emersión de un nuevo liderazgo sindical. Una acción que a su vez tiene el propósito de producir sobre el agrupamiento, un efecto de enervación. El ASD no es neutro a las condiciones refractarias que le opone el estado; él, evaluará siempre frente a la acción represiva del estado, si tendrá suerte en esa lidia, poniendo o no en juego sus escasas fuerzas para lograr obtener el liderazgo sectorial.

El estudio de los conflictos, es central para observar la existencia de actores que disputan el acopio y mantención de recursos. El estudio de los 
conflictos en el mundo sindical,es solo una tipología de aquellos, y a quienes se les ha de aplicar esta perspectiva. No todos los conflictos que suceden en el mundo del trabajo, son conflictos donde se manifiesta una tensión por la representatividad sectorial del universo humano que intentan representar. En este trabajo, la lupa se posa sobre el conflicto puertas adentro de las organizaciones de trabajadores y trabajadoras, entre grupos legitimados oficialismo- y no legitimados, por ese reconocimiento entre pares.-

De las disputas que se sucintan en el mundo del trabajo, la inmensa mayoría de los conflictos laborales son conducidos por agrupamientos sindicales legitimados por el estado. Y una muy pequeña porción de conflictos laborales, son conducidos por grupos disidentes.

De ésta última porción residual de conflictos, solo una parte evidencian un alto grado de intensidad. Son éstos los casos, en los que los ASD son acompañados por gran parte de ese universo de trabajadores y trabajadoras a representar, y en los que han incrementado la movilización de sus recursos (de toda naturaleza); éstos nos permitirán vislumbrar la disputa de modo serio por el traspaso de la representatividad que ya tiene otro agrupamiento de trabajadores y trabajadoras (además del reconocimiento estatal). La represión estatal, de aparecer en este delicado momento del proceso de legitimación del grupo insurgente, correrá el fiel de la balanza, obstaculizando seriamente la aparición de un nuevo legitimado.

Para lograr ese abordaje, necesitamos de un marco teórico que analice los movimientos sociales emergentes, y que explicite la relación entre la conducta represiva del estado y los efectos negativos condicionantes sobre la conducta de los grupos insurgentes.

2. La teoría de movilización de recursos. La teoría de movilización de recursos (TMR) es un instrumento teórico idóneo para captar esta relación, a la vez convergente y antagónica, entre las conductas de los ASD que aspiran a ser reconocidos, y el condicionante adverso que les impone la conducta represiva del estado.

El estudio de los movimientos sociales -en el campo de la sociologíadesde la década del '60, está dominado por perspectivas racionalistas (Paredes, J.: 2013). Para los senderos más significativos de éstas, los individuos -informados y capacitados- en función a la utilidad que le impone 
distintas alternativas para elegir, calculan los distintos costos de su acción, y en función a ellos participará o no en movilizaciones sociales.

En una postura crítica, pero dentro de aquella perspectiva teórica, aparecerá con la Teoría de la Movilización de Recursos (TMR). La TMR entiende por movimiento social a las conductas racionales de los actores colectivos que buscan insertarse en un sistema político, mantenerse y extender su influencia movilizando toda clase de recursos (Brunette, I. y Pizzi , A. : 2010).

"Los conflictos sociales se dan en torno a recursos (materiales, humanos, simbólicos), el análisis se orienta a organizaciones colectivas con capacidad de agenciar y controlar recursos, para conseguir determinados fines. La movilización es un modo de obtener y disponer determinados recursos para la consecución de ciertos fines." (Paredes , J. : 2013)

La TMR "entiende a los movimientos como agregados de individuos que participan de un mercado de bienes colectivos. Concentra su atención en los procesos a través de los cuales los recursos necesarios son movilizados de manera efectiva por los movimientos. Su foco es la acción organizada y su eficacia para conseguir ciertos objetivos, donde los recursos permiten el paso de un colectivo incipiente y de baja organización, a uno organizado. (Paredes, J. : 2013)."

Esta teoría interesa a los efectos de su aplicación en este trabajo, porque no indaga en las causas por las que los grupos sociales se movilizan; su interés se dirige a como se organizan, cuales son las razones que conducen al éxito o fracaso de sus esfuerzos (Brunette, I. y Pizzi , A. : 2010). Al analizar, se pone en el centro de observación a las acciones de los agrupamientos insurgentes, $y$ las restricciones para el acceso a reconocimiento. Su preocupación es como logran eficacia estos grupos no legitimados en el proceso de emisión; el "como hacen uso de los recursos disponibles para la consecución de objetivos, aprovechando las oportunidades políticas que se les presentan (...)"(Brunette, I. y Pizzi , A. : 2010).

Este trabajo recorta para su observación conductas de ASD, y su interés está centrado en poder señalar las restricciones -que le impone el estado- para el acceso de sus derechos a un grupo determinado. ¿Podrá hacer uso de los recursos legítimos de que dispone 
un grupo insurgente?, o ¿ese intento se verá trunco por una conducta selectiva y sistemática por parte del estado?

3.Las oportunidades políticas. Dentro de esta teoría (TMR) se distinguen distintas escuelas, según hagan hincapié cada una de ellas, en los diferentes factores que explican la emersión de los movimientos sociales. Entre éstas, la escuela de "Estructura de oportunidades políticas", prioriza -resultando apropiada para el caso en estudio-, como factor explicativo de la emersión de grupos en una sociedad, a las posibilidades que tienen estos del aprovechamiento de las oportunidades políticas para concretarlo ${ }^{7}$.

¿Qué entienden por oportunidades políticas? Éstas serán las probabilidades que los grupos tienen de acceder al poder e influir sobre el sistema político. Estas probabilidades, son evaluadas por los protagonistas (en nuestro caso los ASD) y constituyen los incentivos externos, positivos o negativos, para actuar colectivamente, e implican evaluar las coyunturas que les posibiliten reducir los costos de su acción colectiva (Brunette, I. y Pizzi , A. : 2010). Recordemos que los agrupamientos insurgentes, disponen de muy escasos recursos para movilizar.

A diferencia de otras líneas escolásticas que priorizan el análisis de los incentivos individuales -marginando relativamente los análisis del contexto socio-político-;esta escuela destaca en su análisis al contexto "(...)(Esta teoría incorpora las condiciones sociales $y$ políticas del entorno como una dimensión constitutiva, inherente, de la acción colectiva" (Brunette, I. y Pizzi , A. : 2010).

Compartimos el instrumento teórico que se propone, pero además nos influye para utilizar a esta teoría en esta tesis, la existencia de un elemento clave: confirmar que ella permite comprender adecuadamente el altísimo grado de incidencia del contexto restrictivo externo, por sobre la conducta de un sujeto social -en este caso vulnerable- que aspira a emerger.

${ }^{7}$ La idea de estructura de oportunidades políticas, fue desarrollada de forma implícita por Lipsky (1968). El concepto fue desarrollado de un modo formal por Tilly (1978), McAdam (1982), Tarrow (1983) y Kitschelt (1986") (Sánchez Estellés, Isis ) 
De todo el universo de elementos que componen el contexto de esos sujetos, se deben analizar cuáles son los factores determinantes para estos grupos no reconocidos para que decidan positivamente llevar adelante esas conductas racionales que les permitan arriesgar y eventualmente emerger, o que realizadas, puedan tener consecuencias positivas.

Los autores fueron agrupando estos diferentes factores ${ }^{8}$, aunque no hay un consenso unánime entre los investigadores respecto de cuáles son las dimensiones más significativas de la estructura de oportunidades políticas. Para una importante corriente de cientistas, entre ese muy reducido grupo de factores, se destacan como relevante la capacidad estatal para reprimir los movimientos sociales y -además- su tendencia a hacerlo (González Callejas, E.: 2012).

La fuerza del Estado, en tanto voluntad y capacidad hegemónica de apelar a la violencia para enfrentar los cuestionamientos sociales, será la que preponderantemente define el escenario de oportunidades políticas que enfrentan los grupos movilizados. Asoma así la represión estatal como dato real condicionante; un elemento que el colectivo emergente evalúa inexorable y pormenorizadamente- antes de decidir accionar.

4. La represión. El factor represivo del estado, se integra así en el análisis de las decisiones y posibilidades de emersión de los movimientos sociales. Aparece destacado el lugar privilegiado que tiene la acción represiva del estado sobre la decisión de movilizar recursos o no. Esta permite analizar los efectos de la acción disuasiva del estado sobre la decisión previa de realizar o no una protesta. La represión será un "incentivo selectivo de carácter negativo a la participación en un movimiento, ya que hace aumentar los riesgos y costes de la acción colectiva (conforme Tilly)" (González Callejas, E.: 2012). Dicho en otros términos, la represión obstaculiza la movilización de recursos de quien va a un conflicto.

\footnotetext{
${ }^{8}$ Estos otros factores determinantes en la emersión de los sujetos insurgentes son el grado de apertura en el acceso a la participación política, los cambios o realineamientos de los gobiernos o los realineamientos electorales, la disponibilidad de aliados influyentes, las divisiones entre las elites dirigentes; y porultimo, la capacidad estatal para reprimir los movimientos sociales y su tendencia a hacerlo"(Brunette, I. y Pizzi , A. : 2010).
} 
En la emersión de agrupamientos o colectivos de una sociedad, el estado es "ese" contexto externoque facilita o dificulta la captación de los recursos imprescindibles (dinero, organización, alianzas, libertad de actuación, derechos, etc.) para el desarrollo y fines del movimiento de protesta." (González Callejas, E. : 2012).

La acción disuasiva del estado sobre los grupos no legitimados es múltiple, y no se limita a la acción policial. El análisis de la acción del estado sobre la representatividad de los grupos de trabajadores y trabajadoras, muestra una omnipresencia, y una alta incidencia negativa sobre los grupos no legitimados. Este trabajo indagará sobre uno solo de todos esos condicionantes que instala el estado, su acción represiva.

En el caso que aquí se estudia, donde los enormes obstáculos estatales para que nazca un nuevo liderazgo sindical ya existen -y forman parte de un paisaje naturalizado-; el factor represivo estatal aparece como un plus casi insalvable de obstrucción, autónomo del marco institucional y legal, que luce como factor externo determinante.

Desatacándose en esta perspectiva, algunos autores de esta corriente sociológica han acotado el estudio de los efectos de la acción del estado centrándola exclusivamente en la represión policial (Della Porta, D.: 1996). Para estos, la observación de la represión policial -por sí sola- ya es un parámetro determinante para relevar adecuadamente la receptividad o rechazo del estado frente a la emersión de un grupo emergente.

La represión policial es para estos autores un parámetro de por sí suficiente y adecuado para valorar las oportunidades políticas de los grupos insurgentes. "Al respecto, para Donnatella Della Porta,el tipo de reacción policial frente a las movilizaciones $y$ las acciones colectivas constituye un indicador idóneo del grado de apertura o receptividad del Estado ante la protesta social"(Brunette, I. y Pizzi , A. : 2010).

Esta apuesta -a la utilización de la represión policial como parámetro único-, que a primera vista puede llegar a lucir arriesgada, se ha sostenido teóricamente en el presupuesto que la incorporación de otros variantes, puede llegar a obstaculizar la observación (al tornarla más compleja); lo que puede impedir a los observadores comprender en lo concreto la relación constatable entre los movimientos sociales y los contextos en los que actúan. 
El estudio de la represión policial recae sobre una de las variables que impactan de modo más directo sobre la protesta. Muchas veces la distancia entre algunas variables y sus presuntos efectos es tan grande, que resulta difícil establecer conexiones lógicas entre ellos. No pasa esto con la represión policial y sus consecuencias en las lidias gremiales; de allí su interés.

La represión policial, resulta así un dato insoslayable en el campo de observación de esta investigación. La importancia determinante que los trabajadores y trabajadoras le reconocen, coincide con la opción metodológica (parámetro único) que se adopta en ésta perspectiva científica. La represión policial, es la "última ratio", de la acción del estado para la mantención de un "statu quo" que tutela. Los trabajadores y trabajadoras y el estado coinciden en reconocerla como un factor casi excluyente para decidir, o no, movilizar recursos en un conflicto colectivo; y cómo hacerlo.

La elección de este marco teórico, nos brinda una posibilidad de análisis sobre los efectos negativos y disuasivos de la acción represiva del estado frente a la emersión de nuevos sujetos colectivos.

5. Los repertorios de acción colectiva. En la perspectiva de esta escuela de "Estructura de oportunidades políticas", deben ser tenidos en cuenta otros elementos, además de la acción represiva estatal. En especial deben observarse, lo que se denominan "repertorios de la acción colectiva",y el respeto social que la sociedad les reserva. Estos son un factor vinculado a las oportunidades políticas de un grupo, y constituye en el caso que se investiga, el recurso excluyente que facilita la movilización social.

Los repertorios de la acción colectiva, individualizan los modos recurrentes de acción colectiva que llevan a cabo los distintos grupos -o movimientos sociales-, y constituyen los productos culturales aprendidos que surgen $y$ cobran forma a partir de confrontaciones anteriores. (Tilly, Charles; citado en Brunette, I. y Pizzi , A. : 2010).

El reconocimiento en las medidas de acción directa (en sus distintas formas), como elementos que se registran en ese repertorio habitual de uso, en el caso de agrupamientos de trabajadores y trabajadoras no ofrece 
mayores duda. Serán los conflictos laborales, y la demostración de fuerza, una parte ineludible de ese repertorio en el mundo sindical. Este trabajo estudia grupos de trabajadores y trabajadoras que accionan para ser reconocidos. Las medidas de acción directa, en la inacabable gama que se la observe, configuran ese repertorio de acción colectiva.Poderlas comprender desde este concepto, permite reconocer su construcción a través del tiempo, y su aceptación social.Las mismas se ejercen para obtener o mantener su legitimación ante el universo personal que aspira representar o representa.

Ese repertorio de acciones colectivas será evaluado por el grupo insurgentes, en el escenario en el que debe actuar; de su análisis se determinará qué acción y con qué intensidad intervenir la realidad.

La realidad observada con este instrumento teórico, nos podrá mostrar el escenario antagónico conformado entre los esfuerzos extraordinarios de los agrupamientos insurgentes que intentan insertarse e influir en su sociedad,movilizando sus escasos recursos en conflictos laborales a través un repertorio tradicional de acciones colectivas y el estado que opera selectivamente a través de la represión policial para intervenir como contexto negativo externo que pretende condicionar las oportunidades de esos grupo.- 


\section{LA REPRESENTATIVIDAD}

1. La disputa por la representatividad. ¿Por qué centramos nuestro interés en observar cuál es el camino para obtener la representatividad de los trabajadores y trabajadoras? ¿Qué trascendencia tiene para estos lograr la representatividad de sus pares?

Los trabajadores y trabajadoras se organizan para defender y promover sus derechos, para defender sus vidas y construir sus sueños. Pero lejos de lo que pueda pensarse por quien no participa de la vida sindical, las disputas que llevan adelante los trabajadores y trabajadoras organizados, no solo tienen por objeto vencer la voluntad de los empresarios -o sus agrupamientos- y del estado. Otra gran disputa se da puertas adentro de las organizaciones de trabajadores y trabajadoras, es la disputa para conservar o para obtener el reconocimiento de la primogenitura sindical ( $y$ política) del universo a representar, la lucha por su liderazgo.

Éste enfrentamiento que es inherente a toda disputa política (su faz agonal), se desarrolla en toda su plenitud en el mundo de los trabajadores y trabajadoras. Muchas veces, los objetivos y los resultados de las luchas sindicales llevados ostensiblemente frente a los empresarios o el estado, tendrán más importancia para los contendientes puertas adentro de las organizaciones, que fuera de ellas. Cualquier espectador advertido, lo puede observar. Allí se dirime la continuidad o los cambios, en los liderazgos sectoriales.

Los trabajadores y trabajadoras agrupados por distintas motivaciones e intereses, buscan obtener el reconocimiento de su liderazgo y la representatividad de sus pares. En toda disputa sindical, en mayor o en menor grado, siempre está presente este razonamiento de supervivencia frente a este adversario.

\section{La representatividad, el recurso vital de todo grupo} insurgente. ¿De quién busca reconocimiento el grupo de trabajadores y trabajadoras insurgente? El colectivo de trabajadores aún no legitimado socialmente, no busca en primer término el reconocimiento como nuevo 
contendiente de parte del estado. Él buscará como primer paso, previo y necesario para consolidarse, el reconocimiento del liderazgo de sus propios pares. Aquí yace el interés de observar la disputa por la representatividad. Es ésta el recurso vital, que como el agua, buscará el colectivo aún no visibilizado. Luego de ascender este pequeño y gran escalón, recién podrá entrar en la disputa por el reconocimiento societal o estatal, y con éste último la obtención del otorgamiento del poder decisorio para el ejercicio de los derechos de representación colectiva. A partir de este segundo momento, será reconocido y respetado socialmente, principalmente por el estado.

2. Representatividad y representación. ¿A qué nos referimos con representatividad en este estudio? Debemos distinguir dos nociones que habitan el mundo sindical, la representatividad y la representación.La representatividad, es una noción que se reconoce en el plano sociológico; la representación, tiene mayor relevancia en el plano jurídico. La primera señala la ascendencia "per se" de un liderazgo grupal; la segunda, pone el acento en la titularidad de derechos que pueden ser ejercidos por la organización sindical -y el agrupamiento que la dirige- que ya ha sido reconocida.En la República Argentina, será el estado quienbrinde este reconocimiento institucional y legal a través del otorgamiento de la personería gremial o la simple inscripción gremial (conforme arts. 230, $25^{\circ}$ Ley 23.551).

Nos auxiliaremos para profundizar en esta distinción, de Ermida Uriarte,"(...) La representación sindical sugiere dentro del campo laboral la noción civil de representación (actuar en nombre de otro), sumado a que afiliarse al sindicato presume un mandato tácito que transforma al sindicato en representante de cada uno de los afiliados." (Trajtemberg, D.: 2012, pág.8).

La representación alude a la relación entre sindicato y sus afiliados o sus representados -cuando el ejercicio de sus funciones alcanza en su protección a sujetos no afiliados- reconocida institucionalmente por el estado. Mientras que la representatividad se refiere a la relación directa entre sindicatos -o como en el caso de estudio, grupos de trabajadores y 
trabajadoras- y el universo profesional que aspiran a liderar o representar (Trajtemberg, D. : 2012, pág.8).

La noción de representatividad a diferencia de aquél, es un concepto más complejo que responde a una construcción social en un determinado contexto político, económico y social .La representatividad no se vincula a decisiones estatales; con independencia de éstas, la representatividad responde de modo dinámico y cambiante a la voluntad que emerge del universo sectorial que los reconoce, o no los reconoce.

La distinción entre representación y representatividad se basa en el tipo de reconocimiento que se busca y obtiene. "(...)Si el reconocimiento del sindicato viene dado por parte del Estado se habla de representación (reconocimiento institucional-legal a través del otorgamiento de la personería gremial); en cambio, si el reconocimiento proviene del colectivo de trabajadores, en otros términos, de las bases, debe asociarse a la noción de representatividad". (Trajtemberg, D.: 2012, pág.8/9).

La representatividad puede acompañar o no, a quien sea representante reconocido por el estado. No obstante, representación y representatividad, no son -0 no son necesariamente- conceptos excluyentes. De hecho, en la inmensa mayoría de los casos se acompañan. Podría incluso afirmarse que ambos conceptos están imbricados entre si y que son en muchas ocasiones difíciles de disociar (...)."(Trajtemberg, D.: 2012, pág.8/9).

\section{El valor de la representatividad como paso insoslayable} hacia el reconocimiento del estado. Parte de la trascendencia que tiene este estudio, nace del interés que se oculta en la disputa por la representatividad en el mundo sindical. ¿Por qué es esto así? Los trabajadores y trabajadoras se organizan para incidir en la sociedad en la que viven. Acceder a la representación que reconoce el estado, les permite el acceso a un inmenso poder que se evidencia en los derechos exclusivos que tienen las asociaciones sindicales con personería gremial (APG) en el modelo sindical argentino (MSA). ${ }^{9}$ Tener la representatividad con que lo invisten sus pares, es el paso previo, necesario e ineludible para obtener los

\footnotetext{
${ }^{9}$ Conforme artículos $31^{\circ}, 38^{\circ}, 39^{\circ}$ y $41^{\circ}$ de la ley 23.551.
} 
derechos que le otorga el estado al reconocerlos como grupo plenamente legitimado. Si se obstruye al grupo incipiente que pueda dar ese paso, se le impide a éste colectivo la disputa por el acceso al reconocimiento posterior estatal, y como consecuencia de éste -en un tiempo no muy lejano- que pueda incidir en la sociedad que vive. Por ello, es un recurso vital para el acopio de un agrupamiento que aún no ha sido reconocido.-

4. Disputas intersindicales e intrasindicales. La disputa por el liderazgo y la representatividad de un universo de trabajadores y trabajadoras entre distintos colectivos, puede darse dentro o fuera de una o más asociaciones sindicales. La circunstancia también es aplicable a las disputas de representación.-

De esta distinción nace una clasificación de las disputas para obtener la representatividad -o representación-, que da lugar a dos tipos específicos de relaciones colectivas de trabajo (Fernández Madrid, J.: 2007, Tomo III pág.7), distinguiéndose entre disputas intersindicales y disputas intrasindicales (Cornaglia, R.: 2004, pág.315).

Las disputas intersindicales, son aquellas lidias que se desarrollan entre grupos de trabajadores y trabajadoras que pertenecen a diferentes organizaciones sindicales. Estas son habituales, cuando distintas organizaciones se enfrentan para obtener o conservar el monopolio de la representación de derechos colectivos (disputa por la personería gremial y los derechos que de ellas nacen). En estos casos, habitualmente ambos contendientes ostentan reconocimiento del estado, aunque solamente uno de ellos obtendrá ese monopolio.

Las disputas intrasindicales, son aquellas lidias que muestran enfrentamientos que se desarrollan entre grupos de trabajadores $y$ trabajadoras que disputan representatividad, pero que pertenecen a una misma asociación sindical de trabajadores y trabajadoras. En estas disputas uno de los dos contendientes, es un agrupamiento de trabajadores y trabajadoras que ya detenta el poder y representación -reconocido por el estado- dentro de esa organización.

Son este tipo de disputas las que nos interesan en este trabajo, pues aquí se estudia la conducta del estado frente agrupamientos de trabajadores y trabajadoras que -en la inmensa mayoría de los casos- no han accedido a ningún grado de la conducción sindical de su sector. Son 
colectivos que aspiran a lograr esa representatividad, y llegar a liderar en algún momento cercano sus universos de representación.

Manteniendo el objeto de análisis sobre las disputas intrasindicales, debemos aclarar que en algunas pocas ocasiones, éstas están forzosamente ocultas bajo disputas intersindicales. Cabe recordar que el mundo sindical, y particularmente la representatividad en los lugares de trabajo, muestra una alta versatilidad. Puede suceder, y de hecho en algunos casos se puede advertir que los agrupamientos insurgentes de trabajadores y trabajadoras, por imposibilidad de disputar frente a sus conducciones desde la propia organización, lo hacen desde el ropaje que le facilita el amparo de una organización sindical hermana o creada a para dar esa disputa.

5. El estado mete la cola. La representatividad, no es un recurso más en el mundo de los trabajadores y trabajadoras; es la puerta de acceso a la existencia política del nuevo grupo.

La representatividad sindical para quien no la tiene, es un recurso esquivo, extremadamente volátil y por sobre todas sus notas, inmensamente preciado. La trascendencia de su disputa no se limita al estricto feudo de los trabajadores y trabajadoras; su importancia obliga a la presencia de otro actor clave, el estado. La posible incidencia y las transformaciones no deseadas -para los distintos estamentos sociales- que acarree la aparición de un nuevo sujeto en el escenario político, pondrá en alerta todos los dispositivos del estado, para conservar las relaciones sociales que lo sustentan(O 'Donnell, G.: 1982).

El estado, en su constante esfuerzo por mantener ese "statu quo" (O 'Donnell, G.: 1982, pág.15/16) ${ }^{10}$, genera una relación con los grupos emergentes, que no resulta para nada sencilla para estos.

10 "El estado burocrático autoritario, es un tipo de estado de una sociedad capitalista.(...) El estado capitalista es garante y organizador de las relaciones sociales capitalistas y, por lo tanto, de la dominación que ellas concretan. Esto implica que el Estado no es garante de la burguesía, sino del conjunto de la relación que establece a esta clase como clase dominante. No es, por lo tanto, un Estado de la burguesía : es un estado capitalista, lo cual no es exactamente lo mismo. Esto entraña que, en tanto el Estado garantiza y organiza la vigencia de principalmente- las relaciones sociales capitalistas, es garante y organizador de las clases que se enlazan en esa relación. Esto incluye a las clases dominadas, aunque su garantía de éstas sea en el sentido de reponerlas, o reproducirlas, como tales clases dominadas. Esto tiene algunas consecuencias importantes. Una de ellas es 
En este trabajo, se investiga si el estado se configura en un factor clave -a través del uso selectivo de la fuerza- para incidir en la elección por parte de los trabajadores y trabajadoras del representante sindical. O dicho de un modo más textual, si el estado incide obstaculizando para que nuevos actores sindicales accedan a la representatividad sectorial.

La disputa por la representatividad permite la desburocratización de una organización sindical, impidiendo que esta se anquilose (Capón Filas, R.: 1989, pág.230). Los principios que rigen la vida democrática deben habitar en toda la sociedad; y el sindicato no es una excepción a esa regla. Lo garantizan los tratados internacionales (Convenio OIIT no 87) y la legislación nacional ( 80 ley 23.551). El estado -enervando su papel de gendarme que le asigna el sistema- tiene la obligación internacional de resguardar esos valores. Ese resguardo democrático que aparece en el momento fundacional de una organización gremial, se debe extender en el tiempo de vida de la institución.

¿Qué sucedería si el estado obstruye la circulación de ese flujo?, ¿ y si lo hiciera a sabiendas para discriminar en perjuicio de un agrupamiento de trabajadores y trabajadoras favoreciendo de este modo a otro? ¿A quién beneficia y a quién se perjudicará con ese bloqueo? ¿Son siempre los mismos actores los perjudicados? Una respuesta de este tipo, ¿reforzará las conducciones ya por sí mismas hegemónicas de estos monopolios?

Esas acciones estatales de bloqueo al ascenso del grupo disidente, de comprobarse, no se produciría en cualquier tiempo; se presume su existencia cuando éstos están en condiciones ciertas de lidiar con alguna suerte la representatividad sectorial. Este trabajo busca detectar y mostrar, una modalidad -evidente- de esa sistematicidad. ¿Se puede encontrar un "algoritmo" que lo muestre?

La tarea de esta tesis es decodificar -si existiese- ésta conducta del estado que desactiva el acopio de recursos, colaborando para que no se logre exteriorizar una nueva representación sindical.

que, no pocas veces, el interés general de reproducción de dichas relaciones ( $y$, por lo tanto de las clases por ellas vinculadas) lleva al aparato estatal a desempeñar un papel custodial respecto de las clases dominadas, incluso en contra de demandas de la burguesía". (O'Donnell , G. : 1982 pág.15/16). 
De ser así, lo que podría aparecer sería el avistamiento de una tendencia del estado a rechazar ciertas conducciones noveles que puedan portar conductas o ideologías críticas o disruptivas del orden constituido. 


\section{LA REPRESENTACION SINDICAL EN LOS LUGARES DE TRABAJO.}

1. EI interés por las Comisiones Internas. En esta investigación, centramos nuestro interés en observar a la representación sindical en los lugares de trabajo, y no en otros ámbitos. ¿Qué "masa madre" se leva allí y no en otro sitio- para los trabajadores y trabajadoras?

Este trabajo trata de responder entre otras, a una pregunta: ¿El estado reprime selectivamente a este sujeto diferenciado de la comunidad (la representación sindical en los lugares de trabajo)? De ser ello así, podríamos avizorar en la representación sindical en el establecimiento, una existencia con rasgos autónomos dentro del colectivo mayor de trabajadores y trabajadoras (la organización sindical total a la que pertenece), y un interés particular por parte de quien reprime.

En el trasfondo de la disputa por la representación sindical en los lugares de trabajo, se observa de modo nítido y vívido,un viejo cruce de miradas. Por una parte, la representación en los establecimientos y su pretensión de consolidación como actor independiente junto a la construcción de un poder autónomo; y por otra parte las conducciones centralizadas, y su pretensión de integración y dependencia de aquel colectivo, a la acción centralizada -y mayor- del sindicato que lo contiene.

Libertad sindical. Derecho de sindicación. Organización. Una de las manifestaciones intocables de la libertad sindical para los trabajadores y trabajadoras, es su libertad para decidir cómo organizarse. Así reza el artículo $2^{\circ}$ del Convenio 87 de la OIT, lo que es un dogma inalterable -e indomable- que rige la vida sindical, a pesar de todos los esfuerzos normativos que pretendan encasillarlo.

La garantía prevista en el artículo $2^{\circ}$ del Convenio 87 de la OIT, otorga a los trabajadores y trabajadoras -también a los empleadores-, "sin ninguna distinción y sin autorización previa, el derecho a constituir las organizaciones que estimen convenientes". Destacamos,"sin ninguna distinción y de la forma que estimen conveniente (...)".El Convenio 87 resguarda la voluntad de los trabajadores y trabajadoras que tienen como 
único propósito en esta decisión, la de defender y promover adecuadamente sus intereses. Esta potestad incluye a todas las posibilidades organizativas, formas, niveles, universos territoriales, universos personales, etc. (Capón Filas, R.: 1989, pág.206 - p.210; Corte, N. : 1994, pág.92)

En concordancia con ello, la libertad sindical también alcanza con su tutela a la decisión de los trabajadores y trabajadoras de organizarse gremialmente "intra muros" de las empresas donde prestan servicios. Aparece allí, la representación sindical en los lugares de trabajo.-

\section{La representación en los lugares de trabajo, rasgo propio} del modelo sindical argentino. No todos los modelos de organización sindical en el mundo preveen representación sindical en los lugares de trabajo. En la Argentina, ésta, es una característica propia del modelo sindical adoptado (Corte, N. : 1994, pág.47; Basualdo, V.: 2010, pág.82); ya sea por admitir la existencia de esta representación (y su generalizada propagación), como por su particular formato ${ }^{11}$.

La existencia de estas formas representativas en los lugares de trabajo se rastrean en nuestro país, desde las primeras décadas del siglo pasado (Corte, N.: 1994, pág.395), y puede reconocerse como práctica sindical impulsada por el propio movimiento obrero de modo consistente incluso- con anterioridad al ascenso del peronismo al poder (Ceruso, D.: 2013). Después de 1945 pasará a ser un rasgo ya distintivo del modelo organizativo sindical legal en la Argentina (Basualdo, V.: 2010, pág.85).

\section{¿Cómo es la representación sindical en los establecimientos de}

trabajo en Argentina? La ley argentina denomina a los representantes de los trabajadores y trabajadoras en los distintos establecimientos, como delegados o miembros de Comisiones internas. Esta representación es

\footnotetext{
11 No responde a formatos generalizados en otras latitudes, o en los países centrales. La representación es elegida por todos los trabajadores y trabajadoras del establecimiento, sean o no afiliados al sindicato; logrando la unificación de la representación (sindical y de las bases) en el lugar de trabajo. No hay otro representante del sindicato, ni de los trabajadores y trabajadoras (lo que en algunos sistemas se denomina de "doble canal"). En algunos sistemas, la representación es elegida directamente por el propio sindicato.
} 
admitida por el ordenamiento legal, en los establecimientos que tengan diez o más trabajadores y trabajadoras. Ese tope mínimo de trabajadores que habilita legalmente la presencia del representante, podría variar si se acuerda reducirlo convencionalmente -en tiempos de mayor poder sindical en nuestro país fue fijado por el propio estado en un número significativamente menor (cinco trabajadores). El número máximo de delegados puede variar también de acuerdo a la norma legal (artículo $45^{\circ}$ de ley 23.551) o el convenio colectivo de aplicación, de acuerdo a la dimensión del personal a representar, por la existencia de turnos o por otras circunstancias dadas por la modalidad de trabajo que se acuerdan convencionalmente entre empresarios y sindicato.

Para ser representantes se requiere ser afiliado al sindicato con personería gremial otorgada por el estado -conforme artículo $41^{\circ}$ Ley 23.551-, y tener una antigüedad mínima de un (1) año en la afiliación y también en la prestación de servicios trabajado en el establecimiento en cuestión. Los delegados son elegidos por voto directo por la totalidad de los trabajadores y trabajadoras que prestan servicios en el establecimiento, sean afiliados o no al sindicato. Esta representación directa y de carácter "sistémico", es clave para evitar la burocratización de la estructura sindical a que nos referíamos antes.

Los representantes obreros pueden integrarse en cuerpos colegiados. "La comisión interna (...) es un cuerpo colegiado compuesto porun número reducido de delegados que, de acuerdo a los distintos reglamentos internos de las organizaciones sindicales, pueden ser elegidos por la totalidad de los trabajadores del establecimiento por voto simple $y$ directo, o, en su defecto, por los mismos integrantes del cuerpo de delegados" (Basualdo, V.: 2008, pág. 258).

Actividad que incumbe a la representación. La comisión interna es la encargada de representar a la totalidad de los trabajadores y trabajadoras del establecimiento ante el Ministerio de Trabajo, ante la patronal y ante el propio sindicato; llevando adelante los reclamos originados en muy variadas cuestiones, tales como condiciones de trabajo, la salubridad, reclamos salariales, cumplimientos de normas convencionales y cualquier otra demandas que se pudiese originar en los lugares de trabajo. Pero además, estos representantes integran estructuralmente el 
sindicato. Son un órgano del propio sindicato y ejercen la representación de éste, frente a los trabajadores y empleadores (Capón Filas, R.: 1989, pág.238).

\section{Funciones de las representaciones en los lugares de trabajo} Las representaciones sindicales en los lugares de trabajo, pueden realizar distintas funciones, que aparecen, mutan, se superponen y se entremezclan, variando de país en país, y de tiempo en tiempo.

Cada movimiento sindical, ha dado forma y funciones a los distintos instrumentos con los que en cada tiempo se ha valido. De esa instrumentalidad, nace el reconocimiento de diferentes funcionalidades. Reconocer sus variadas funciones, nos permite conocer su historia, saber que decisiones política intentaron y pudieron adoptar. Esta reflexión, corre vigente al momento de esta lectura.

¿Cuáles son las distintas funciones que puede adoptar la representación sindical en los lugares de trabajo? Abrevamos para auxiliarnos, en la distinción clásica tal como lo ha catalogado Sturmthal (Consejos en su terminología), bajo los diferentes tipos que se desarrollan a continuación ${ }^{12}$.

Cada una de las funciones habla de los propósitos políticos y de la fuerza adquirida por los trabajadores y trabajadoras, y de su tiempo. "La primera forma es la (...)que los delegados en la empresa son en realidad los "cobradores de cuotas sindicales" (cardsteward, ticket steward). Ello estaría vinculado a una estructura sindical territorial. Un segundo tipo estaría relacionado con el proceso de negociación (como "arbitro de querellas") entre trabajadores y empresas. Un tercer tipo se asocia con el movimiento sindicalista que buscaba que la organización sindical en la empresa asumiera progresivamente el control obrero. El cuarto tipo lo ofrecen los movimientos de consejos revolucionarios como el soviético de 1917 o la revuelta obrera de Hungría de 1957 contra el stalinismo, en los que los comités en las empresas asumen una función directamente política

12 La tipología está tomada de Sturmthal, Adolfo, en "Consejos obreros", de Editorial Fontanella, Barcelona, año 1971 
coordinando la acción en las empresas sobre la arena política (Santela, A.: 2011, pág.17) .

A estas cuatro funciones, Sturmthal agrega otra que permanece vívida en el ideario obrero en la República Argentina. Una función que se caracteriza por intentar la generación de un poder autónomo para los trabajadores de los establecimientos. "Las rebeliones periódicas de las bases sobre los dirigentes pueden tener a las organizaciones en empresas como base organizativa autónoma, un fenómeno observado especialmente en los años 1960 y 1970 a nivel internacional y en la Argentina" (Santela, A.: 2011, pág.17).

Esta función, individualiza la acción de la representación obrera instrumentando un poder de decisión que se gesta en el establecimiento. Intramuros, los trabajadores y trabajadoras intentan tener autonomía para decidir en su contexto sindical.

Paradójicamente este quinto tipo o "quinta función" en la enumeración de Sturmthal, es absolutamente legal y formalmente admitida por el propio ordenamiento argentino. Debemos recordar aquí, que la propia ley sindical argentina en su artículo $40^{0^{13}}$, al enumerar la compleja red de representaciones que ejerce un representante de los trabajadores y trabajadoras en su lugar de trabajo, expresamente reconoce su función representativa de los aquellos"frente" al sindicato.

Esta investigación tiene presente a esta "quinta función", y su necesidad de resguardo. Por ello, resulta de interés en este trabajo registrar si existe cierta respuesta impeditiva a los trabajadores $y$ trabajadoras por parte del estado, cuando se organizan y proyectan la construcción de un poder que resulte autónomo de la dirección central del sindicato. La misma se instrumenta a través de las disputas intrasindicales.

\footnotetext{
13 "Artículo $40^{\circ}$ (ley 23.551) Los delegados del personal, las comisiones internas y organismos similares, ejercerán en los lugares de trabajo según el caso, en la sede de la empresa o del establecimiento al que estén afectados la siguiente representación: a) De los trabajadores ante el empleador, la autoridad administrativa del trabajo cuando ésta actúa de oficio en los sitios mencionados y ante la asociación sindical. b) De la asociación sindical ante el empleador y el trabajador."
} 


\section{Tensión entre Sindicatos y representación sindical en los}

lugares de trabajo. Un actor diferente en el movimiento obrero. La tensión entre las conducciones centralizadas de los sindicatos y las representaciones en los lugares de trabajo, es una compañera de viaje en la construcción de las organizaciones sindicales. Esta tensión es consustancial en ese camino de construcción. Ha estado presente y en expansión desde los orígenes de la "gran industria". Es por ello que ante la introducción de nuevos principios de organización frente al sindicalismo de oficio predominante hasta pasada la 1ra. Guerra mundial, ha permitido percibir desde ese tiempo y en esa organización de base, un nuevo sujeto político (Santella, A.gustín: 2011, pág.19).-

Suele observarse en la comprensión de estas diferentes formas organizativas, la asociación de sus diferentes estructuras con las diferentes estrategias que han dividido y siguen dividiendo al movimiento obrero en el mundo. Esta distinción suele ver en los sindicatos un accionar reformista que limita su cuestionamiento al orden capitalista, frente a una visión de las representaciones obreras en los lugares de trabajo que suelen asociar su accionar a posiciones revolucionarias. (Santella, A.: 2011, pág.20).-

Tendencia al disciplinamiento de las representaciones en los establecimientos. En las relaciones que se anudan entre sindicatos y representaciones sindicales en los lugares de trabajo, aparece naturalmente una tendencia al disciplinamiento de las segundas por parte de la conducción centralizada que tiene el sindicato. Esta tendencia nace de la función "co-ordenadora" de las relaciones laborales, que ejercen los sindicatos por participar en la negociación colectiva de las condiciones de trabajo, y la consecuente necesidad de lograr el cumplimiento de las obligaciones acordadas.

Agustín Santella, explica sintéticamente el esfuerzo que lleva adelante la organización, hacia la representación en los lugares de trabajo. "Se identifican otros conflictos entre CI y sindicatos que tienen que ver con la formación de una estructura sindical centralizada, la "fuerza sindical", los requerimientos de la disciplina laboral y la negociación colectiva. La política sindical tiene como objetivo el logro de mejoras para los trabajadores arrancadas mediante la lucha a los empresarios y el estado, pero esta lucha no se propone desplazarlos del control de la industrial y el poder político en 
la sociedad. La conflictividad para los dirigentes sindicales es un medio para pactar mejores condiciones en el sistema capitalista. Llegar a estos pactos requiere de una importante fuerza colectiva sindical, que se logra con la capacidad de organizar a los trabajadores, y movilizarlos. La organización se obtiene con la unidad, la centralización y la disciplina a la dirección. Pero a su vez los sindicalistas mantienen su capacidad de negociación si muestran que como mediadores pueden mantener esta organización y disciplina, haciendo cumplir lo pactado. En este sentido, la dinámica de la negociación colectiva se vincula con una expansión de la disciplina sindical hacia la disciplina laboral. El sindicato vigilará el cumplimiento del convenio colectivo tanto en lo que hace a las conquistas obreras como en los límites a la movilización disruptiva que este mismo compromiso implica" (Santella, A.: 2011, pág.20).

Las dos caras de Jano.En las representaciones de trabajadores en las empresas habita la lucha que señala esta tensión, entre el sometimiento a los intereses sectoriales "transmuros" -que impulsa el sindicato-, y los intereses renovadores que -de existir-impulsan sus bases. Como dijimos, que la propia ley les reconoce.

La realidad de cada tiempo histórico, mostrará el nivel de predominio de la primera, y la aparición intermitente de la segunda. Lo cierto es que esta necesidad de sometimiento a la directriz política centralizada del sindicato, le impone a las Comisiones Internas un sesgo de predominio de los intereses sectoriales/sindicales que intenta reducir su función a complementar la acción de la conducción centralizada. Siguiendo la tipología de Sturmthal, un "complementario" arbitro de querellas entre sindicato y empresa.

"La combinación de estos procesos de conflictos explica la presión hacia la subordinación de las comisiones internas bajo la estructura sindical. Las comisiones internas forman una parte subordinada dentro de la estructura sindical. Pero además estas comisiones internas se añaden como una condición de posibilidad del mantenimiento de la disciplina estratégica del poder capitalista en la industria, aunque esta forma disciplinaria implique, de manera distinta al período clásico pre-sindical, una concesión de poder hacia los sindicatos en el lugar de trabajo" (Santella, A.: 2011, pág.20). 
La aparición de posicionamientos u organización crítica, cuando no autónoma y opuestos a las visiones e intereses de las conducciones centralizadas, producen una tensión ascendente que suele percibirse como anómalo a la lógica que intenta preservar el orden dominante. Este desajuste representará intereses diferenciados con el empresario, con la conducción central del sindicato al que pertenecen, y con el estado, que tiene la manda expresa de remover lo que observa como un obstáculo ${ }^{14}$ (MTESS: 2008, pág.17).

5. Las comisiones internas como poder autónomo. No siempre la representación sindical en la empresa, reduce su función a la vigilancia del cumplimiento de la negociación colectiva o complementar la presión dispuesta desde la conducción centralizada para el resguardo de los intereses de los trabajadores y trabajadoras.

La libertad sindical -bien enseña Néstor Corte- es una libertad compleja, que suele resolverse entre las contradicciones de intereses que tienen los propios trabajadores (Corte, N.: 1994, pág.77).

Cuando las comisiones internas llevan adelante acciones que manifiestan funciones que afectan la normalidad del sistema, emerge el atisbo de un poder autónomo que se detenta en la base ( $O$ 'Donnell, G.: 1982). La construcción de ese poder dentro de las propias paredes de un establecimiento productivo, es una realidad difícil de digerir para los sujetos que impulsan o garantizan el orden socioeconómico.-

Cuando las comisiones internas se vuelven díscolas, rebeldes 0 autónomas, quienes tienen función de resguardar o mantener esa normalidad entran a corregir lo que suponen una anormalidad.

Mal que les pese a otros actores sociales, esta función ha sido un carácter que ha acompañado -y acompaña-un buen tramo de la historia sindical argentina.-

14 " La existencia de sistemas de canalización institucional de dichos conflictos constituye un incentivo para que los trabajadores recurran al aviso o manifestación pública de su disposición a realizar huelgas, de modo de movilizar el aparato estatal de mediación entre las partes, uno de cuyos fines es, precisamente, evitar las interrupciones del trabajo" (MTESS: 2008, pág.17). 


\section{El Rubicón. La visualización del poder autónomo. La disputa}

intrasindical. Cuando la fuerza, la masa crítica de los trabajadores y trabajadoras en el establecimiento, entienden que puede acompañar su suerte para el enfrentamiento contra la conducción centralizada del sindicato, el conflicto será claramente visibilizado en una disputa "intrasindical".

Allí donde se detecten estas manifestaciones, aparecerá en potencia lo que Adolfo Gilly bautizó como la "anomalía argentina". "Aquí es donde surge, en Argentina, una anomalía ubicada en el núcleo de la dominación celular cuya sede es el ámbito de la producción, el lugar donde se produce y se extrae el plusproducto, el punto de contacto y fricción permanente entre capital y trabajo asalariadoen la sociedad capitalista (...).Esta anomalía consiste en que la forma específica de organización sindical politizada de los trabajadores en el nivel de la producción no sólo obra en defensa de sus intereses económicos dentro del sistema de dominación -es decir, dentro de la relación salarial donde se engendra el plusvalor-, sino que tiende permanentemente a cuestionar (potencial y efectivamente) esa misma dominación celular, la extracción del plusproducto y su distribución y, en consecuencia, por lo bajo del modo de acumulación y por lo alto del modo de dominación específicos cuyo garante es el estado." (Gilly, A.: 1990, pág. 197/8).-

Este posicionamiento crítico, se reconoce de modo consistente y constante en el tiempo, desde la década del ' 40 hasta la actualidad.

La obstaculización a la Quinta función. El estado reprimiendo, intenta seleccionar "de hecho"el tipo de funciones que puede ejercer las comisiones internas en los lugares de trabajo.

Este trabajo tiene presente esta pregunta, ¿El estado interviene cuando se ejerce esta quinta función -en la clasificación de Sturhtall-?, y ¿no intervendrá cuando las comisiones internas se limiten a otras funciones que no resultan disfuncionales del ordenamiento? En ese sentido, pero confirmando la conducta selectiva del estado, ¿se podrá observar que el estado tampoco intervendrá cuando las mismas conductas se originan en decisiones adoptadas o coordinadas por las conducciones centralizadas de los sindicatos? ¿Se puede determinar si tiene cierta sistematicidad?, y en 
ese caso ¿cuándo y en qué circunstancias se produce esa injerencia? De ser así, esa conducta selectiva, viola la libertad sindical.

Yendo a un plano estrictamente jurídico, se produciría un conflicto originado en la aparición de una conducta jurídica y un sujeto que la cristaliza que es selectivamente reprimido. Lo que Sturhtall tipifica como una función diferencial, que Gilly y Santella rastraen y ubican en forma permanente en la historia sindical de nuestro país. Su portador, son exclusivamente los representantes sindicales en los lugares de trabajo.

Si está individualizada la conducta jurídica protegida por el ordenamiento, y la intervención estatal solo se ejerce sobre agrupamientos aún no legitimados; entonces la intervención represiva del estado, resultaría ilegal y estaría relacionado con el propósito de impedir la aparición de este nuevo sujeto colectivo.

El riesgo que se corre, es que esa voz crítica se pierda. 


\section{LA INCIDENCIA DEL ESPACIO EN LAS DISPUTAS SINDICALES}

1. El lugar de trabajo, la fragua de sueños. ¿Por qué nos interesan observar la acción del estado y las disputas sindicales en los lugares de trabajo?

El lugar de trabajo ha sido para los trabajadores y trabajadoras por mucho tiempo $-y$ aún sigue siéndolo en muchos de ellos-, el sitio donde se encuentra con sus pares, para comenzar a transformar su mundo, y su vida. Entre esos muros se cobijará para una buena parte de la humanidad, la primer trinchera para defender y concretar sus sueños.

El lugar de trabajo, es un lugar hostil para acunar conductas o pensamientos que puedan ser críticos hacia la normalidaddel orden socioeconómico reinante ${ }^{15}$ (O'Donnell, G.: 1982, pág.36/37), particularmente para los trabajadores y trabajadoras. Los establecimientos de producción, son lugares de altísima fricción. Allí, entre tantas moliendas de intereses, se oponen -centralmente- las lógicas contradictorias del mundo empresario y del mundo organizado de los trabajadores $y$ trabajadoras (Capón Filas, R.: 1989, pág.51). Esa presión antagónica, es recibida en forma directa por la representación de quienes trabajan allí.

Una presión que crecerá exponencialmente, cuando esa representación resulta crítica con la propia organización sindical a la que pertenece.En esa fragua de sueños, en ese espacio, es donde vamos a poner la mirada.

15. ¿QQué es "normal"?(...)¿Qué quiere decir la "normalidad" del funcionamiento económico de una sociedad capitalista? Qué tiene lugar su expansión, o reproducción dinámica, sin grandes saltos en la acumulación de capital, especialmente por parte de grandes unidades económicas que en ese proceso van transformando, y -parcialmente- eliminando a otros agentes económicos. Esa normalidad es la crisis perpetua - pero no evidente- de un crecimiento desigual y desigualizante en principal beneficio de unidades mono u oligopólicas, cuya acumulación subordina los comportamientos económicos y la distribución general de recursos en el resto de la sociedad. Esto suele traducirse en varios planos. Primero, que el comportamiento de algunos indicadores, que aluden a ciertas regularidades, define una situación "satisfactoria" o "saludable" de la economía, en tanto señalan que aquel patrón de acumulación se está reproduciendo con escasos entorpecimientos. Segundo, que dicha evaluación es efectuada por actores que, en conjunto, tienen peso decisivo como para causar, con sus actos y omisiones, esa situación" (O 'Donnell, G.: 1982, pág.36/37). 
2. El lugar de trabajo como espacio político. El espacio no es un objeto neutro, separado de toda ideología o todo interés político. Todo espacio, es un espacio político (Oslender, U.: 2002, pág.2; citando a Henri Lefebvre). Sobre ese "tapete" se disputan los intereses encontrados de la sociedad. Si por el contrario, apareciese ante nuestra mirada como neutro e indiferente a los intereses que lo habitan, será porque ese espacio ya ha sido ocupado, colonizado y naturalizado para nuestra percepción.

Pero esta neutralidad, no existe. Todo espacio es continuamente formado y modelado por elementos históricos y naturales; aunque nuestra conciencia lo perciba como naturalmente dado. ${ }^{16}$ Por ello, aunque no muestre las huellas de los alfareros que lo construyeron, un establecimiento productivo -como todo espacio- ha sido el fruto de un proceso político. $Y$ por ser político, -inexorablemente- surgen conflictos en su uso. El espacio será entonces, un sitio de constante interacción y lucha entre dominación y resistencia (Oslender, U.: 2002, pág.2; citando a Chantal Mouffe). Luchas éstas, que frecuentemente estarán articuladas por movimientos sociales . En los lugares de trabajo, los trabajadores y trabajadoras son quienes impulsen esa conflictividad.-

\section{Relación entre espacio y fortalecimiento de agrupamientos}

insurgentes. Para comprender un movimiento social -los ASD lo son-, y las causas de su buena o mala fortuna en su acción política, tenemos que tener en cuenta los lugares específicos en los que se desenvuelve dicha acción. Existen relaciones múltiples entre la emersión de un agrupamiento insurgente de trabajadores y trabajadoras -una forma de movimiento social, en los términos de la TMR- con el espacio en donde prestan servicios.

\footnotetext{
16 "Ser conciente de un objeto entraña verlo en un contexto, percatarse del lugar que ocupa en un marco de referencia más amplio. La conciencia por tanto, puede considerarse, no solo como un percatarse en general, sino también una capacidad para evocar un contexto más vasto(...)La conciencia se mantiene con frecuencia a bajo nivel debido a que existen elites externas que intentan coartar la acción política de colectividades desposeídas, lo que puede conseguirse, por ejemplo, limitando el nivel de educación, controlando la información y las interpretaciones contextuales y promoviendo una visión del mundo que subraye la importancia de los fragmentos sobre el contexto"(Etzioni, A.: 1980,pág.256/7).-
} 
Un espacio puede resultar propicio o no, a ese agrupamiento, para el acopio de los recursos que le permitan incidir en la organización sindical o en la sociedad en la que están inmersos. Un espacio puede hacerlos fuertes o debilitarlos, frente a los desafíos en los que decidan aventurarse.

Para los ASD, sus lugares de trabajo son espacios propicios para esa disputa. En un establecimiento productivo, se reserva un numeroso arsenal de recursos -a veces imperceptibles- que impulsarán favorablemente la acción de los trabajadores y trabajadoras. Cuestiones tan concretas como la experiencia compartida de vida -e intereses- en ese sitio; los sentimientos subjetivos comunes generados en la decisión de un actor social para involucrarse en un movimiento social; las historias locales -que trasciende e impulsan a los protagonistas de un conflicto-, que muchas veces permiten entender las formas en que la gente reflexiona sobre su participación en un movimiento social, y la formas ya conocida en la que acciona; entre otras.

¿Qué tan decisivo es un espacio para que pueda desarrollarse favorablemente un grupo? En el caso de movimientos impulsados por trabajadores y trabajadoras, es claro observar las particularidades por demás positivas con que el lugar de trabajo impactará sobre la acción del grupo en ciernes. El espacio es un elemento constitutivos de las formas específicas en que se desarrolla un conflicto dado.(...)". (Oslender, U.: 2002, pág.3). Y ese, es el lugar donde los trabajadores y trabajadoras tendrán más posibilidades de salir airosos en sus luchas.

El lugar de trabajo como espacio de resistencia. En la observación de esta investigación no debemos olvidar al sujeto particular que provoca la conflictividad, estos son agrupamiento sindicales insurgentes con carácter corrosivo hacia el "statu quo". Los posicionamientos críticos, serán parte de sus insumos básicos para lograr su conservación y crecimiento. El territorio natural para construir su poder deberá ser receptivo a acciones críticas al orden que pretende cambiar. Un espacio, que le permita movilizarse con mayor naturalidad, también frente a su antagonista oficialista en la lucha gremial.

¿Por qué es importante observar los conflictos en los lugares de trabajo? Porque el lugar de trabajo es -además- propicio para generar espacios críticos, espacios de resistencia al orden constituido; y como 
consecuencia de ello, aquí existen más posibilidades de cambiar liderazgos en las organizaciones, por conducciones más críticas.

Los movimientos sociales -en la TMR, los trabajadores y trabajadoras en estos conflictos lo son- tratan de desarrollar sus disputas en espacios favorables a su fuerza. Los establecimientos productivos, en la inmensa mayoría de los casos lo son. Allí, frente al espacio concebido y derivado de una lógica y saberes vinculados con las instituciones del poder dominante, los trabajadores y trabajadoras pueden oponer espacios que son construidos y modificados en resistencia a aquellos. Allí tratarán de construir su propio sentido del espacio. Son lo que Oeslender denomina "espacios de resistencia" o "contra-espacios". Lo que Lefebvre define como espacios de representación ${ }^{17}$.

Los agrupamientos de trabajadores y trabajadoras insurgentes buscan movilizar sus recursos en los establecimientos productivos donde trabajan, porque allí es donde pueden construir su poder sobre basamentos más fuertes, frente a las disputas desproporcionadas que deberán enfrentar en otros espacios. El lugar de trabajo, es la posibilidad firme de construir un contra espacio.

17 Frente a las representaciones del espacio, aparecen los espacios de representación. "Las representaciones del espacio se refieren a los espacios concebidos y derivados de una lógica particular y de saberes técnicos y racionales, "un espacio conceptualizado, el espacio de científicos, urbanistas, tecnócratas e ingenieros sociales" Estos saberes están vinculados con las instituciones del poder dominante y con las representaciones normalizadas generadas por una "lógica de visualización" hegemónica. Están representados como espacios legibles, como por ejemplo en mapas, estadísticas, etc.. Producen visiones y representaciones normalizadas presentes en las estructuras estatales, en la economía y en la sociedad civil. Esta legibilidad produce efectivamente una simplificación del espacio, como si se tratara de una superficie transparente. De esta manera se produce una visión particular normalizada que ignora a luchas, ambigüedades, y otras formas de ver percibir e imaginar el mundo". Los espacios de representación. "Estos son los espacios vividos que representan formas de conocimientos locales y menos formales; son dinámicos, simbólicos y saturados con significados, construidos y modificados en el transcurso del tiempo por los actores sociales. (...) Los espacios de representación no necesitan obedecer a reglas de consistencia o cohesión. Llenos de elementos imaginarios y simbólicos, tienen su origen en la historia -en la historia del pueblo y en la historia de cada individuo que pertenece a ese pueblo (conforme Henri Lefebvre, citado por Oslender, Ulrico)."(..) Se desarrollan constantemente en una relación dialéctica con las representaciones dominantes del espacio que intervienen, penetran y tienden a colonizar el mundo-vida del espacio de representación. El espacio de representación es entonces también el espacio dominado lo cual la imaginación busca apropiar. Es a la vez sujeto a la dominación y fuente de resistencia, el escenario entonces de las relaciones entre dominación y resistencia (...)".(Oslender, U.: 2002, pág.3). 
3. El lugar de trabajo, como arena inexorable. Aquí, tratamos de detectar la acción represiva selectiva del estado contra grupos disidentes al oficialismo de un sindicato; un lugar particular (el establecimiento en el que trabajan) y no en otro sitio. ¿Por qué es trascendental observar los conflictos laborales en los lugares de trabajo y no en otro espacio geográfico? Más allá de las argumentaciones teóricas que se mencionaron precedentemente, existe una razónexcluyente $\boldsymbol{y}$ pragmática por la que los noveles agrupamientos sindicales disputan en los lugares de trabajo sus posibilidades de liderazgo sectorial; solo allí, éstos tienen alguna lejana oportunidad -pero oportunidad al fin- de enfrentar con suerte a las conducciones oficialistas de sus gremios.

¿Por qué? ¿Cuál es la razón que marca este determinismo? El motivo es sencillo y de fácil reconocimiento. La distribución de poder que consolidó a través del tiempo el modelo sindical argentino, impide que cualquier conflicto laboral que tenga una dimensión mayor a la que enmarca las paredes de un establecimiento productivo, pueda llegar a ser liderado por otra estructura de conducción que aquellas que detentan su inveterado liderazgo.

Para poder comprender esta idea, se debe tener presente la construcción casi monolítica del poder que han logrado las organizaciones sindicales argentinas. Este se caracteriza por el dominio por parte de relativamente pocas estructuras, que ejercen su poder sobre vastísimas extensiones geográfica de representación, y munidas de una legislación específica que establece mecanismos que profundizan la uniformidad en la representación -priorizando a la "gran" organización-, que es protegida judicialmente por principios de interpretación que consagran la concentración (Corte, N.: 1994, pág. 20). Entre los que se destaca el reconocimiento por ley -para estas organizaciones-, del monopolio de representación de derechos colectivos.

Pero más allá de toda esta descripción, debemos comprender el efecto del paso del tiempo que asentó el poder de estas organizaciones, logrando una consolidación granítica de éstas a través de siete (7) décadas. Quienes accedan a las conducciones de estas estructuras, tendrá a su disposición todo tipo de recursos, en cantidad, calidad, y en la dimensión 
que se le requiera para realizar sus acciones. Esos recursos, puertas adentro de la organización, se vuelven aún más desproporcionados. Este es el escenario que impide "de hecho" que los grupos incipientes de oposición a esas conducciones puedan aprovechar otro espacio, que no sea aquel acotado a los establecimientos o empresas, para movilizar sus recursos y disputar el liderazgo.

Pero además, por otra parte, el grado de organización y recursos que tiene que disponer un grupo para poder promover y lograr iniciar una medida de fuerza que resulte de trascendencia al colectivo que debe representar, son de una magnitud tal, que exceden largamente a los recursos con los que cuenta -casi siempre- un grupo disidente. Estos últimos solo tendrán su oportunidad de movilizar con suerte sus escasos recursos y lograr representividad -y así lo piensan-, en los límites cercanos, conocidos y propios que configuran sus lugares de trabajo.

Los grupos no oficialistas en un sindicato, promueven sus disputas allí. No solo porque se sienten más seguros y más fuertes, sino porque ese es el único lugar donde pueden desarrollar su lucha y madurar un liderazgo en disputa con los oficialismos que enfrentan.

El lugar de trabajo, dada la realidad que impone la organización sindical de los trabajadores y trabajadoras en nuestro país, es el lugar excluyente e inexorable donde las agrupaciones de trabajadores y trabajadoras insurgentes, puedan disputar con algo de suerte la representatividad sectorial frente a las conducciones consolidadas.

Aquí, en este invernadero, es donde interesa observar las posibilidades de los nuevos agrupamientos críticos. Aquí también interesa más que en otro sitio- controlar si existe acción selectiva y discriminatoria del estado hacia ellos.

4. El lugar de la crisis de dominación celular. ¿Qué hay detrás de la escena de esta disputa? ¿Qué orden económico-social protege el estado? Quizás en las respuestas a estas preguntas, radiquen las razones más profundas de la represión. ¿Se pueden relevar hechos críticos a ese orden y relacionarlos con las conductas represivas?

Los trabajadores y trabajadorasmuchas veces intentarán transformar el orden social dominante, y naturalmente ese intentolo harán en el lugar 
de trabajo. Los trabajadores y trabajadoras generan conflictos en los lugares de trabajo, porque saben que allí puede que se produzcan situaciones de crisis (y las oportunidades) en el sistema que quieren transformar. Lo saben ellos, los saben los dueños de los establecimientos, lo saben el resto de los actores que se benefician del orden, y lo sabe el estado como garante del mismo.

En los establecimientos productivos, se puede llegar a producir lo que Guillermo O Donnell denomina "crisis de dominación celular" o "social" (O'Donnell, G.: 1982, pág.52). Una crisis que afecta al fundamento mismo de la sociedad capitalista. Los trabajadores y trabajadoras, desde su historia y tradición, lo saben e impulsan su reproducción. Por su conciencia y decisión, en oportunidades las conductas y gestos que reproducen al sistema, son cuestionados o no se reproducen.

¿En qué consiste esa crisis? "(S)e trata de la aparición de comportamientos $y$ abstenciones de clases subordinadas que ya no se ajustan, regular y habitualmente, a la reproducción de las relaciones sociales centrales en una sociedad qua capitalista. (...)" O 'Donnell, G.: 1982, pág.51).

¿Dónde se evidencian esas crisis? "Esto puede aparecer en la caducidad de ciertas pautas de deferencia hacia el superior social, en diversas formas expresivas (incluso artísticas) "inusuales", en cuestionamientos de la autoridad habitual en ámbitos como la familia y la escuela,y -categorizando específicamente esta crisis- como una impugnación del mando en el lugar de trabajo. Esto implica no dar por irrefutable la pretensión de la burguesía de decidir la organización del proceso de trabajo, apropiarse del excedente económico generado y resolver el destino de dicho excedente." ( O 'Donnell, G.: 1982, pág.51). El lugar central donde aparece manifestada esta crisis, ha sido hasta este tiempo histórico, el establecimiento productivo.

¿Se pueden registrar esas conductas que denotan crisis de dominación celular? Entendemos, que se pueden identificar y relevar. Con posterioridad se podrá establecer una correlación entre represión y conducta crítica hacia el orden.- 
En nuestro estudio, ¿qué conductas concretas serán? Siguiendo las nociones que brinda O'Donnell, esas conductas se registran indubitablemente cuando las acciones de los trabajadores y trabajadoras consisten en una ocupación o un bloqueo de la planta. De esto no habría duda; ninguna ocupación dejaría de tener este carácter.

No obstante este registro podría ser objeto de alguna crítica, si se cuestionara una posible convencionalidad en estas medidas, y su posible desactivación disruptiva (Tarrow, S.: 1997, pág. 191). Ello se podrán suponer - por ejemplo- cuando las acciones son adoptadas por un sindicato oficialista, en el camino natural y circunstancial de confrontación propio del proceso de negociación con los empresarios.

En ese caso también deberíamos volver la mirada para observar que sucede con la representación de los trabajadores y trabajadoras"intra muros" de la empresa en conflicto y esas conductas críticas. La representación de los trabajadores y trabajadoras allí, ¿cumple con un rol complementario a ese proceso de negociación y confrontación que lidera el sindicato oficial? o ¿tendrá otra funcionalidad? Porque de ser otra la funcionalidad, una función que resulte autónoma -y confrontrativa- de la propia dirección centralizada del sindicato, podríamos acercarnos de un modo más confiable al registro de esas conductas críticas del sistema de las que habla O 'Donnell.

¿De qué funcionalidad podríamos estar hablando?, lo que Sturhtall numera en su tipología como "quinta función"; aquellas rebeliones periódicas que los trabajadores y trabajadoras orientan sobre sus dirigentes, y que pueden tener a las representaciones sindicales en las empresas como base organizativa autónoma. En este caso, sumando ambos registros -acción de ocupación o bloqueo, y el relevamiento de la función de construcción de poder autónomo - se disiparán en términos generales las mayores dudas al investigador, de estar frente a un registro cercano de crisis de dominación celular.

¿Se puede hacer ese relevamiento sobre los propios registros que analiza este trabajo? Entendemos que sí. EI MTESS lleva un pormenorizado registro de todo lo que sucede en el ámbito de trabajo. De sus propios monitoreo es que se puede buscar la existencia o no de estos registros, y relacionarlos. De concretarse, se podrá establecer una correlación de interés 
a nuestro objeto de observación, para poder analizar si existe una acción coercitiva del estado frente a la aparición de esta crisis; o si el estado tiene otra actitud.-

Alerta para el sistema. La aparición de elementos que releven esta crisis, es una señal de alerta que se produce en aquellos que ejercen su posición dominante. ¿Por qué motivo? Porque la conducta anormal se puede esparcir, conservarse y hacerse resistente al medio hostil; al fin de cuentas, propagarse y poner en riesgo al propio sistema.De no mediar corrección, la crisis se agravará para el orden imperante (O'Donnell , G.: 1982 , pág.53) $)^{18}$.

18"La crisis de dominación puede,y tiene en el medio plazo, a combinarse con crisis de gobierno, de régimen y de expansión (así como, obviamente, de acumulación).Es decir, la combinación de la primera -que por sí misma se limita a los intersticios celulares de la sociedad- con partidos y/o personal gubernamental que, engarzándose con aquel sacudimiento celular,proponen desde los grandes escenarios políticos nuevos criterios de representación y nuevos sujetos políticos dominantes para la instauración de un nuevo orden social, no ya la recomposición del dado" (O 'Donnell, G.: 1982, pág.53).- 


\section{LOS CONFLICTOS LOCALIZADOS.}

1 . Conflicto Laboral y espacio. Clasificación de los conflictos. ¿Qué tipo de conflicto laboral resulta de interés para este estudio? Como todo concepto, el interés del cientista social o del operador del sistema, lo introduce en una tipología o clasificación, según sea su necesidad de observación y su interés para comprender el fenómeno; o -en el segundopara poder operar con éxito sobre la realidad que observa (Roldán, P. L.: 1996 pág. 9-29).

Existen en la sociología y en la disciplina jurídica, distintas clasificaciones de los conflictos. Ellas pretenden auxiliar al observador $u$ operador del sistema a resolver los variados problema que enfrentan.Por ejemplo, la distinción clásica entre medidas de acción directa motivadas en conflictos de interés o en conflictos de derecho (Capón Filas, R.: 2014, pág.851); auxilian a los operadores del sistema judicial para establecer las responsabilidades contractuales concretas -salarios, licencias, etc.- que deban soportar o no, los huelguistas o sus empleadores al momento de evaluar las conductas originadas en una huelga.

Las clasificaciones son tantas como tantas las necesidades de los cientistas; conflictos diferenciados por las distintas causas que lo originan (Spaltemberg, R.: 2012), conflictos que se distinguen por la tipología de las medidas adoptadas (Capón Filas, R.: 1989, pág.431), conflictos intrasindicales o intersindicales, etc. (Cornaglia, R.: 2004, pág. 315; Capón Filas, R.: 2008, pág.323 y 462).

2. Conflictos industriales y localizados. Una de las clasificaciones más relevantes para los operadores del sistema, es la que distingue los conflictos en razón al espacio o límite geográfico en el que se desarrollan. Esta tipología clásica en la disciplina laboral, distingue entre conflictos "de rama de actividad" -también llamados "industriales"- y los conflictos "localizados".

Aparecen aquí, dos niveles de conflictos laborales con diferentes configuraciones y que reflejan la incidencia de factores de distinta naturaleza. 
Conflicto de rama de actividad Son los conflictos que no se desenvuelven en espacios de interacción acotados a los lugares de trabajo. Su ámbito es siempre mayor. En el nivel de rama de actividad, se caracteriza este tipo de conflicto por una tendencia a registrar huelgas de gran tamaño y breve duración. La interpretación de esta configuración permite conocer lo que sucede anualmente en las disputas protagonizadas por sindicatos centralizados en el nivel nacional (o vastas regiones) que nuclean a la mayor parte de los asalariados. Estos conflictos son siempre liderados por agrupamientos de trabajadores legitimados (Spaltemberg, R.: 2012, pág.1).

Siguiendo la caracterización de estos,los conflictos de rama carecen de interés para este estudio. Los conflictos de rama, siempre son liderados por conducciones oficiales. ¿Por qué los agrupamientos no legitimados no incursionarán en roles protagónicos en estos enfrentamientos? ¿Cuáles son las principales razones? Ya fueron brevemente referidas, los distintos factores que componen al modelo sindical argentino, impiden en la realidad que cualquier conflicto laboral que se suscite y exceda las reducidas dimensiones de un establecimiento o una empresa, pueda llegar a ser liderado por otra estructura de conducción que las que ya detentan su inveterado liderazgo. Remitimos aquí, a lo ya expresado.

El grado de organización y recursos de que dispone un agrupamiento disidente para poder promover, articular y liderar una medida de fuerza de estas dimensiones, son de una magnitud sideral que exceden largamente a los pocos recursos con los que cuenta -casi siempre- un grupo aún no legitimado. Por otra parte recordemos, que estos agrupamientos no están legitimados por el estado para representar los derechos colectivos del sector.

Esta situación asimétrica ya consolidada, muestra crudamente los límites que la realidad le impone a un agrupamiento disidente. Una vez que se asienta una conducción al frente de un sindicato (extenso y con gran número de trabajadores), a los futuros contendientes se le presentarán obstáculos inalcanzables de vencer para imponer sus políticas y lograr el desplazamiento de la conducción de su sindicato y acceder a la misma. Entre esos condicionamientos se destaca el marco legal fuerte que tiene el 
ordenamiento argentino (Trajtemberg, D.: 2012, pág.22). Estos agrupamientos, no pueden ejercer el control sobre este tipo de conflicto de entidad. Esto no quiere decir que los agrupamientos disidentes de las conducciones oficiales no participen, por el contrario lo hacen y activamente en los mismos; pero no lo harán liderándolo, o poniendo en serio riesgo la posibilidad de obtener el reconocimiento de la representatividad de sus pares.

De aquí deviene el desinterés en los conflictos industriales para esta investigación. Existe una negativa de los agrupamientos no legitimados a disputar el liderazgo sectorial en estos conflictos; y la misma se motiva en ese fárrago enorme de condiciones adversas que tienen para intentar promoverlos y controlarlos; lo que resultaría un dispendio irremediable de recursos.

Estos agrupamientos de trabajadores y trabajadoras buscarán inexorablemente disputar el liderazgo sectorial en otro escenario que no le resulte tan desmedidamente adverso. Una arena de lidia más acotada, donde no se le escurran sus escasos recursos. Una arena, donde puedan ejerce el liderazgo en acciones que decidan ellos y no su antagonista, las conducciones oficiales de los sindicatos a los que aspiran sustituir.-

3. Conflictos localizados. Los grupos insurgentes solo tendrán posibilidades fácticas de disputar el liderazgo de representación en ámbitos más reducidos. De allí la importancia que para este estudio reviste observar las conductas de trabajadores y trabajadoras y del estado en conflictos localizados.Los grupos no oficialistas en un sindicato, promueven sus disputas allí, porque ese es el único lugar donde pueden desarrollar su lucha y madurar un liderazgo en disputa con los oficialismos que enfrentan.-

Conflictos localizados, son aquellos conflictos que se desenvuelven en espacios de interacción acotados a los lugares de trabajo. "Los conflictos circunscriptos al lugar de trabajo, es decir, los que afectan la relación laboral entre un solo empleador y los trabajadores que se desempeñan en su unidad económica (establecimiento o empresa)" (Spaltemberg, R.: 2012, pág.97/8). Caracterizan a estos conflictos, huelgas en este tipo de enfrentamientos que tienden a ser de menor tamaño y de mayor duración.( Spaltemberg, R.: 2012, pág.96) 
Los conflictos localizados responden a una variada gama de factores de diverso orden. Pero es en este tipo particular de conflictos, donde el observador puede registrar la movilidad de las representaciones sindicales en los lugares de trabajo. Es importante observar los conflictos localizados para este trabajo, porque es en esas lidias, donde puede aparecer la disputa por un nuevo liderazgo en una organización sindical.( Spaltemberg, R.: 2012, pág.96).

La desagregación de los conflictos localizados, permitiría individualizar para su análisis, aquellos conflictos que posibilitan la emersión de agrupamientos de trabajadores disidentes. Estos grupos tienen una tendencia a movilizar recursos en este tipo de conflictos.

De conformidad a las contribuciones teóricas del llamado enfoque sobre "movilización de recursos" -y reconocido por los propios observadores del MTESS-, éste es el espacio donde los grupos insurgentes tienen mayores posibilidades de movilizar recursos (frente al estado y frente a los agrupamientos de trabajadores y trabajadoras legitimados); y donde estos grupos pueden realizar mayores acopios de recursos, materiales y simbólicos (Spaltemberg, R.: 2012, pág.96). ${ }^{19}$.

Los agrupamientos disidentes saben $-y$ el sentido común lo acompaña-, que solo aquí tienen posibilidades ciertas de disputar con suerte un enfrentamiento que les permita acceder a la representatividad sectorial. Estamos en el escenario y frente al primer "gran paso", para acceder a la conducción sindical del sector. Los trabajadores, los antagonistas sectoriales, los empresarios y el estado, también lo saben.-

19 "El comportamiento de los conflictos de este nivel evidenciaría un implante creciente de las representaciones sindicales en los lugares de trabajo. (...) Esta interpretación estaría en sintonía con algunas de las principales contribuciones teóricas del llamado enfoque sobre "movilización de recursos" (Spaltemberg, R.: 2012, pág.96). 


\section{LA TRASCENDENCIA DEL DERECHO DE HUELGA PARA LOS TRABAJADORES Y TRABAJADORAS.}

1. La lucha. ¿Qué tan trascendente para los trabajadores y trabajadoras es el ejercicio del derecho de huelga?Todas y cada una de las instituciones que hoy integran el edificio del derecho del trabajo, hunden sus cimientos y fueron precedidas inevitablemente, por la lucha de los trabajadores.

La huelga ha sido, y es, la partera de todos sus derechos. Por ello debe observarse con mucho interés sus manifestaciones; aún, cuando ésta se acune en las frágiles manos de un inadvertido grupo. Del tesoro fecundo que para ellos guarda, nace la importancia y la razón que origina su protección.

Las representaciones artísticas que asocian a "la Justicia" con una figura humana munida de una invencible espada -cuyo origen se pierden en el tiempo-, atestiguan la creencia inveterada que la fuerza es un elemento constitutivo para garantizar todo orden justo. Una fuerza que hoy monopoliza el estado, pero que el ordenamiento social y legal, reconoce y autoriza -latente y cierta- también en las manos de los más débiles cuando se defienden. El ejercicio del derecho de huelga, es una de sus más claros ejemplos.

Ese permiso no debe ser olvidado. Por esas mismas razones, esta disputa antagónica -y consustancial con el sistema democrático- deba ser mirada sin prejuicios, como oportunidad de resguardo de derechos a construir que se manifiestan en la contienda, y no como una patología que deba ser eliminada del cuerpo social (Capón Filas, R.: 1989, pág.416) .

Los trabajadores como fuente de derechos. La conducta de lucha de los propios trabajadores y trabajadoras es la fuente de sus derechos. Por eso debe ser resguardada. Cada una de las instituciones del derecho del trabajo han nacido de sus propias luchas. No ha sido el Estado, quien graciosa y desinteresadamente reconoció u otorgó esos derechos. El derecho laboral es creación primigenia de los propios actores sociales - 
empresarios y trabajadores, pero prioritariamente impulsado por los trabajadores-, y no del estado. Éste último, no ha de extrañar, ante la aparición de un nuevo poder social, un nuevo contendiente que -de modo creciente e irremediable- impulsa reclamos postergados, los reconocerá. Muchas veces tardía y de forma incompleta, pero los reconocerá.-

Al igual que otros tantos grupos humanos que emergen, los trabajadores y trabajadoras logran una mejor posición en la sociedad, conquistando derechos a través de la lucha. La idea no es nueva; por el contrario, el reconocimiento de este elemento agonal, es antiguo. La tesis central de Rodolfo Von Ihering en su libro "La lucha por el derecho" (1872), que acompaña a cada generación de abogados, recuerda la necesidad insoslayable de esa lucha para parir un derecho y para mantener su vigencia $^{20}$

\section{Los mecanismos de protección de los trabajadores y} trabajadoras preceden al constitucionalismo social y la existencia de la OIT. Por ser pertinente, es oportuno recordar que los institutos más relevantes del derecho del trabajo -entre ellos la huelga- han nacido con anterioridad al Constitucionalismo social (Constitución Mejicana y de Weimar) y a la obra señera de Organización Internacional del Trabajo. El derecho del trabajo -parafraseando a Cornaglia- ha nacido "sin autorización y sin ley". La lucha de los trabajadores, es la matriz de los derechos más esenciales de este colectivo humano. Su conducta intransigente, y su obrar encajonado en las instituciones que ellos mismos supieron construir -las que conforman la denominada autonomía sectorial-, son la matriz desde donde nacen los derechos en el derecho del trabajo

Coincide con esta afirmación, la idea difundida hoy de comprender al derecho constitucional como una superposición de derechos adquiridos por las sucesivas minorías a través del tiempo (Ferrajoli, L.: 1997, pág.54) .

\footnotetext{
20 "La finalidad del derecho es la paz, el medio para ello es la lucha. En tanto que el derecho tenga que estar preparado contra el ataque por parte de la injusticia -y esto durará mientras exista el mundo- no le será ahorrada la lucha. La vida del derecho es lucha, una lucha de los pueblos, del poder del Estado, de los estamentos o clases, de los individuos. Todo derecho en el mundo ha sido logrado por la lucha, todo precepto jurídico importante ha tenido primero que ser arrancado a aquéllos que le resisten, y todo derecho, tanto el derecho de un pueblo como el de un individuo, presupone la disposición constante para su afirmación. El derecho no es mero pensamiento, sino fuerza viviente" (Von Ihering, R.: 1872).
} 


\section{La hiposuficiencia y su respuesta, la autonomía sectorial.}

Los trabajadores y trabajadorasconforman un grupo humano siempre expuesto a condiciones políticas, económicas y sociales que lo ponen en una posición vulnerable. Es su necesidad, lo que las hace personas en condiciones de vulnerabilidad. Los trabajadores y trabajadoras conforman un colectivo dentro de la sociedad, los agrupa su nota distintiva, su condición hiposuficiente ${ }^{21}$. Todo trabajador vive en una posición hiposuficiente. "Esta necesidad (...), se agrava por las circunstancias concretas del sistema social, que no sólo la mantiene sino que la multiplica, concentrando el capital de la potencia activa o suficiente en titularidad de escasas personas. Esta concentración se aumenta más aún en nuestra sociedad, que coloca la tecnología útil en esas mismas manos, generando un poderío totalizante (económico, cultural, social, político) como hasta ahora no se había conocido en la historia humana" (cita de Mater et Magistra, párrafo no 171, en Capón Filas, R.: 1979, Tomo I, pág.75).

¿Cuál es la respuesta del grupo vulnerable para transformar su realidad desde su condición hiposuficiente? La autonomía sectorial, será su respuesta. El ser humano -sujeto gregario al fin-, frente a los avatares que sufre en la vida, se acercará a aquellos que sufren sus mismos problemas, para lograr una respuesta común. Cada sector de una sociedad tiende a agruparse con personas que tienen similares intereses. Los trabajadores y trabajadoras decididamente entonces, construirán los instrumentos que les permitan transformar su realidad.

La consecuencia de esta hiposuficiencia, y su respuesta como grupo en condiciones de vulnerabilidad será la autonomía sectorial. (Capón Filas, R.: 1989, pág. 35). Ésta, es un dato de la realidad,una respuesta inevitable, que se da en el plano sociológico. Es la forma -y las manifestaciones organizacionales- en que los propios sectores de una sociedad -en este caso

\footnotetext{
${ }^{21}$ En el sistema social aparecen posiciones de poder o de disponer. "Posición es el lugar dado al hombre en el sistema social para que con su libertad, pero condicionado a las circunstancias, construya su propio camino, de acuerdo a los acontecimientos que le sobrevienen y según lo que el mismo logra determinar". "Considerando la posición en el aspecto económico, podemos tipificarla como suficiente o hiposuficiente, según la posibilidad de cada hombre para desarrollar su vida sin mayores ataduras o con pesadas trabazones" (Capón Filas, R. :1979, Tomo I, pág.73).
} 
los trabajadores y trabajadoras- construyen sus derechos y buscan que sean reconocidos por el resto de la sociedad (incluyendo en un primer plano a los empresarios).

Autonomía sectorial. Manifestaciones. La autonomía sectorial, existe pues, como respuesta de los trabajadores y trabajadoras en la realidad del sistema jurídico. Perseguidas por la burguesía, luego toleradas y finalmente aceptadas (si bien han sido parcialmente desactivadas en tiempos autoritarios de la vida política de los países), sus distintas manifestaciones constituyen los grandes institutos que conforman el derecho colectivo de trabajo (la organización sindical, la huelga y la negociación colectiva). Los trabajadores y trabajadoras para ser autónomos, se organizan, luchan con sus antagonistas y se sentarán a negociar con ellos el nacimiento o la conservación de sus derechos.

Importancia de la autonomía sectorial. La autonomía sectorial en el mundo laboral, reúne los instrumentos de que se valen los trabajadores y trabajadoras para construir sus propias normas. El respeto por ese interés y protección que tienen los trabajadores como grupo vulnerable, es de tal trascendencia que se reconoce como principio axiológico específico (que nos permite valorar la justicia y constitucionalidad de una norma) y fundante del derecho colectivo del trabajo (Capón Filas, R.: 1992, pág. 23).

Organizarse, luchar y negociar son los instrumentos que le permiten a trabajadores y trabajadoras, defenderse y promover sus derechos. No son elementos estáticos; como en un film que narra una historia, así de encadenados estos tres (3) institutos pueden contar todas y cada una de los derechos que han conquistado. Todos estos elementos están íntimamente ligados, y no pueden ser desactivado ninguno de ellos, sin que esa inhibición constituya un ataque a las instituciones básicas que protegen a este grupo vulnerable.

Cuando queremos observar el valor central que tiene la conducción de la conflictividad colectiva -o ejercer el derecho de huelga-, no debemos perder de vista su presencia, básica y constitutiva, en el nacimiento y la protección de todos los derechos laborales que han tenido existencia. 


\section{EL DERECHO DE HUELGA.}

1. Libertad sindical. Definición. Cuando nosotros observamos desde el plano jurídico la noción sociológica de la autonomía sectorial, aparece el concepto de "Libertad sindical". La Libertad sindical es el principio universalmente reconocido que garantiza a los trabajadores el poder "actuar gremialmente en forma libre". (Cornaglia, R. :2004, pág.91). Sobre ese presupuesto existencial, los trabajadores pueden "actuar libremente y sin interferencias de terceros (incluso la autoridad), según la disposición que crean más conveniente para la defensa de sus derechos e intereses." (Cornaglia,R. : 2004, pág.92). Sobre esta base se ha construido -repetimos- todo el edificio moderno del derecho del trabajo (Corte, N.: 1994, pág.74).

Libertad sindical. Contenido. El contenido de lo que se denomina Libertad sindical, es vasto. La doctrina lo ha definido como "el conjunto de poderes individuales y colectivos, positivos y negativos, que aseguran la independencia de sus respectivos titulares en orden a la fundación, organización, administración y gobierno y actividad externa (actividad sindical) de las asociaciones profesionales de trabajadores" (Corte, N.: 1994, pág.74;citando a López Justo, "Aspectos de la libertad sindical", LT, XX-673"). Las manifestaciones de la autonomía sectorial de los trabajadores y trabajadoras, cobran aquí su vigencia, se reconocen como derechos.

El derecho de asociarse y de ejercer la huelga como manifestaciones inescindibles de la libertad sindical. La libertad sindical, importa el pleno ejercicio del derecho a organizarse y del derecho de huelga. Ambos son inseparables. El Comité de Libertad Sindical "ha reconocido siempre el derecho de huelga como un derecho legítimo al que pueden recurrir los trabajadores y sus organizaciones en defensa de sus intereses económicos y sociales"122, constituyendo "uno de los medios

\footnotetext{
${ }^{22}$ Véanse Recopilación de 1996, párrafo 474 y, por ejemplo 302.0 informe, caso núm. 1809, párrafo 381; 304.0 informe, caso núm. 1863, párrafo 356; 307.0 informe, caso núm. 1850, párrafo $120 ; 308 .^{\circ}$ informe, caso núm. 1900, párrafo 183; 311.er informe, caso núm. 1934, párrafo 126; $324 .{ }^{\circ}$ informe, caso núm. 2072, párrafo 587; 327.0 informe, caso núm. 1581, párrafo $111 ; 328.0$ informe,
} 
esenciales de que disponen para promover $y$ defender sus intereses profesionales" ${ }^{23} \mathrm{Y}$ para despejar toda duda lo considera el "corolario indisociable del derecho de sindicación protegido por el Convenio núm. $87^{\prime 24}$.

La Libertad sindical como forma del derecho de libertad de asociación. La libertad de asociación en materia sindical. La Libertad sindical y sus distintas expresiones, no son más que una forma en la que se manifiesta el derecho de libertad de asociación. Así lo expresa la COIDH: la libertad de asociación "(...)debe ser analizada en relación con la libertad sindical. La libertad de asociación, en materia sindical, consiste básicamente en la facultad de constituir organizaciones sindicales y poner en marcha su estructura interna, actividades y programas de acción, sin intervención de las autoridades públicas que limite o entorpezca el ejercicio del respectivo derecho.(...) Se trata pues, de un derecho fundamental de agruparse para la realización común de un fin lícito sin presiones o intromisiones que puedan alterar o desnaturalizar su finalidad". 25

\section{La libertad de asociación en materia sindical, integra el corpus} iuris de los derechos humanos. En el Caso Baena Ricardo y otros, también en el caso HuilcaTecse, la COIDH señaló: "[...] la libertad de asociación, en materia sindical, reviste la mayor importancia para la defensa de los intereses legítimos de los trabajadores y se enmarca en el

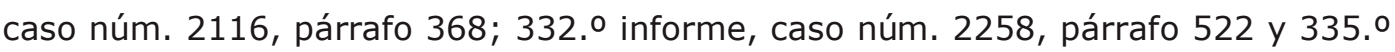
informe, caso núm. 2305, párrafo 505 (Oficina Internacional del Trabajo: 2006).

\footnotetext{
${ }^{23}$ Véanse Recopilación de 1996, párrafo 475 y, por ejemplo 299.0 informe, caso núm. 1687, párrafo 457; $300 .{ }^{\circ}$ informe, caso núm. 1799, párrafo 207; 306.0 informe, caso núm. 1884, párrafo 695; 308.0 informe, caso núm. 1934, párrafo $131 ; 310.0$ informe, caso núm. 1928, párrafo 176; 316.0 informe, caso núm. 1930, párrafo $365 ; 327.0$ informe, caso núm. 1581 , párrafo $111 ; 330.0$ informe, caso núm. 2196, párrafo 304; 335.0 informe, caso núm. 2257, párrafo 466; $336 .{ }^{\circ}$ informe, caso núm. 2340, párrafo 645 y $337 .{ }^{\circ}$ informe, caso núm. 2365, párrafo 1665 (Oficina Internacional del Trabajo: 2006).
}

\footnotetext{
${ }^{24}$ Véase 311.0 informe, caso núm. 1954, párrafo 405 (Oficina Internacional del Trabajo: 2006).

${ }^{25}$ Caso Baena párrafo 156.
} 
corpus juris de los derechos humanos". 26

\section{El derecho de huelga, su reconocimiento en el derecho}

positivo. El fenómeno social de la huelga, aunque tardíamente, ganó su reconocimiento positivo. ${ }^{27}$ Esta incorporación al ordenamiento resulta trascendente, legitimando así la aceptación de un instrumento jurídico que garantiza la socialización del poder y la democratización de las relaciones entre las personas.

Derecho de huelga en el Derecho Internacional. Este derecho también se ha positivizado internacionalmente. Sin perjuicio que la Organización Internacional del Trabajo (OIT) no ha incorporado en forma expresa, en sus Convenios, el derecho de huelga está plenamente reconocido por el organismo especializado de ONU. "La ausencia de normas expresas no debe llevar a inferir, sin embargo, que la OIT desconozca el derecho de huelga o se exima de garantizar un ámbito de protección al ejercicio del mismo. Dos resoluciones de la propia Conferencia Internacional del trabajo -que señalan pautas para la política de la OIT- han insistido de un modo u otro en el reconocimiento del derecho de huelga en los estados miembros. Concretamente, la resolución sobre abolición antisindical de los estados miembros, adoptada en 1957, instaba a la adopción de la legislación que asegure el ejercicio efectivo y sin restricción alguna, de los derechos sindicales por parte de los trabajadores, con inclusión del derecho de huelga"."(...) El derecho de huelga ha sido reafirmado también en varias resoluciones de conferencias regionales y de comisiones sectoriales de la OIT, asi como por otros organismos internacionales.... Por otra parte,aunque no menciona expresamente el derecho de huelga, el Convenio sobre Libertad Sindical y la Protección del Derecho de Sindicación, 1948 (núm.87), consagra el derecho de las

\footnotetext{
${ }^{26}$ CasoBaena Ricardo y otros, supra nota 13, párr. 158.
}

${ }^{27}$ Los mejicanos tienen el privilegio de ser el primer estado en el mundo que reconoce constitucionalmente el derecho de huelga (1917). El que comenzará a ser asumido en el resto de nuestro continente promediando el siglo pasado (Uruguay en 1942, Bolivia en 1945, Brasil en 1946). La República Argentina, que no lo incorporará en la reforma constitucional del año 1949, recién lo reconocerá de modo expreso en la reforma del año 1957. También se destaca un fuerte proceso de constitucionalización del derecho de huelga a las provincias que conforman nuestro país. 
organizaciones de trabajadores $y$ de empleadores "de organizar su administración y sus actividades y el de formular su programa de acción (art.3), y establece como objeto de dichas organizaciones "fomentar $y$ defender los intereses de los trabajadores o de los empleadores"(art.10)... A partir de estas normas de la OIT, el Comité de Libertad Sindical (desde 1952) y la Comisión de Expertos en Aplicación de Convenios y Recomendaciones (desde 1959), han reconocido en numerosas ocasiones el derecho de huelga, como derecho fundamental de los trabajadores y de sus organizaciones y han delimitado en que debe enmarcarse su ejercicio, elaborando un cuerpo de principios sobre el derecho de huelga (...)" (Dobarro, V. ; 2001).

\section{Derecho de huelga en el Derecho Internacional de Derechos}

Humanos. El derecho de huelga se encuentra -además- reconocido expresamente como derecho humano. Lo podemos relevar en forma expresa en el artículo $27^{\circ}$ de la Carta Internacional Americana de Garantías Sociales (1948), en el artículo 80.1.d) del Pacto Internacional de Derechos Económicos, Sociales y Culturales.; en el artículo $\left.8^{\circ} 1, b\right)$ del Protocolo Adicional de San Salvador de la Convención Americana sobre Derechos Humanos. El mismo además estará tutelado a través de otros derechos. Así la Convención Americana sobre Derechos Humanos en su artículo $16^{\circ}$ y la Declaración Americana de los Derechos y Deberes del Hombre en su artículos XIV lo harán a través del derecho de asociación; y a través del reconocimiento del derecho a fundar sindicatos, se podrá recoger en los artículos $22^{\circ}$ y 230 de la Declaración Universal de Derechos Humanos y el artículo $22^{\circ}$ del Pacto Internacional de Derechos Civiles y Políticos. 


\section{LAS MEDIDAS DE FUERZA COMO RECURSOS.}

\section{Los conflictos laborales en la teoría de movilización de}

recursos. Partamos de una pregunta básica, ¿qué es un conflicto laboral? Por conflicto laboral se entiende la serie de eventos desencadenados a partir de una acción conflictiva realizada por parte de un grupo de trabajadores y y trabajadoras o empleadores con el objeto de alcanzar sus reivindicaciones laborales" (MTESS: 2007).La acción conflictiva ${ }^{28}$, reúne a la totalidad de las numerosas modalidades de acción que ejercitan los trabajadores y trabajadoras para defender y promover sus derechos. Las mismas van desde la simple comunicación de un conflicto, hasta formas más intensas como bloquear una planta u ocuparla.

¿Por qué utilizamos como unidad de análisis la noción de conflicto laboral y no la noción de huelga? La noción de conflicto laboral contiene la totalidad de las acciones conflictivas de los trabajadores y trabajadoras; no solo aquellas que responden a través de la interrupción del trabajo -que caracteriza a la huelga-.

Tomamos así, la perspectiva adoptadapor el MTESS en el año 2006, cuando cambia el indicador para observar la conflictividad en el mundo del trabajo. El MTESS deja de tomar a la huelga como unidad de análisis, para pasar a registrar el conflicto laboral, y de este modo se comienzan a relevar a todas las formas de acción que llevan adelante los trabajadores y trabajadoras. Esta noción -notoriamente más amplia- permite a los

28 "La OIT distingue diferentes tipos de acciones. Por un lado, la clásica de huelga: "Se entiende por huelga una interrupción temporal del trabajo efectuada por uno o varios grupos de trabajadores con objeto de obtener reivindicaciones o rechazar exigencias o expresar quejas o apoyar las reivindicaciones o las quejas de otros trabajadores". Por otro lado, las otras acciones conflictivas: "Se entiende por otras acciones causadas por conflictos laborales las acciones desarrolladas por uno o varios grupos de trabajadores o por uno o varios empleadores con objeto de lograr reivindicaciones, rechazar exigencias o expresar quejas o apoyar las reivindicaciones o las quejas de otros trabajadores, sin que impliquen una interrupción del trabajo" (OIT, 1993).Son además de las huelgas, "otras acciones con efectos similares sobre la producción, como el denominado boicot o la expresión de los reclamos traducidos en manifestaciones y "movilizaciones", también se incluían en el repertorio de acciones a ser registradas y medidas por las estadísticas del trabajo" (MTESS: 2007, pág.19) 
operadores del sistema un conocimiento más profundo e íntegro de los $\operatorname{conflictos}^{29}$. Un conocimiento -además- que permite una mejor intervención sobre las relaciones de producción, porque en el relevamiento es casi en tiempo real.

Por el contrario, el relevamiento acotado exclusivamente a los conflictos que interrumpen la producción, solo permite ver una porción -si bien, la más álgida- de los conflictos que se desarrollan en el mundo de las relaciones de producción; pero quedando en este caso fuera del análisis, todas las primeras fases de menor intensidad en los conflictos, tiempo este en el que se podría activar los dispositivos preventivos y de encausamiento de los conflictos. El estudio, y encauzamiento de los conflictos en etapas tempranas resultaría a todas luces valiosa, pues produciría una menor pérdida de energía societal -y económica-.

Por otra parte, tomar como dato significante para entender la conflictividad laboral, solamente a la pérdida o interrupción del trabajo, presume una visión rígida -muchas veces irreal- acerca de los objetivos que los trabajadores y trabajadoras organizados tienen en el momento de llevar adelante una medida de acción.

2. Complementación metodológica con fuente principal. La adopción de esta unidad de análisis responde -además- a una razón metodológica. Con la utilización en esta investigación del concepto de conflicto laboral, desde un punto operativo y práctico, nos adecuamos a las modalidades de análisis y seguimiento que realiza el MTESS, pudiendo realizar nuestra investigación de modo integrado con su base de datos, que resulta fuente principal a la que abrevamos en este trabajo.

29 "La definición de una nueva unidad de análisis, el conflicto laboral, busca resolver los diversos problemas planteados a través de la integración de diferentes formas de acción de los trabajadores. Las otras acciones incluidas en los conflictos laborales, que van desde el mero aviso de la disposición de los trabajadores a realizar paros hasta otras acciones mucho más "intensas" como bloqueos de rutas y calles, ocupaciones, etc., constituyen otras tantas manifestaciones del conflicto laboral. Además, a lo largo de un mismo conflicto laboral, esas diferentes acciones pueden coexistir, lo que habilita la posibilidad analítica de distinguir una gama amplia de "tipos" de conflicto laboral" (MTESS: 2007, pág. 21). 
En nuestra investigación, la elaboración partimentada por tipo de medida y los diferentes grados de intensidad alcanzados en ellas, nos permitirán relevar la adhesión alcanzada por el resto de los trabajadores y trabajadoras. $Y$ además, poder precisar -medianamente- que es en ese momento favorable en el que las fuerzas de seguridad intervienen en el conflicto; limitando las posibilidades de alcanzar nuevos acopios de recursos (entre ellos lograr la representatividad de sus pares) y la aparición de nuevos liderazgos por los agrupamientos de trabajadores y trabajadoras no legitimados.

\section{Los conflictos laborales y la teoría de movilización de}

recursos. ¿Por qué nos interesa estudiar los conflictos laborales en este trabajo?Los conflictos laborales siempre son, en torno a la búsqueda y acopio de recursos (materiales, humanos, simbólicos). En este trabajo analizamos un sector de la realidad, donde la movilización es realizada por agrupamientos sindicales aún no reconocidos.

Nos interesa estudiar los conflictos laborales, porque a través de ellos, los trabajadores y trabajadoras movilizan recursos, mantienen o acopian nuevos (la representatividad sectorial, principalmente en nuestro caso). $\mathrm{Y}$ todo lo hacen para posicionarse mejor, y para lograr en forma inmediata o en el tiempo, poder incidir en el universo sectorial y societal en el que están insertos.

En este trabajo se debe observar la acción conflictiva, sostenida por este sentido. Si el estado corta este circuito, estará entorpeciendo la emersión del nuevo agrupamiento sindical. Pero si a ello agregamos la comprobación de su ilegalidad, surgirá la obligación de remover dicho obstáculo. 


\section{LA REPRESION. LA LUCHA POR EL PODER, $\begin{array}{lll}\text { ESTADO } & Y & \text { CONTENDIENTES } \\ \text { NO }\end{array}$ RECONOCIDOS.}

1. La represión y los grupos insurgentes. ¿Por qué analizamos a la represión en este estudio? ¿qué incidencia tiene en la emersión de la voluntad colectiva de un grupo de trabajadores y trabajadoras?

"La lucha por el poder político radica, en esencia, en la obtención de recursos para influir sobre otros grupos, y hacer prevalecer los intereses propios sobre los de otros colectivos con los que se está en conflicto". (González Callejas, E.: 2012) "La movilización es un modo de obtener y disponer determinados recursos para la consecución de ciertos fines. La disputa será dada por las organizaciones colectivas con capacidad de agenciar y controlar recursos. (conforme citas de Zald y McCarthy, 1977; en Paredes J.: 2013)".

Los contendientes -reconocidos o no- tratan y deciden $-\mathrm{y}$ en ello arriesgan-movilizar sus recursos con la mayor eficacia posible. Las medidas de acción directa que llevan adelante los trabajadores y trabajadoras organizados, no es más que una forma que expresa esa pretensión de obtención de recursos y de incidencia en la sociedad.

Pero esta competencia por el poder, implica la movilización de intereses y de recursos en presencia de una organización particular, que es el Estado. Éste, controla los principales resortes para alentar o frenar la movilización de reivindicaciones.

Y el trato que el Estado tiene con relación a los distintos actores sociales, no es el mismo. "Si un grupo ha conseguido ver reconocidos sus derechos colectivos, tener poder sobre el gobierno, y desarrollado medios rutinarios y aceptados para ejercer esos derechos, se transforma en un contendiente reconocido que actúa como miembro de la comunidad política. Pero los contendientes que no utilizan medios rutinarios ni aceptados legalmente para presentar reclamaciones al gobierno son retadores ajenos a 
esa politeya y susceptibles de ser atacados por el Estado u otros grupos rivales" (conforme TILLY, Charles; citado en González Callejas, E.: 2012).

Los agrupamientos sindicales insurgentes, obligadamente se deberán enfrentar con este particular actor. De esto, habla este trabajo.

La TMR -esa es la perspectiva teórica que se impone en este trabajo- entiende por movimiento social a las conductas racionales de los actores colectivos que buscan insertarse en un sistema politico, mantenerse y extender su influencia movilizando toda clase de recursos, incluida, dado el caso, la violencia.(Brúñete, I. y Pizza, A.: 2010, pág.28).

2. Noción de represión. En nuestro estudio, ponemos el foco sobre la represión que ejerce el estado sobre los trabajadores. ¿Qué entendemos por represión en este trabajo? La represión puede ser conceptualizada como "una acción reguladora que los gobiernos adoptan contra los individuos o los grupos que desafían las relaciones existentes de poder" (conforme DAVENPORT, Christian, citado en González Callejas, E.: 2012); o como el "empleo o la amenaza de coerción en grado variable, aplicada por los gobiernos sobre los opositores reales o potenciales con vistas a debilitar su resistencia frente a la voluntad de las autoridades" (conforme STOHL, Michael y LOPEZ, George A.; citado en González Callejas, E.: 2012).

En esencia, la represión -siempre- consiste en un acto de discriminación, hacia algún actor en detrimento de otro. Los gobiernos discriminan a "personas o a organizaciones que se considera que presentan un desafío fundamental a las relaciones de poder existentes o las políticas clave del gobierno"( conforme GOLDSTEIN, Robert J.;citado en González Callejas, E.: 2012).

Es también un acto restrictivo que tiene por objeto el control y la sanción de conductas entendidas como "desviadas" en el orden ideológico, político, social o moral. La represión queda así, más cercana al concepto de fuerza legítima monopolizada por los gobiernos.

La represión no se identifica con violencia física. La represión no es identificada con la violencia física o corporal. Su noción en las ciencias sociales hoy, está más vinculada a la idea del control social que al uso de la 
fuerza. La represión desde esta comprensión, incluiría en este ideario un amplio espectro de conductas que van desde la eliminación del actor social que desafía sus decisiones o políticas, hasta el aparentemente imperceptible estímulo para cooptar políticas públicas o modificar conductas privadas de los individuos.

La noción de control social puede ser definida como"el conjunto de medios de intervención, positivos o negativos, que utiliza una sociedad o un grupo social para conformar a sus miembros a las normas que le caracterizan, impedir o desanimar los comportamientos desviados, $y$ reconstruir las condiciones de consenso en caso de un cambio en el sistema normativo".(conforme GARELLI, Franco; citado en González Callejas, E.: 2012). El perfeccionamiento de los mecanismos de control social, el auxilio muchas veces invisible y silencioso de nuevos medios tecnológicos, amplía y consolida ese control social ajeno al uso de la violencia física.

El uso de la fuerza. Diremos lo obvio, aún ante la omnipresencia de este control social sobre los individuos que viven en una sociedad determinada, el uso de la fuerza mantiene su vigencia. En este estudio nos dedicamos a observar el uso de la fuerza, y su función.

Los propósitos que impulsan el ejercicio del uso de la fuerza pueden ser variados, pero siempre responden a la intención del poder (en este caso el estado) de impedir la realización de conductas no deseadas por otros actores sociales; que no han podido ser desactivadas. Y por eso, el estado alcanza a ejercer la violencia como "última ratio", cuando el resto de su batería de actos no pudo impedir la conducta del díscolo. Sea que la violencia física se ejerza para disuadir preventivamente la realización de las conductas no queridas, o sea cuando tenga por objeto sancionar o castigar a los actores sociales que no respetan el orden dado.

3. Factores que determinan las movilizaciones. De todo el universo de elementos que componen su contexto, ¿cuáles son los factores que son evaluados por los trabajadores y trabajadoras por tener mayor incidencia en el éxito o en el fracaso de las movilizaciones (en el éxito o fracaso del acopio de recursos)? ¿qué elementos del contexto consideran los grupos antes de decidir movilizarse?; o dicho de otro modo, ¿qué factores ordenan la racionalidad de sus actos? 
Ya lo referimos. Allí aparece en el horizonte de sus pensamientos y memoria, la represión y el uso de la fuerza. Proyectar la realización de movilizaciones, enfrenta a los sujetos que las llevan adelante ante una crucial disyuntiva, evaluar los distintos factores que las influencian positiva o negativamente para el resultado de su acción.

¿Qué factores son los determinantes para decidir esas conductas racionales por parte de los grupos? La doctrina clasifica los diferentes grupos de factores tenidos en cuenta para determinar y ordenar las conductas racionales por parte de los grupos.

\section{La acción represiva del estado como factor determinante de}

la acción del grupo. La represión es entendida como un incentivo selectivo negativo. Como señaláramos, las modernas corrientes de análisis de los movimientos sociales integran el factor represivo como un contexto externo clave a ser tenido en cuenta, porque facilita o dificulta la captación de los recursos imprescindibles para el desarrollo y fines de la movilización.

La previsión de las consecuencias de la acción del estado sobre la movilización, es crucial para una adecuada comprensión de la determinación o no de la acción colectiva.Aparece así destacado el lugar privilegiado que tiene la acción represiva del estado sobre la decisión de movilizar recursos. Esta permite analizar, no solo los efectos de la acción del estado sobre la protesta realizada en sí; también evaluará el condicionamiento de la acción represiva -en menor o en mayor medida- sobre la decisión de movilizar recursos en ese entorno donde opera y repele la acción del estado. Se determinará allí, gran parte de la decisión del grupo de ir al conflicto o no. "En un modelo de elección racional, los disidentes tratan de maximizar su participación en la política sustituyendo sus movilizaciones no violentas por acciones violentas, y viceversa, en función de la respuesta represiva del Estado.(conforme LICHBACH, Mark I.; citado en González Callejas, E.: 2012)

Surge así la naturaleza estructural del acto represivo. "La represión es un incentivo selectivo de carácter negativo a la participación en un movimiento, ya que hace aumentar los riesgos y costes de la acción colectiva para los contendientes, en sus dos principales 
condiciones: la organización de la protesta y la movilización de la opinión pública (conforme TILLY, Charles;citado en González Callejas, E.: 2012).

Las formas que ese incentivo negativo puede llegar a tomar, son infinitos y eficaces siempre. El Estado tiene a su mano una batería inagotable de medios para elevar hasta el nivel que sea necesario e inaccesible los costos para que no movilicen sus contendientes, en este caso los agrupamientos de trabajadores y trabajadoras no reconocidos y críticos del orden.

Los ejemplos que pueden obrar en la memoria del lector son inagotables,ya sea desarticulando una organización o ilegalizándola, dificultando o impidiendo su logística (a partir de prohibir sus actos públicos, su propaganda y sus medios de difusión), bloqueando los recursos a su disposición, en medios materiales, afectando posiciones institucionales (impidiendo la integración a instituciones o reconociendo los derechos que les corresponden por su posicionamiento), usando elementos de influencia (información, dominio de los medios de comunicación), el uso de medios coercitivos (policiales, militares, paramilitares). Esta estrategia de la antimovilización neutraliza la acción, aunque también puede tener por objeto -y llegar a- destruir al actor si es enérgica o si es persistente en el tiempo .

\section{Las consecuencias de la represión policial sobre las}

protestas.La discusión sobre la relación y consecuencias entre una acción colectiva por parte de agrupamientos críticos y la represión oficial, no se encuentra saldada.

No obstante una gran parte de los autores, sostienen y reconocen los efectos nocivos sobre aquellos agrupamientos que la reciben. En ese colectivo, Donatella Della Porta, Sydney Tarrow y Charles Tilly afirman que la mayor represión que pueda ser ejercida sobre un colectivo, tendrá como efecto directo la detención de la movilización en ciernes; aunque pueda tener otros efectos como la tendencia a radicalizar a los sectores más comprometidos (conforme Della Porta, D.: 1996; y Tarrow, S.: 1997).Si el análisis que se transcribe fuera correcto, y la consecuencia directa de la represión fuese el debilitamiento del grupo (no alcanzar la representatividad), y su aislamiento; el cometido del estado estaría 
cumplido. Del análisis de campo efectuado, se observa similares consecuencias a las narradas.

Y convergente con estas afirmaciones, sobre lo que no existe mayores discusiones en cuanto a los efectos de la represión violenta, es su efecto dispersivo. "Pese a que existen discusiones teóricas en relación a los efectos de la represión, y respecto a su impacto sobre el nivel de movilización. Es evidente que los niveles extremadamente elevados de represión restan atractivo a la acción colectiva para una gran mayoría de activistas (...) (Sánchez Estellés, I.: 2004)"

Correlativamente existe otro consenso entre los autores, que sostiene que ante la reducción en la intensidad de la represión, se produce como consecuencia de esta, la promoción y el desarrollo de los movimientos sociales. Una hipótesis que -en el caso de estudio- solo podría apreciarse en el caso que el estado cumpla con sus obligaciones internacionales frente a los agrupamientos aún no legitimados. "Hay concordancia en aceptar que las revoluciones sociales se disparan con el "debilitamiento del control político y la capacidad estatal de represión". (conforme SKocpol 1979) p.138; Mac Adam, Kitschelt, Goldstein, abonan a esta idea genérica; citado por Della Porta, D.: 1996)

El estudio del uso de la represión por parte del estado, lo muestra como vaso comunicante entre la posibilidad de crecimiento o no, de un grupo insurgente. Allí se ha de poner la observación. 


\section{METODOLOGIA DE LA INVESTIGACION.}

1. Análisis cualitativo. Esquema. Esta parte de la investigación se desarrolla a través del relevamiento de dos (2) fuentes diferentes de acopio de información. Éstas, serán volcadas con posterioridad a una misma matriz de constatación de datos. Por una parte, se usará como fuente la base de información del Ministerio de Trabajo Empleo y Seguridad Social de la Nación (MTESS). Por otro lado, se usará la información remitida por un agrupamiento político sindical con amplia inserción en la zona territorial a investigar. Esta última fuente, fue ampliada y enriquecida por el relevamiento realizado -sobre esas guías- por el maestrando.

Se analizan en ambas fuentes el universo total de los conflictos laborales desatados en el ámbito de los lugares de trabajo (conflictos localizados), en empresas pertenecientes al sector privado, durante el período extendido de tiempo que va de enero 2007 a diciembre 2013, y sobre un ámbito geográfico significativo representado por los 10 partidos que integran -en su totalidad- los (2) dos departamentos judiciales que componen la zona norte del Gran Buenos Aires. Estos distritos, no solo tienen una alta tasa de densidad poblacional, sino que aglutinan una de las zonas del país con mayor densidad de establecimientos productivos.

2. Fuente del MTESS, y metodología de trabajo. En cuanto al registro ministerial, las fuentes para la formación de su información surge de una amplísima gama de medios, con extensión territorial nacional y con entrecruzamiento con otras fuentes pertenecientes al MTESS (conteniendo también a sus agencias territoriales),y al Sistema Estadístico Nacional.

Las fuentes de la información utilizada son 125 medios de prensa (electrónicos) de todo el país. A esta consulta diaria, se le suman los informes del MTEySS sobre medios editados en Capital Federal y los informes que se derivan de la consulta a las Agencias territoriales asentadas en todo el territorio nacional "( MTESS: 2008, pág. 23). 
La información recogida por el MTESS, les permite construir una importantísima bases de datos de conflictos laborales. En base a ella, se elabora un archivo de noticias para cada conflicto laboral que ingresa en la base de datos. Cabe aclarar que la totalidad de la información recabada, el MTESS -que puso a disposición del alumno- la selecciona y guarda separadamente en archivos WORD. Estos son individualizados numéricamente, y contienen la información mes por mes, y discriminando por provincia, de todos los conflictos laborales que se registran en el país. El trabajo de clasificación en el MTESS, tiene otras selecciones que fueron chequeadas en forma puntual, y en razón de su aplicación para este trabajo (pueden clasificarse los conflictos que corresponden al núcleo CABA y GBA; y pueden distinguir -entre otros- como conflictos de ámbito nacional 0 pertenecientes a Conflictos que transcurren en un Procedimiento Preventivo de Crisis $^{30}$ ).

Cada uno de estos WORD, reúnen una importante extensión de información (solo texto, no imágenes) de entre 150 y 500 hojas, dependiendo ello del nivel de conflictividad y difusión periodística mensual. Los conflictos allí son individualizados y numerados, manteniéndose inmodificable esta numeración. Debemos aclarar que un conflicto laboral puede durar más de un mes, u ocupar el tiempo -parcial- que corresponde a meses diferentes. El MTESS en ese caso, le asignará al mismo conflicto más de un número. A través de su lectura se puede observar la evolución que puede llegar a tener un conflicto; la variación en cuanto a los agrupamientos que lideran al conflicto, la variación en cuanto a la intensidad de la medida, etc. Los conflictos laborales, muestran en esta breve muestra, su naturaleza cambiante ${ }^{31}$.

\footnotetext{
30 Se tienen identificados otros diez (10) conflictos localizados que no nos fue remitida la información, que son archivados nueve (9) de ellos bajo la clasificación como pertenecientes a conflictos nacionales de cada sector; y uno (1) de esos dentro de los conflictos que transcurren el Procedimiento Preventivo de Crisis (Ley 24.013). En este último, y por esta selección no lo registran como conflicto. Los mismos son relevados en la fuente del APS, y procesados en su matriz.

${ }^{31}$ En el anexo obran la totalidad de los Word, discriminados conflicto por conflicto. Solo faltan en este anexo, tres (3) conflictos relevados en el excels, que por su baja relevancia y sus características no reportan interés ni alteran el trabajo.
} 
Ya numerados, esa información se procesa individualizando sus elementos salientes -o por lo menos, aquellos que la agencia estatal valora identificar en los conflictos-, y éstos son volcados en archivos excels (que obra como una gran matriz). A partir de allí, la agencia lo utilizará para realizar los diferentes trabajos estadísticos, de estudio o de operación sobre el territorio.

En esta investigación, con el auxilio de la preselección de los excels (que ingresa todo el país) y su posterior confronte con los WORD, se realizó el relevamiento de la totalidad de los conflictos asentados. Allí se realizó un filtro en función a seleccionar los conflicto que se originan en la provincia de Buenos Aires, y conjuntamente su pertenencia a los diez (10) distritos de GBA Norte. Se realiza un segundo filtro, excluyendo los conflictos de trabajadores estatales. Por último, y ya con la utilización de los WORD, se filtra parar seleccionar a los conflictos localizados (limitados a los establecimientos).

Terminada esa primer etapa, y con los conflictos que son objeto del estudio ya individualizados, se toman los archivos WORD mensuales (preseleccionados) y en estos (auxiliados por números identificatorios que también obran en los WORD) se recorta y analiza la información precisa recogida por la prensa en cada conflicto. Esa masa filtrada de información, será la base sobre la que se hace la investigación.

3. La Matriz utilizada. La información recogida de prensa y obrante en los WORD, se vuelca -procesada- pero de conformidad a una nueva matriz excels confeccionada a efectos de esta tesis, no la que utiliza el MTESS. La matriz confeccionada, toma como base la estructura de construida por la agencia estatal, pero reduciéndola en datos -e incorporando otros- para adecuarla al interés de la investigación.

La matriz que la agencia estatal es muchísimo más amplia en cuanto a los datos que recoge, lo que le permite una gran versatilidad para su operatividad en el campo sindical y político; pero también para su operatividad en el área económica y muy particularmente en la incidencias sobre el aparato productivo. 
No obstante esta matriz no tiene una mayor aproximación sobre otros tópicos -trascendentes- como la incidencia del aparato represivo del estado en un conflicto. Información esta, que busca analizar esta investigación. La información de esta incidencia está en los WORD, pero no resulta volcada, por no ser de interés inmediato para la Agencia. Nosotros si la valoramos, y por ello la recogemos.

En esta nueva matriz, aparecen muchos datos que son ya individualizados por el MTESS, y solo se repiten; a saber: (A) Número de individualización del conflicto en registros del MTESS (para que se favorezca el confronte); (B) Mes; (C) año del conflicto; (D) Sindicato (o universo personal de representación sindical) en el que se produce el conflicto; (E) Empresa en la que se produce el conflicto; (G) Agrupamiento Oficialista que lidera el conflicto; $(H)$ Agrupamiento disidente que lidera el conflicto; (I) Liderazgo conjunto de ASO y ASD; (J) Liderazgo por otro actor; 6) Medidas de acción directa, discriminadas en orden a su intensidad: (S) alerta,(T) movilización,(U) paro,(V) corte,(W) bloqueo de planta y (X) ocupación de planta. Ésta es una muy acotada simplificación de la desagregación que realiza la agencia estatal ${ }^{32}$ (por fines metodológicos para distinguir en cada conflicto los bloqueos y ocupaciones). Los relevamientos son precisados con la información cualitativa que describe las medidas y los contextos en que se llevan adelante.

Y nosotros incorporamos a esa matriz otras variables: (F) Existencia o no, de disputa intrasindical. El MTESS recoge estos datos -y con mucha más precisión sobre los diferentes actores de los conflictos-, pero en su seguimiento no busca definir este dato. Se puede ver en forma intermitente en la identificación del tipo de organización que moviliza, pero no tiene un item preciso que la destaque. Quizás se deba a lo cambiante de las situaciones. En nuestra matriz, se procesa la exteriorización de la existencia o no de disputa intrasindical.

Además se desagrega en nuestra matriz, cuando las medidas de acción directa son de mayor intensidad (bloqueos u ocupaciones), es

32 EI MTESS desagrega (1) Anuncios y alertas; (2) Movilización y acciones similares; (3) Bloqueos, cortes u ocupaciones sin paros; (4) Paros; (5) Paros más bloqueos, cortes u ocupaciones. 
liderada por una ASO $(Y)$ o una ASD ( $Z$ ). $Y$ lo que es central en el trabajo, se desagrega, ante la presencia de estas acciones de alta intensidad, si la misma es liderada por ASO y recibe represión (AB), o si las lidera una ASD y recibe represión $(A A)$.

Se registra también la Acción represiva del estado ${ }^{33}$, discriminada en orden a su intensidad (N) presencia policial, $(\mathrm{O})$ uso de la fuerza, $(\mathrm{P})$ militarización de la planta. En este último rango -militarización de planta-, se registra si la acción represiva es dirigida cuando lidera la medida de acción directa una ASO (Q) o una ASD (R).

Se registra además, la presencia de uso de la fuerza por fuerzas de choque parapoliciales $(K)$, distinguiendo además si la misma es ejercida cuando quien lidera una medida de acción directa es una ASO (L), o una ASD (M).

En nuestra matriz, se agrega el relevamiento en cada caso de la existencia de una función creadora de poder autónomo en las representaciones sindicales de base (AC).

Por último se releva la presencia de crisis de dominación celular (AD), y si esa acción puede revestir un carácter convencional (AE) o disruptivo (AF).

Las mismas columnas con idéntica denominación, aunque variando la letra que las registra, se precisan en la matriz que vuelca la fuente de la APS que se refiere en el siguiente apartado.

El cruzamiento de estos datos, en ambas matrices, nos permite individualizar en cada conflicto: que agrupamientos los lideran; si está exteriorizada allí una disputa intrasindical; si las medidas de acción directa (son de alta intensidad) consisten en bloqueos u ocupaciones de los lugares de trabajo y sus accesos; y nos permite precisar en qué casos hubo intervención de fuerzas de seguridad estatal en los conflictos de trabajo.

33 Cabe aclarar, que entre la información adicional que se ocasionalmente se incorpora al excels del MTESS (no con el interés de señalarlo en una columna), se releva en pocas oportunidades la intervención de fuerzas de seguridad del estado en los conflictos 
4. La Fuente del Agrupamiento político sindical. La fuente de información del agrupamiento político sindical, ampliada y enriquecida, son las recopilaciones en el mismo acotado tiempo y espacio geográfico de la investigación, sobre similar tipología de conflictos a la ya referida. Ese acopio consiste en el relevamiento de conflictos a través de medios periodísticos u organismos no gubernamentales (en redes sociales), propios o de terceros; y en algunos casos -casi exclusivamente- a través de redes alternativas.

Al listado original que me fuera suministrado, se lo enriqueció con la búsqueda y producción del tesista. En este caso se recurre a otros medios digitales, tratando de echar luz sobre datos necesarios para la investigación, y que no aparecen contenidos en el relevamiento suministrado. Los datos recogidos, se vuelcan a la matriz común ya descripta.

Complementación de fuentes. El cruce de las fuentes que utilizamos en este trabajo, no solo tienen la utilidad de contrastarlas para saber si existe coincidencias en sus resultados o no; y en qué medida. Existe además otro interés, que en este caso se suma. Si bien se recogen los mismos datos, las características de sus miradas de las fuentes es diferente.

Si bien los dos relevamientos se vuelcan en una misma matriz, la selección del conflicto y el interés práctico sobre el mismo es diferente. Pero paradójicamente, se refuerzan y complementan. Los relevamientos del MTESS, son exhaustivos. Los relevamientos del agrupamiento político sindical son -por el contrario- acotados en número (aunque allí encontramos registrados conflictos que no registra la agencia estatal). En realidad esto no debe llamar la atención, el ministerio dispone de recursos enormes frente a cualquier otra agencia. El agrupamiento político sindical, no relevará todos los conflictos; solo se pone el foco sobre parte de los que se suscitan. Serán aquellos de intensidad media o alta en la conflictividad, o los que tienen trascendencia pública para el universo sindical o político en el que están insertas sus disputas. De allí el número menor de la muestra que elabora. 
Pero a diferencia de la fuente que utiliza el MTESS, por su particular interés -preponderantemente la difusión-, la mirada del agrupamiento político sindical profundiza la observación de los conflictos, y particularmente en los elementos importantes para evaluar la disputa intrasindical, y la acción represiva del estado. Dos elementos que son de necesarios en nuestra investigación.

Se destaca así -en el registro del agrupamiento político-sindical- un nivel más "microscópico" en la mirada; donde el detalle de la acción represiva (a veces son informes de noticieros partidarios, o de informativos de cables locales, o videos caseros) apunta a aspectos que no registra el MTESS, salvo en los conflictos de mayor trascendencia pública.

Como en los viejos telescopios astronómicos, en realidad siempre se está frente a dos (2) lentes. Los dos nos muestran el mismo cielo, pero uno de ellos es mucho más acotado en el espacio de observación y nos permite ver con más profundidad el sector que se visualiza. Ambos nos permiten ver el mismo cielo, ambos se complementan. 


\section{RESULTADOS.ANALISIS CUALITATIVO.}

Resultado. Análisis cualitativo. En este capítulo, hemos de mostrar los datos duros que se relevaron en el volcado de la información, en las matrices.

Nuestra hipótesis investiga la exclusión selectiva de agrupamientos sindicales disidentes. "Cuando agrupamientos de trabajadores no legitimados lideran acciones colectivas de altísima intensidad en sus lugares de trabajo, en momentos de disputa con otros grupos sindicales legitimados, el estado recurre en forma selectiva al uso de la fuerza para evitar (impidiendo) el surgimiento de estos nuevos grupos sindicales no legitimados por el estado".

Para poder tener por confirmada la hipótesis propuesta en este trabajo, entendemos que se debe realizar un doble análisis que resulte coincidente en las observaciones. Por un lado confirmar esta situación de exclusión selectiva positiva hacia el agrupamiento disidente bajo determinadas condiciones; y por otra, confirmar que bajo idénticas condiciones, no se alcanza con tal conducta a otros agrupamientos. En nuestros registros, se constata ambos extremos.

\footnotetext{
1.La represión policial del estado (RPE) hacia agrupamientos sindicales se manifiesta en conflictos localizados, solo cuando se reúnen un número cerrado de condiciones (Conflictos localizados, existencia de disputa intrasindical, liderazgo del conflicto laboral por ASD, altísima intensidad de las medidas de acción (bloqueo u ocupación del establecimiento).

Es evidente que estamos en el momento preciso de emersión del agrupamiento disidente. Siguiendo los instrumentos teóricos que señala la TMR, el agrupamiento está tomando aquellas decisiones trascendentales que importan la puesta "en juego" de sus -escasos- recursos. El registro de medidas de altísima intensidad y la confrontación o autonomía de las decisiones del aparato sindical al que pertenece, nos muestran que el agrupamiento está transitando ese deseado "enclave" desde donde se
} 
avista, el acopio de representatividad y la asunción de su carácter de contendiente a reconocer. En ese momento aparece la represión estatal, y su pretensión de desactivación del acopio de recursos y emersión del agrupamiento..

Se pueden ver en los casos de la fuente del MTESS, los numerados como:37, 42, 48, 141, 143, 160 y 161. Y en la fuente del Agrupamiento Político-Sindical, los numerados como: 4, 7, 14, 15, 19, 22, 47, 51 y 52.-

La acreditación de estos extremos, nos confirmaría un primer elemento de constatación de la hipótesis propuesta.

\section{La ausencia de cualquiera de los elementos que conforman este número cerrado de condiciones, es acompañada en todos los casos por la ausencia de represión estatal en todos los conflictos. Si} no están dadas todas las condiciones, no hay represión. Si están dadas dos (2) condiciones -las que pueden varían indistintamente- , de las tres (3) condiciones, tampoco existe represión policial.

Esta casuística en los que están presentes solo dos (2) de estas condiciones y no existe represión, se pueden ver en los casos de la fuente del MTESS. Porque falta la condición de ocupación de planta los numerados como: 16, 29, 30, 35, 36, 44, 45, 49, 50, 51, 53, 58, 61, 65/71, 74/75, 78, 81/82, 85, 91, 93, 103, 111/2, 114, 118, 122, 138, 142, 144, 147, 151, 157 y 164 . Porque falta la condición de liderazgo de ASD, los numerados como:18, 19, 73, 134, 137, 162 y 166.-

Y en la fuente del Agrupamiento Político-Sindical, porque falta la condición de ocupación de planta los numerados como: 9/12,16/8, 29/8, $45 / 6,48$ y $54 .-$

Y porque falta la condición de liderazgo de ASD, los numerados como: $13,28,40,43 / 4,53$ y 55 .-

La acreditación de estos extremos, nos confirmaría el segundo elemento para la constatación de la hipótesis propuesta ${ }^{34}$.

${ }^{34}$ El caso "La nueva Italia". En la totalidad del relevamiento efectuado, solo existe un solo registro de carácter dudoso. Es un caso donde la actuación del estado no se traduce en uso de la fuerza. No se registra represión policial.Es el caso no 19.389 (ver anexo), que corresponde a la toma de el establecimiento dedicado al rubro panadería bajo la denominación "la Nueva Italia". La fuente del MTESS la registra, no asi la segunda fuente (agrupación política-sindical).El conflicto se 


\section{Si ampliamos la mirada sobre el universo de casos, aparecen}

otros relevamientos que son complementarios y concordantes a los primeros.

En la totalidad de los casos en los que el liderazgo del conflicto laboral lo llevan adelante agrupamientos sindicales oficialistas (ASO), en ninguno de ellos sufren la represión policial del estado (RPE).

4. Esa impunidad frente a la represión estatal, se mantiene inclusive cuando las ASO adoptan medidas de acción directa de altísima intensidad. Esta casuística se pueden ver en los casos relevados de la fuente del MTESS numerados como 2, 12, 18/9, 20/2, 25/6, 33, 43, 47, 66, 68, 72/3, 76, 79, $84,86,92,94,102,107,116 / 7,120,123 / 7,129,131 / 2,135,140,149$, $156,158,162 / 3$ y $166 .-$

Y también se pueden ver en los casos relevados de la fuente del Agrupamiento político sindical, numerados como 39/40, 44, 54, 56. Podrían incluirse, los casos de otros liderazgos numerados como 13 y 28.-

5. En el recorte tempo-espacial del estudio, se relevan casos de represión policial estatal disuasiva (RPED). Estos se caracterizan por tener un accionar preventivo y de altísima intensidad en el uso de la fuerza. El propósito de esta modalidad represiva es impedir la elevación de la intensidad de la conflictividad laboral por parte del agrupamiento sindical que lo lidera. Con ese objetivo, se produce la militarización de la planta. Esta casuística se pueden ver en los casos relevados de la fuente del MTESS numerados como 30, 37 y 42.-

Y también se pueden ver en los casos relevados de la fuente del Agrupamiento político sindical, numerados como 4 a $8,15,19$, 47.-

desata en razón a las gravísimas condiciones laborales (entre las que se destaca el hecho que trabajen en el lugar 40 trabajadores, que prestan servicios en una dependencia que tiene una sola letrina, que se desborda), pronunciada precarización laboral (abultada ausencia de registración) y violación a las normas de trabajo infantil. Se detecta presencia de organizaciones políticas acompañando la toma. No existe disputa intrasindical, ni liderazgo del conflicto en manos de un ASD. La respuesta de las fuerzas de seguridad relevadas, se limitaron a realizar lo que se denomina "presencia policial". No hubo uso de la fuerza física. Los trabajadores denunciaron que los policías no permitían que los familiares permanecieran en la puerta del establecimiento, y ordenaron que se bajen carteles que exteriorizaban el conflicto. 
7. Coincidente con esta situación, se releva en la totalidad de los casos en los que se produce represión policial estatal disuasiva (RPE), el liderazgo del conflicto es llevado adelante por ASD. Esta casuística se pueden ver en los casos indicados en el párrafo anterior en la columna (R) del MTESS y $(T)$ de la APS.

7.1. Y como contrapartida, no se releva ningún caso en los que el liderazgo del conflicto lo lleva adelante ASO que hayan sufrido RPE. Esta casuística se pueden ver en los casos indicados en el párrafo anterior en la columna (Q) del MTESS y (S) de la APS. Esta situación de no represión se releva, aún ante situaciones de acciones conflictivas de altísima intensidad (bloqueos y ocupaciones).

8.Junto a los relevamientos que se describen, podemos señalar otros que nos permiten establecer conexidad con posibles razones que explicitarían esta conducta represiva, y nos auxilien a aventurar otras conjeturas.

En primer lugar, y aunque no formen parte de la tesis, no es un dato menor y resulta coincidente en la individualización de los actores gremiales que sufren violencia por su accionar sindical, los relevamientos de casos de violencia paraestatal (seguridad privada o grupos de choque).

8.1. En el análisis de los mismos, se puede reconocer que en la totalidad de casos en que se releva violencia para-estatal (seguridad privada o grupos de choque), la misma es sufrida porASD liderando los conflictos laborales.

8.2. Como contrapartida, no se releva ningún caso en los que el liderazgo del conflicto sea llevado adelante por ASO, y que estos hayan sufrido represión para-estatal. Recordemos que esta situación se observa, aún ante situaciones de acciones conflictivas de altísima intensidad (bloqueos y ocupaciones) lideradas por ASO.

Esta casuística se pueden ver en los casos relevados de la fuente del MTESS numerados como 30, 35, 54, 75 y 148.

Y también se pueden ver en los casos relevados de la fuente del APS, numerados como 4, 5, 14, 41 y 50.-

Aparece nuevamente en esta observación complementaria, el mismo actor sindical sufriendo en forma excluyente ( $y$ bajo discriminación) la 
violencia para desactivar su accionar sindical. Una violencia que no sufren en ningún caso, los agrupamientos que conducen las estructuras sindicales.

Estas situaciones (accionar parapolicial), cuando se observan pormenorizadamente algunos casos, se observa que solo se pueden ejercer con la aquiescencia estatal.

9. En nuestra observación se ha relevado la existencia de aquella función de las representaciones sindicales en los lugares de trabajo, que tiene por objeto construir poder autónomo frente a la conducción de la organización sindical que integra. Son identificadas como conductas independientes de las representaciones sindicales en los establecimiento. Allí se verá el liderazgo de ASD, confrontando o no acompañado por ASO. Se observará principalmente en medidas de acción directa de altísima intensidad, pero también se observará otras acciones de menor intensidad.

Esta casuística se pueden ver en los casos relevados de la fuente del MTESS numerados como 16, 18/9, 30, 36/7, 40/2, 48/50, 51/2, 54, 56, 58, 60/2, 65/72, 74/5, 77/8, 80, 85, 87, 90/1, 93, 97, 99, 103, 111/4, 118/9, $122,134 / 5,138 / 9,141 / 2,144 / 5,147 / 8,151,153,155,157,159 / 61$ y 164.

Y también se pueden ver en los casos relevados de la fuente del Agrupamiento político sindical, numerados como 4/13, 15/9, 22, 25/7, $29 / 38,41 / 43,45,47 / 53$ y $55 . .-$

10. Lo que resulta de interés para ulteriores estudios, se produce cuando relacionamos a las manifestaciones de esta "función de formación de poder autónomo" con los registros de la represión estatal. Allí se releva lo previsible, solo ante la presencia de esta funcionalidad de las representaciones sindicales en los lugares de trabajo, se evidencia la existencia de represión por parte del estado. Esta casuística se pueden observaren los casos precisados en las conclusiones contenidas en el parágrafo $\mathrm{n}^{\circ} 1$, confrontando las columnas respectivas (AA y AC del MTESS; y, AC y AE de la APS).-

11. Un tema que es crucial para observar la discriminación selectiva en el accionar estatal es la observación sobre el repertorio de conductas conflictivas que Ilevan adelante los diferentes agrupamientos sindicales. 
Para poder valorar la conducta discriminatoria, se destaca en el registro, que tanto los ASO como los $A S D$, tienen idéntico repertorio de conductas ante situaciones de conflictividad laboral.

11.1. En el mismo sentido, y por ser de interés para este estudio, se individualiza que también en las acciones de alta intensidad (bloqueo y la ocupación) se registran como recursos indistintamente usados por los agrupamientos de trabajadores y trabajadoras.

Se releva al bloqueo y a la ocupación por parte, tanto de ASO, como de ASD. Esta casuística se pueden ver las columnas ( $Y$ y $Z$ del MTESS; y , $A A$ y $A B$ de la APS)

Este no es un dato menor. Teniendo confirmado este elemento, se elimina un elemento objetivo de importancia para poder afirmar la existencia de una respuesta represiva imparcial por parte del estado. Todos los agrupamientos sindicales recurren a los mismos repertorios.

12. Otro registro que nos permiten establecer conexidad con las posibles razones que expliciten la conducta represiva estatal a estos grupos, está dada por la observación sobre las conductas que evidencien lo que O 'Donnell denominó Crisis de Dominación Celular (CDC).

Como primer dato, se puede afirmar que se releva registro de situaciones que evidencian CDC. Esta casuística se pueden ver en los casos relevados de la fuente del MTESS numerados como 2, 12, 18/9, 21/2, 25/6, $33,37,42 / 3,47 / 8,64,68 / 69,71 / 4,76,79,84,86,94,102,107,116 / 8$, $120,123 / 7,131 / 2,135,137,140,143,148 / 9,153,155 / 6,158,160$, $162 / 3$ y 166.

Y también se pueden ver en los casos relevados de la fuente del APS, numerados como $4,6 / 7,13,15,19 / 20,22,25 / 28,40,43 / 4,51 / 4$ y 56.-

13. Como ya fuese precisado en el registro del repertorio habitual de todos los agrupamientos sindicales,y en forma coincidente con ese registro las situaciones que evidencian $\mathrm{CDC}$, son protagonizadas tanto por ASO como por ASD. Esta casuística se pueden ver en las columnas respectivas (AE y AF del MTESS; y, AG y AH de la APS)

14. De ese total de ese registro las situaciones que evidencian $C D C$, una porción importante de estas crisis son protagonizadas por ASD. 
Lo que resulta de interés, se produce cuando relacionamos a este registro reducido de conductas que conformarían CDC lideradas por ASD,con los registros de la represión estatal. Allí registraremos nuevamente lo que presupone este trabajo, solo ante la presencia de estas conductas críticas de las representaciones sindicales en los lugares de trabajo, se evidencia la existencia de represión por parte del estado.

Nunca este tipo de acciones, cuando las llevan adelante los ASO, son objeto de represión estatal.

De este registro se desprenden indicios que relacionan, la represión del estado con la aparición de aquellas conductas que se el orden establecido considera anormales, y por ende de necesaria remoción para la salud del sistema. 


\section{XV.Análisis Estadístico}

1. Correlación entre variables. El análisis estadístico de la asociación entre variables representa una parte básica del análisis de datos. En este trabajo la hipótesis planteada implica analizar la existencia de relación entre variables construidas puesto que, la existencia de algún tipo de asociación entre dos o más variables representa la presencia de algún tipo de tendencia o patrón de emparejamiento entre los distintos valores de esas variables.

La correlación es en esencia una medida normalizada de asociación o covariación lineal entre dos variables. Esta medida o índice de correlación ( $r$ ) puede variar entre -1 y +1 , ambos extremos indicando correlaciones perfectas, negativa y positiva respectivamente. Un valor de $r=0$ indica que no existe relación lineal entre las dos variables. Se dice entonces que existe una correlación positiva entre dos variables cuando al aumentar los valores de una lo hacen también los de la otra o al disminuir unos, los otros también lo hacen. En el caso contrario, la correlación negativa se da cuando al aumentar los valores de una variable disminuyen los de la otra.

El coeficiente de correlación $r$ de Pearson viene dada por:

$$
\boldsymbol{r}=\frac{n \sum_{i=1}^{n} x_{i} y_{i}-\sum_{i=1}^{n} x_{i} \sum_{i=1}^{n} y_{i}}{\sqrt{\left[n \sum_{i=1}^{n} x_{i}{ }^{2}-\left(\sum_{i=1}^{n} x_{i}\right)^{2}\right]\left[n \sum_{i=1}^{n} y_{i}{ }^{2}-\left(\sum_{i=1}^{n} y_{i}\right)^{2}\right]}}
$$

Es importante destacar que los valores de correlación deben ser acompañados con valores de probabilidad. La probabilidad se expresa como un número que varía de 1 a 0 , que refleja la posibilidad de que se dé algún suceso previamente definido. En términos generales, un número bajo de probabilidad como el de 0,001 implica un suceso con pocas posibilidades de ocurrir, en este caso, un evento positivo de cada mil veces que se ensaye el evento. En estadística se utiliza para medir la posibilidad de cometer un 
error al hacer una inferencia, de tal manera que en el caso de un valor de 0,001 al hacer una afirmación (por ejemplo confirmar una hipótesis) la probabilidad de cometer un error es de una milésima. En general los valores aceptados de probabilidad para ensayos estadísticos son de valores menores de 0,05 (5\% de probabilidades de cometer un error al confirmar la asociación) y 0,01 (1\%de probabilidades de cometer un error al confirmar la asociación). Estos valores pueden ser expresados como de un 95\% y 99\% de confianza respectivamente. Este valor de probabilidad es importante, ya que el análisis que está empleando un coeficiente de correlación o asociación no es inferencial o predictor (es libre de probabilidad y descriptivo). Un test del nivel significativo de los coeficientes de correlación valida la prueba convirtiéndola en un análisis inferencial (Triola, 2004).

Cuando se consideró la interrelación entre las variables construidas para el análisis, el procedimiento elegido fue el denominado correlación múltiple.

Dada una serie de variables, todas las correlaciones posibles entre las mismas dan por resultado una matriz simétrica en donde cada elemento de la diagonal principal $r_{\mathrm{ii}}$ es igual a 1.0, representando la correlación perfecta positiva de cada variable respecto de si misma. Una característica de esta matriz es que las mitades superior e inferior son idénticas(Zar, H. 2010).

De esta forma, la matriz de correlación permitió visualizar en forma general las relaciones entre las distintas variables para comparar los valores de correlación y de probabilidad de tal manera de poder asumir que los valores de correlación altos en donde la probabilidad indique significación estadística sean tomados como prueba fehaciente de una asociación.

\section{Estructura de asociación entre variables: Análisis de} Componentes Principales (ACP) El ACP es un método algebraico estadístico descripto por Karl Pearson (Pearson, K.: 1901), que trata de sintetizar y dar una estructura a la información contenida en una matriz de datos. Es una herramienta estadística normalmente utilizada para cribar datos de variables múltiples correlacionadas entre sí, de tal manera que, al crear nuevas variables no correlacionadas, denominadas "componentes principales" se reduce la dimensionalidad del conjunto de datos a unos 
pocos componentes sin perder información. Este análisis permite a su vez comprender mejor la estructura de correlación entre las variables (Hair, J. , Anderson, R. , Tatham, R.\& Black, W. : 1999).

Está considerado como un método de ordenación ya que, a diferencia de los métodos de agrupamiento, el ACP no traza los límites entre los grupos, sino que los ordena en un espacio de dimensionalidad reducida, confeccionado a partir de los componentes construidos en el análisis.

Matemáticamente, la ACP consiste en un análisis propio de una matriz de covarianza o correlación calculada sobre los datos de medición originales. Gráficamente, se puede describir como una rotación de un enjambre de puntos de datos en un espacio multidimensional de modo que el eje más largo (el eje con mayor varianza) sea el primer eje PCA, el segundo eje más largo perpendicular al primero sea el segundo eje PCA, Etcétera.

Cuando el ACP se realiza sobre una matriz de correlación, cada componente contiene una parte de la correlación entre las variables. El primer componente es el que contiene la mayor correlación. De las correlaciones restantes, el segundo componente es el que incluye más información no contenida en los componentes anteriores y así se continúa hasta que toda la variabilidad ha sido distribuida diferencialmente entre los componentes (Crisci, J. \& Armengol, M.: 1983). Es así que cada componente contiene información de todas las variables, pero en diferentes proporciones.

Cada Componente principal está compuesto por valores llamados cargas de componentes para ese eje. Cada variable en la matriz de datos original tiene una carga de componente asociada. Estas cargas pueden considerarse una medida de la importancia relativa de cada variable en el Componente del PCA extraído. El signo del valor indica con qué extremo del eje está asociada la variable.

$\mathrm{Si}$ bien es posible realizar un ACP a partir de una matriz de covarianza, en el presente estudio, tratándose de datos sociales, se ha realizado sobre los datos estandarizados, es decir sobre sus transformaciones $Z$ (se obtuvo así un ACP sobre la matriz de correlaciones).

Es de suma importancia al realizar el ACP determinar la dimensionalidad real de los datos, esto es, el número de componentes 
principales que se tomarán del análisis. Existen varios métodos utilizados para la toma de decisión, pero deberá tomarse en cuenta que a medida que se incrementa el número de componentes, se reduce la capacidad explicativa de cada uno.

En el caso de realizar un ACP sobre datos estandarizados, existe un método que consiste en tomar las componentes con eigenvalores mayores perdiendo la menor cantidad de información, pero utilizando la menor cantidad de componentes ${ }^{4}$. En el presente estudio se decidió utilizar los componentes con mayor eigenvalor que 2, ya que en este caso la varianza de cada variable estandarizada es igual a $1 \mathrm{y}$, por lo tanto, no se toman aquellos componentes que no puedan explicar más variación que un par de variable por sí misma(Colina, C. y Roldan,P. : 1991).

Para el análisis estadístico se construyó una base de datos en Excel donde se numeró cada uno de los conflictos registrados y se les otorgó un número en código para identificarlo. Sobre cada conflicto entendido como una unidad de evento específica se registró el distrito de ocurrencia, fecha, duración, el grupo o grupos que conducen el conflicto, el tipo de medida tomada, tipo de reclamo, el organismo ó empresa de trabajo, la acción de la policía frente al conflicto, y todo registro que sea considerado como un indicador compartido en los eventos registrados. Consecuentemente se construyeron variables que indican la presencia o ausencia de algunas de las condiciones de cada conflicto. Las variables y su definición se muestran en la Tabla de Variables (tabla 1).

El análisis estadístico consistió en una primera etapa en análisis de fiabilidad para comparar ambas fuentes de información y corroborar su confiabilidad, grado de consistencia y estabilidad. Para el análisis vinculado a la contrastación de la hipótesis planteada se utilizaron métodos descriptivos, análisis de correlación y análisis de ordenación a partir del Análisis de Componentes Principales para datos presencia/ausencia. El análisis de correlación fue acompañado de análisis inferencial para verificar el grado de significación estadística de cada par de correlaciones ajustadas. Para el análisis estadístico se utilizaron los programas SPSS y MVSP. 


\section{Resultados estadísticos.Análisis de correlación entre}

variables. El análisis de correlación mostró alto grado de asociación entre las variables Lider ASO, Lider ASD, Intrasindical, CDC, CDC Disruptiva, Ocupación y 5 ta. Los valores más altos de correlación y de significación estadística se dieron entre las parejas de variables Lider Aso con Lider ASD $(-0,798$ /correlación negativa); Lider ASO con Intrasindical (-0,726 /correlación negativa); 5ta. con Lider ASO (-0,619/correlación negativa); 5ta. con Intrasindical $(0,756$ / correlación positiva); Lider ASD con Intrasindical (0,704 / correlación positiva); CDC Disruptiva con Ocupa+ASD $(0,696$ / correlación positiva); 5ta. con Lider ASD $(0,677$ / correlación positiva);CDC Disruptiva con CDC (0,577 / correlación positiva) y CDC con Ocupación (0,511 / correlación positiva). Los valores de correlación se muestran en la tabla 2.

\section{Análisis de componentes principales sobre matriz de} correlación. Los resultados generales para los primeros cinco componentes del Análisis de Componentes Principales se muestran en la tabla 3. Debido a que los eigenvalores descienden abruptamente después del segundo componente (Figura 1: Grafica Scree-plot) se decidió tomar los primeros dos componentes del ACP para realizar el análisis de ordenamiento.

El primer Componente del ACP acumula una varianza del $24 \%$, mientras que el segundo Componente un 18\%. De esta manera los dos primeros componentes acumulan por si solos un $42 \%$ de la varianza total de las 22 variables originales (Tabla 3 ).

Las cargas de cada variable para cada Componente Principal muestran que sobre el primer componente las variables más importantes con valores positivos son: Bloq+Oc X ASO y CDC Convencional, mientras que las mas importantes con valores negativos son Intrasindical, Lider ASD, 5ta., Oc o Bloq+ASD+intra+R3, Uso Fuerza, OCUPA x ASD, CDC Disruptiva, Militar., Mil ASD y Corte.

Sobre el segundo Componente las cargas muestran que las variables más importantes con valores positivos son: movilización, 5ta., Lider ASD e Intrasindical. Las más importantes con valores negativos son: CDC, Bloqueo, Bloq+Oc X ASO, CDC Convencional, Ocupación, CDC Disruptiva, OCUPA x ASD y Oc o Bloq+ASD+intra+R3 (Tabla 3). 
Se ha desarrollado en apartados anteriores la definición del ACP como un método de ordenación, es decir, que no modifica los valores originales de las variables. Los dos primeros Componentes al ser cruzados (ploteados) permiten visualizar las posiciones de cada unidad de análisis, las cuales pueden ser distinguidas por el resultado de cualquiera de las variables utilizadas. Es así que se las puede distinguir tanto por tener un tipo de respuesta (presencia/ausencia) a la variable elegida, como por la naturaleza de su definición nominal (la variable que la identifica).

A partir de esta posibilidad que brinda el análisis se han realizado ploteos de estos dos primeros componentes para visualizar: las cargas de las variables y ubicación de eventos en coordenadas de escores; la asignación del sindicato principal para cada evento, los eventos donde se da el uso de la fuerza pública, entre otros (Figuras 2 a 5 ). Esto permite corroborar en primera instancia si la pertenencia a sindicatos genera alguna fuente de error, y en segundo término si la asignación de los eventos genera algún tipo de agrupamiento. De hecho, las figuras 4 y 5 muestran que tanto el hecho del uso de la fuerza pública, como el de ser asignado con presencia de "Oc o Bloq+ASD+intra+R3" genera el mismo tipo de agrupamiento.

El ploteo entre los dos primeros Componentes permite además armar un campo bidimensional donde establecer cuatro cuadrantes que posibilitan tener una concepción simple de la trama conformada por las 22 variables construidas (Figuras 6). Estos campos pueden ser interpretados como conformados por un eje horizontal que denominaremos "uso de la fuerza sobre acción sindical oficial/no oficial" y un eje vertical que podríamos denominar como "intensidad de las acciones sindicales" (Figura 7)

Las posiciones de los eventos sobre ese campo bidimensional muestran que ante igual intensidad de la acción sindical se aplica el uso de la fuerza sobre los grupos sindicales no legitimados, pero no sobre los legitimados (Figura 7; cuadrante 3).

Apoyando lo dicho se muestra claramente en la figura no 4, una traza que denota la violencia estatal en este estudio. Un marcado sendero en diagonal que se estira y crece hacia a la izquierda y hacia abajo sobre el cuadrante 3 obrante en la figura 7 . Una representación que muestra el uso 
de la fuerza con un sentido que responde a las directrices de mayor intensidad y direccionada predominantemente sobre ASD.

En definitiva, el análisis estadístico realizado es coincidente con el análisis cualitativo realizado en el presente estudio. Las pruebas de correlación y el Análisis de Componentes Principales permiten, en primer término, establecer un grado de asociación probado entre variables altamente correlacionadas entre si y a la vez comprender la matriz de asociación entre los eventos presentados en las variables. El Análisis de Componentes Principales permite reducir la dimensionalidad para generar dos componentes (o funciones) que da cuenta de la trama de asociaciones (correlaciones) en función del uso de la fuerza y de la intensidad de la acción sindical en un único plano explicativo.

En relación con lo planteado, puede entonces aceptarse el presupuesto afirmado en la hipótesis presentada oportunamente como: "Cuando agrupamientos de trabajadores no legitimados lideran acciones colectivas de altísima intensidad en sus lugares de trabajo, en momentos de disputa con otros grupos sindicales legitimados, el estado recurre en forma selectiva al uso de la fuerza". 


\section{Tabla 1}

\begin{tabular}{|c|c|}
\hline Intrasindical & Presencia de disputa intrasindical. \\
\hline Líder ASO & $\begin{array}{l}\text { Conflicto laboral liderado por agrupación sindical } \\
\text { oficialista. }\end{array}$ \\
\hline Líder ASD & $\begin{array}{l}\text { Conflicto laboral liderado por agrupación sindical } \\
\text { disidente. }\end{array}$ \\
\hline Líder otro $o$ ausencia & $\begin{array}{l}\text { Conflicto laboral liderado por otro actor sindical o } \\
\text { social. }\end{array}$ \\
\hline Presencia policial & $\begin{array}{l}\text { Intervención de las fuerzas de seguridad sin uso } \\
\text { de la fuerza pública. }\end{array}$ \\
\hline Uso de la fuerza & $\begin{array}{l}\text { Intervención de las fuerzas de seguridad con uso } \\
\text { de la fuerza pública. }\end{array}$ \\
\hline Militarización & $\begin{array}{l}\text { Ocupación preventiva del establecimiento por } \\
\text { parte de la fuerza pública. }\end{array}$ \\
\hline Militarización ASO & $\begin{array}{l}\text { Militarización en conflicto liderado por agrupación } \\
\text { sindical oficialista.- }\end{array}$ \\
\hline Militarización ASD & $\begin{array}{l}\text { Militarización en conflicto liderado por agrupación } \\
\text { sindical disidente.- }\end{array}$ \\
\hline Alerta & $\begin{array}{l}\text { Acción declarativa y primer exteriorización del } \\
\text { conflicto de los trabajadores. }\end{array}$ \\
\hline Movilización & $\begin{array}{l}\text { Acción de visibilización del conflicto fuera del } \\
\text { establecimiento. }\end{array}$ \\
\hline Paro & $\begin{array}{l}\text { Cese general y consensuado de la prestación de } \\
\text { servicios en el establecimiento. }\end{array}$ \\
\hline Corte & $\begin{array}{l}\text { Acción de visibilización del conflicto fuera del } \\
\text { establecimiento, consistente en la interrupción d } \\
\text { circulación vehicular. }\end{array}$ \\
\hline Bloqueo & $\begin{array}{l}\text { Acción sindical consistente en impedir el ingreso y } \\
\text { egreso en las puertas del establecimiento. }\end{array}$ \\
\hline Ocupación & $\begin{array}{l}\text { Acción sindical consistente en la ocupación del } \\
\text { establecimiento.- }\end{array}$ \\
\hline Bloqueo + Ocupación + ASO + R3 & $\begin{array}{l}\text { Acciones referidas lideradas por una ASO que son } \\
\text { reprimidas por el uso de la fuerza estatal. }\end{array}$ \\
\hline Bloqueo + Ocupación X ASO & Acciones referidas lideradas por una ASO. \\
\hline Ocupación X ASD & Acción referida liderada por una ASD. \\
\hline Bloqueo + Ocupación +ASD + intra + R3 & $\begin{array}{l}\text { Acciones referidas, lideradas por una ASD, en } \\
\text { interna sindical, que es reprimida por el uso de la } \\
\text { fuerza pública. }\end{array}$ \\
\hline 5ta. & $\begin{array}{l}\text { Función que ejerce la representación sindical en } \\
\text { los lugares de trabajo que aspira a generar poder } \\
\text { autónomo de sus conducciones sindicales } \\
\text { centralizadas. }\end{array}$ \\
\hline CDC & $\begin{array}{l}\text { Conductas que manifiestan Crisis de dominación } \\
\text { celular. }\end{array}$ \\
\hline CDC Disruptiva & $\begin{array}{l}\text { Conductas que manifiestan Crisis de dominación } \\
\text { celular, que importan una conducta disruptiva. }\end{array}$ \\
\hline
\end{tabular}


Tabla 2

Matiriz de Correlación entre variables construidas sobre eventos sindicales

\begin{tabular}{|c|c|c|c|c|c|c|c|c|c|c|c|c|c|c|c|c|c|c|c|c|c|c|}
\hline & $\begin{array}{l}\text { Intrasi } \\
\text { ndical }\end{array}$ & $\begin{array}{l}\text { Lider } \\
\text { ASO }\end{array}$ & \begin{tabular}{|l|} 
Lider \\
ASD
\end{tabular} & \begin{tabular}{|c|} 
Lider \\
otros \\
desco \\
nocid \\
0
\end{tabular} & $\begin{array}{c}\text { Prese } \\
\text { ncia }\end{array}$ & \begin{tabular}{|c|} 
Uso \\
Fuerz \\
a
\end{tabular} & Militar & $\begin{array}{c}\text { Mil. } \\
\text { ASO }\end{array}$ & \begin{tabular}{|c|} 
Mil \\
ASD
\end{tabular} & alerta & $\mid \begin{array}{c}\text { movili } \\
\text { zacion }\end{array}$ & Paro & Corte & $\begin{array}{c}\text { Bloqu } \\
\text { eo }\end{array}$ & $\begin{array}{c}\text { Oc o } \\
\text { Blog+ } \\
\text { ASO+ } \\
\text { R3 }\end{array}$ & $\begin{array}{c}\text { Ocupa } \\
\text { ción }\end{array}$ & $\mid \begin{array}{l}\text { Bloq }+ \\
\text { Oc X X } \\
\text { ASO }\end{array}$ & $\mid$\begin{tabular}{c|} 
OCUP \\
$A x$ \\
ASD
\end{tabular} & $\begin{array}{c}\text { Oco } \\
\text { Bloq } \\
\text { ASD+i } \\
\text { ntra+ } \\
\text { R3 }\end{array}$ & 5ta. & $\operatorname{CDC}$ & $\begin{array}{c}\text { CDC } \\
\text { Distu } \\
\text { ptiva }\end{array}$ \\
\hline $\begin{array}{l}\text { Intrasindic } \\
\text { al }\end{array}$ & 1 & & & & & & & & & & & & & & & & & & & & & \\
\hline Lider ASO &, $726^{* *}$ & 1 & & & & & & & & & & & & & & & & & & & & \\
\hline Lider ASD &, $704^{* *}$ &,$- 798^{* *}$ & 1 & & & & & & & & & & & & & & & & & & & \\
\hline $\begin{array}{l}\text { Lider } \\
\text { otroslo } \\
\text { desconoci } \\
\text { dn }\end{array}$ & $-0,087$ &,$- 249^{* *}$ & $\mid-183^{*}$ & 1 & & & & & & & & & & & & & & & & & & \\
\hline Presencia &, $171^{*}$ &,$- 138^{*}$ &, $185^{* *}$ & $\mid-, 059$ & 1 & & & & & & & & & & & & & & & & & \\
\hline $\begin{array}{l}\text { Uso } \\
\text { Fuerza }\end{array}$ &, $222^{* *}$ &,$- 274^{* *}$ & ", $312^{* *}$ & , 037 & , 019 & 1 & & & & & & & & & & & & & & & & \\
\hline Militar. &, $181^{* *}$ &,$- 195^{* *}$ & * $244^{* *}$ & \begin{tabular}{|l|}
,- 062 \\
\end{tabular} &, $176^{* *}$ &, $477^{* *}$ & 1 & & & & & & & & & & & & & & & \\
\hline Mil. ASO & $\mathrm{N} / \mathrm{C}$ & $\mathrm{N} / \mathrm{C}$ & $\mathrm{N} / \mathrm{C}$ & $\mathrm{N} / \mathrm{C}$ & $\mathrm{N} / \mathrm{C}$ & $\mathrm{N} / \mathrm{C}$ & $\mathrm{N} / \mathrm{C}$ & $\mathrm{N} / \mathrm{C}$ & & & & & & & & & & & & & & \\
\hline Mil ASD &, $181^{* *}$ &,$- 195^{* *}$ & "244** & \begin{tabular}{|l|}
-062 \\
\end{tabular} &, $176^{* *}$ &, $477^{* \prime}$ & $1,000^{*}$ & $\mathrm{~N} / \mathrm{C}$ & 1 & & & & & & & & & & & & & \\
\hline alerta &,- 128 &, $155^{*}$ & $-144^{*}$ & \begin{tabular}{|l|}
, 022 \\
\end{tabular} & | & $|-, 066|$ &,$- 047 \mid$ & $\mathrm{N} / \mathrm{C}$ & |-,047 & 1 & & & & & & & & & & & & \\
\hline $\begin{array}{l}\text { movilizaci } \\
\text { on }\end{array}$ &, $242^{* *}$ &,$- 195^{* *}$ & *, $182^{* * *}$ & $\mid-079$ & $\mid-099$ & | & 012 & $\mathrm{~N} / \mathrm{C}$ & $\mid$ &,$- 163^{*}$ & 1 & & & & & & & & & & & \\
\hline Paro & , 053 & $-0,032$ &,- 063 & \begin{tabular}{|l|}
, 083 \\
\end{tabular} & , 084 & , 039 & ,063 & $\mathrm{N} / \mathrm{C}$ & , 063 & $|-027|$ &,- 128 & 1 & & & & & & & & & & \\
\hline Corte &, $401^{* *}$ &,$- 370^{* *}$ & * $353^{* * *}$ & $|-084|$ & , 102 &, $338^{* *}$ & ,128 & $\mathrm{N} / \mathrm{C}$ & , 128 & $-0,058$ &,- 004 & , 041 & 1 & & & & & & & & & \\
\hline Bloqueo &,- 073 & , 073 &,- 090 &,- 078 & ,094 &, $272^{* *}$ & ,127 & $\mathrm{N} / \mathrm{C}$ & |127 &,- 125 &,$- 263^{* *}$ & , 026 & | & 1 & & & & & & & & \\
\hline $\begin{array}{l}\text { Cco } \\
\text { Blog+ASO } \\
+R 3\end{array}$ & $\mathrm{~N} / \mathrm{C}$ & $\mathrm{N} / \mathrm{C}$ & $\mathrm{N} / \mathrm{C}$ & $\mathrm{N} / \mathrm{C}$ & $\mathrm{N} / \mathrm{C}$ & $\mathrm{N} / \mathrm{C}$ & $\mathrm{N} / \mathrm{C}$ & $\mathrm{N} / \mathrm{C}$ & $\mathrm{N} / \mathrm{C}$ & $\mathrm{N} / \mathrm{C}$ & $\mathrm{N} / \mathrm{C}$ & $\mathrm{N} / \mathrm{C}$ & $\mathrm{N} / \mathrm{C}$ & $\mathrm{N} / \mathrm{C}$ & $\mathrm{N} / \mathrm{C}$ & & & & & & & \\
\hline Ocupación & ,084 & $-0,090$ &,- 061 & ,024 &, $162^{*}$ &, $309^{* *}$ &, $144^{*}$ & $\mathrm{~N} / \mathrm{C}$ &, $144^{*}$ & $-0,094$ &,- 026 & , 061 & , 096 &, 067 & $\mathrm{~N} / \mathrm{C}$ & 1 & & & & & & \\
\hline $\begin{array}{l}\mathrm{B} \text { Bloq+Oc } \mathrm{X} \\
\mathrm{ASO}\end{array}$ &, $416^{*}$ &, $400^{* *}$ &,$- 383^{\prime \prime}$ & $-0,086$ & $-0,099$ &,$- 148^{*}$ &,- 105 & $\mathrm{~N} / \mathrm{C}$ & $\mid-105$ &,- 105 &,$- 233^{* *}$ &,- 099 & $-261^{\circ \prime}$ & , $495^{* *}$ & $\mathrm{~N} / \mathrm{C}$ &, $264^{* *}$ & 1 & & & & & \\
\hline$\underset{\text { ASD }}{\text { OCCPAX }}$ &, $290^{* *}$ &,$- 254^{* *}$ & "187" &,- 043 &, $370^{\circ \prime}$ &, $360^{\circ "}$ &, $274^{* \prime}$ & $\mathrm{N} / \mathrm{C}$ &, $274^{* *}$ &,- 076 &,$- 080 \mid$, & ,222" &, $193^{* \prime}$ &, $338^{* *}$ & $\mathrm{~N} / \mathrm{C}$ &, $407^{* *}$ &,- 131 & 1 & & & & \\
\hline $\begin{array}{l}\text { Oc } \\
\text { Bloq+ASD } \\
+ \text { intra+R3 }\end{array}$ & $246^{* *}$ &,$- 298^{* *}$ & $\mid, 343^{* *}$ & \begin{tabular}{|l|} 
\\
\end{tabular} & , $390^{* *}$ &, $815^{\circ "}$ & $\mid, 364^{* *}$ & $\mathrm{~N} / \mathrm{C}$ &, $364^{* *}$ &,- 072 & $\mid-, 079$ & , &, $318^{* *}$, &, $333^{* *}$ & $\mathrm{~N} / \mathrm{C}$ & , $394^{* *}$ &,$- 160^{*}$ &,, $564^{* *}$ & 1 & & & \\
\hline 5 ta. &, $756^{* *}$ &,$- 619^{* *}$ & * $677^{* *}$ &,$- 137^{*}$ & $|| 120$, &, $250^{\prime \prime}$ &, $223^{* *}$ & $\mathrm{~N} / \mathrm{C}$ &, $223^{* *}$ &,$- 168^{*}$ &, $259^{* *}$ & , 058 &, $346^{* *}$ &,- 078 & $\mathrm{~N} / \mathrm{C}$ &,- 075 &,$- 447^{* *}$ &, $213^{* *}$ &, $250^{* *}$ & 1 & & \\
\hline $\operatorname{CDC}$ &,- 093 & , 122 & $-185^{* *}$ & $\mid-, 072$ & |, &, $212^{\prime \prime}$ &, $136^{*}$ & $\mathrm{~N} / \mathrm{C}$ & |, 136 &,$- 146^{*}$ &,$- 245^{* *}$ & , 084 &,- 029 &, $652^{* * *}$ & $\mathrm{~N} / \mathrm{C}$ &, $511^{* *}$ &, $645^{* *}$ &, $456^{* *}$ &, $266^{* *}$ &,$- 147^{*}$ & 1 & \\
\hline $\begin{array}{l}\text { CDC } \\
\text { Disruptiva }\end{array}$ &, $281^{* *}$ &,$- 307^{* *}$ & *, $189^{* * *}$ & | 035 &, $246^{* *}$ &, $387^{* 1}$ &, $288^{* *}$ & $\mathrm{~N} / \mathrm{C}$ &, $288^{* *}$ & - & $|-126|$, &, $183^{* *}$, &, $191^{* *}$ &, $376^{* * *}$ & $\mathrm{~N} / \mathrm{C}$ &, $360^{* *}$ &,- 026 & ,696" &, $475^{* *}$ &, $282^{* *}$ &, $577^{* *}$ & 1 \\
\hline
\end{tabular}

* La correlación es significante al nivel 0,05

** La correlación es significativa al nivel 0,01

$\mathrm{N} / \mathrm{C}$. No se puede calcular porque al menos una variable es constante. 
Tabla 3

Resultados de los primeros cinco Componentes Principales del ACP

\begin{tabular}{|c|c|c|c|c|c|c|}
\hline \multicolumn{7}{|c|}{ Eigenvalores y varianza acumuladapor Componente } \\
\hline & & Coponente 1 & Coponente 2 & Coponente 3 & Coponente 4 & Coponente 5 \\
\hline Eigenvalues & & 5,286 & 3,966 & 1,832 & 1,579 & 1,269 \\
\hline Percentage & & 24,027 & 18,026 & 8,329 & 7,179 & 5,769 \\
\hline \multicolumn{2}{|c|}{ Cum. Percentage } & 24,027 & 42,053 & 50,382 & 57,561 & 63,331 \\
\hline \multicolumn{7}{|c|}{ Cargas de cada variable para cada Componente Principal } \\
\hline \multicolumn{2}{|l|}{ Intrasindical } & $-0,321$ & 0,148 & 0,262 & $-0,129$ & 0,024 \\
\hline Lider ASO & & 0,321 & $-0,144$ & $-0,237$ & 0,046 & 0,107 \\
\hline Lider ASD & & $-0,317$ & 0,174 & 0,07 & $-0,249$ & 0,213 \\
\hline \multicolumn{2}{|c|}{ Lider ASO+ASD } & $-0,039$ & $-0,089$ & 0,404 & 0,122 & $-0,418$ \\
\hline \multicolumn{2}{|c|}{ Lider otros/o desconocido } & 0,012 & 0,023 & 0,018 & 0,352 & $-0,362$ \\
\hline Presencia & & $-0,15$ & $-0,08$ & $-0,051$ & 0,227 & 0,354 \\
\hline Uso Fuerza & & $-0,277$ & $-0,153$ & $-0,228$ & $-0,042$ & $-0,062$ \\
\hline Militar. & & $-0,238$ & $-0,115$ & $-0,472$ & $-0,152$ & $-0,28$ \\
\hline Mil ASD & & $-0,238$ & $-0,115$ & $-0,472$ & $-0,152$ & $-0,28$ \\
\hline alerta & & 0,068 & 0,051 & $-0,196$ & 0,346 & 0,175 \\
\hline \multicolumn{2}{|l|}{ movilizacion } & $-0,06$ & 0,188 & 0,087 & $-0,291$ & $-0,297$ \\
\hline Paro & & $-0,062$ & $-0,055$ & 0,043 & 0,366 & $-0,105$ \\
\hline Corte & & $-0,223$ & 0,029 & 0,137 & $-0,019$ & 0,102 \\
\hline Bloqueo & & $-0,044$ & $-0,359$ & 0,054 & $-0,148$ & 0,269 \\
\hline Ocupación & & $-0,108$ & $-0,277$ & 0,17 & 0,083 & $-0,312$ \\
\hline \multicolumn{2}{|c|}{ Bloq+Oc X ASO } & 0,205 & $-0,346$ & 0,102 & $-0,278$ & 0,017 \\
\hline \multicolumn{2}{|l|}{ OCUPA $\times$ ASD } & $-0,261$ & $-0,23$ & 0,103 & 0,246 & 0,071 \\
\hline \multicolumn{2}{|c|}{ Oc o Bloq+ASD+intra+R3 } & $-0,299$ & $-0,19$ & $-0,138$ & 0,111 & 0,152 \\
\hline 5ta. & & $-0,309$ & 0,175 & 0,141 & $-0,183$ & 0,098 \\
\hline CDC & & $-0,033$ & $-0,453$ & 0,159 & $-0,084$ & 0,026 \\
\hline \multicolumn{2}{|c|}{ CDC Convencional } & 0,199 & $-0,339$ & 0,093 & $-0,289$ & $-0,012$ \\
\hline \multicolumn{2}{|c|}{ CDC Disruptiva } & $-0,261$ & $-0,234$ & 0,113 & 0,2 & 0,038 \\
\hline
\end{tabular}


Figura 1

Gráfico Scree-Plot de ACP en variables construidas sobre eventos sindicales

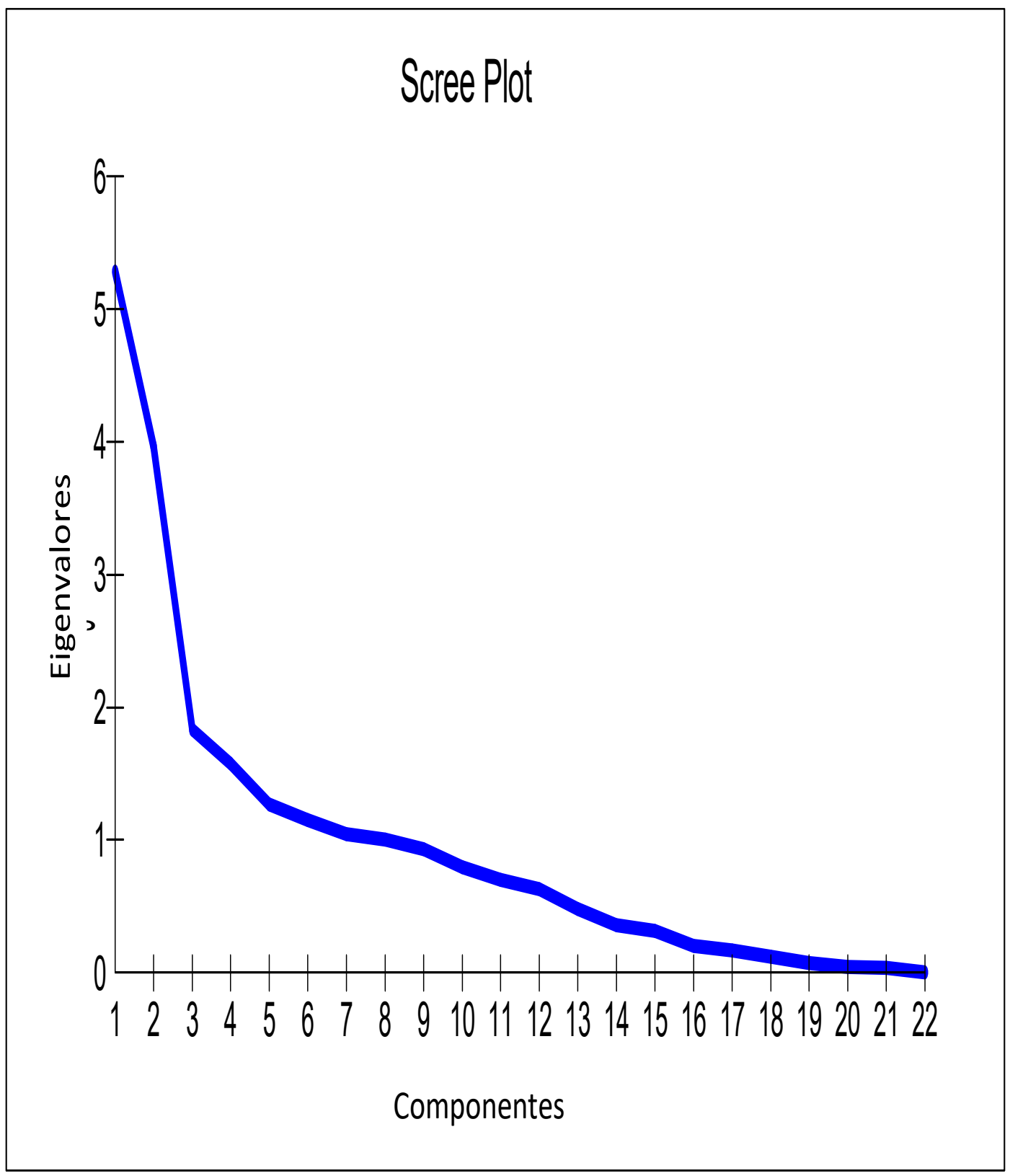


Figura 2

Ploteo de los dos primeros Componentes Principalers del ACP

Cargas de las variables y ubicación de eventos en coordenadas de escores

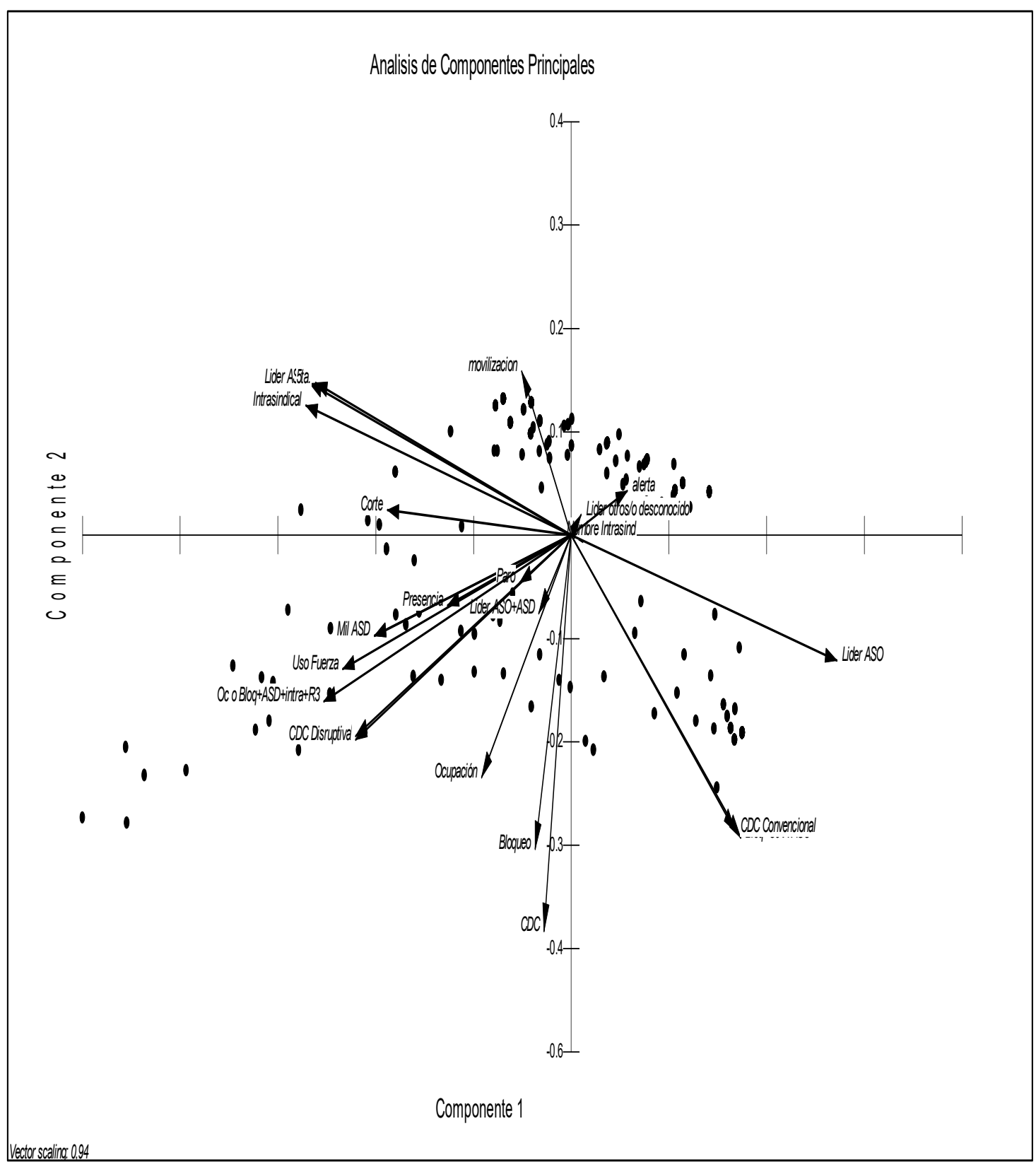


Figura 3

Ploteo de los dos primeros Componentes Principalers del ACP

Asignación del sindicato principal para cada evento

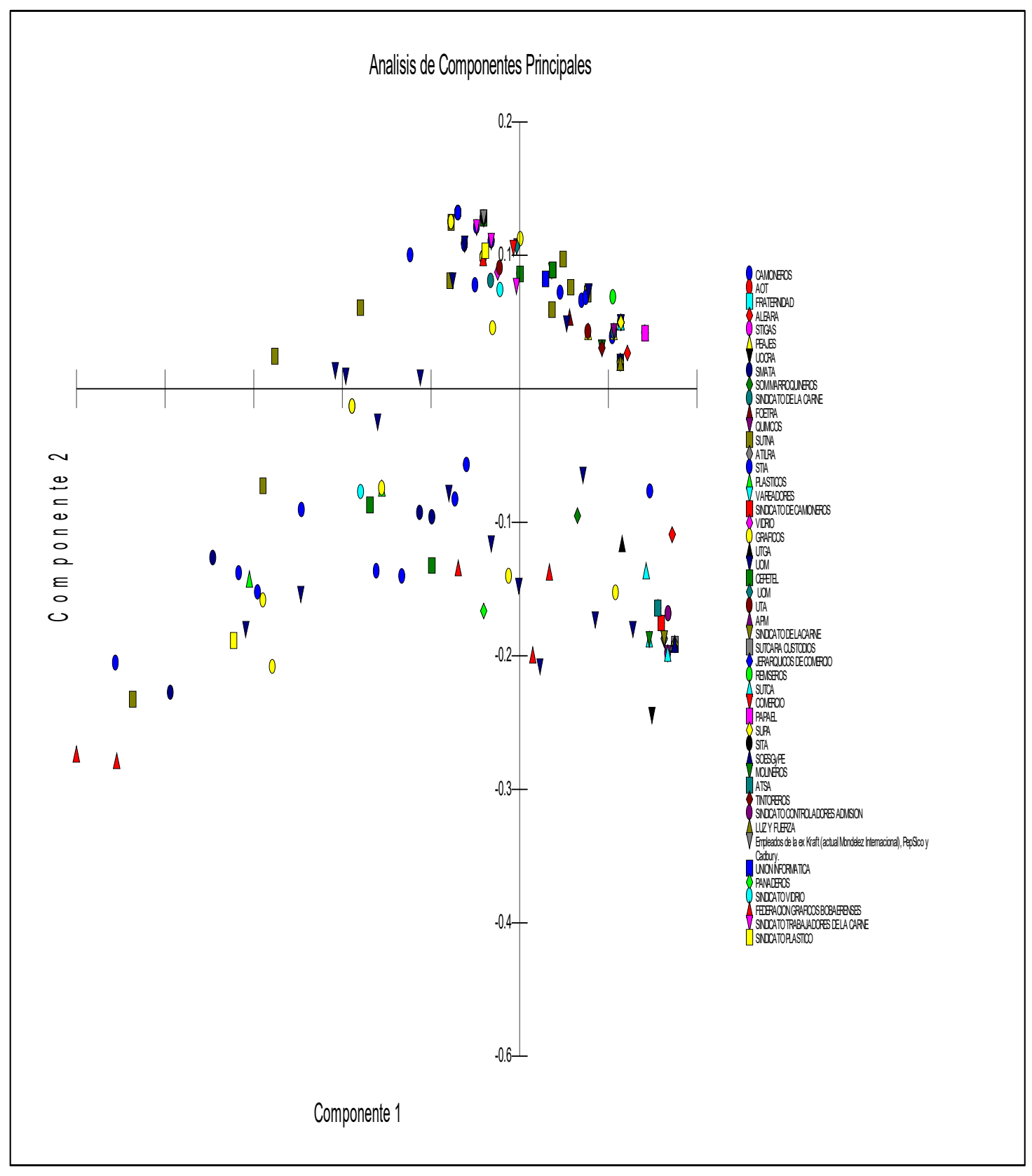


Figura 4

Ploteo de los dos primeros Componentes Principalers del ACP

Uso de la fuerza pública

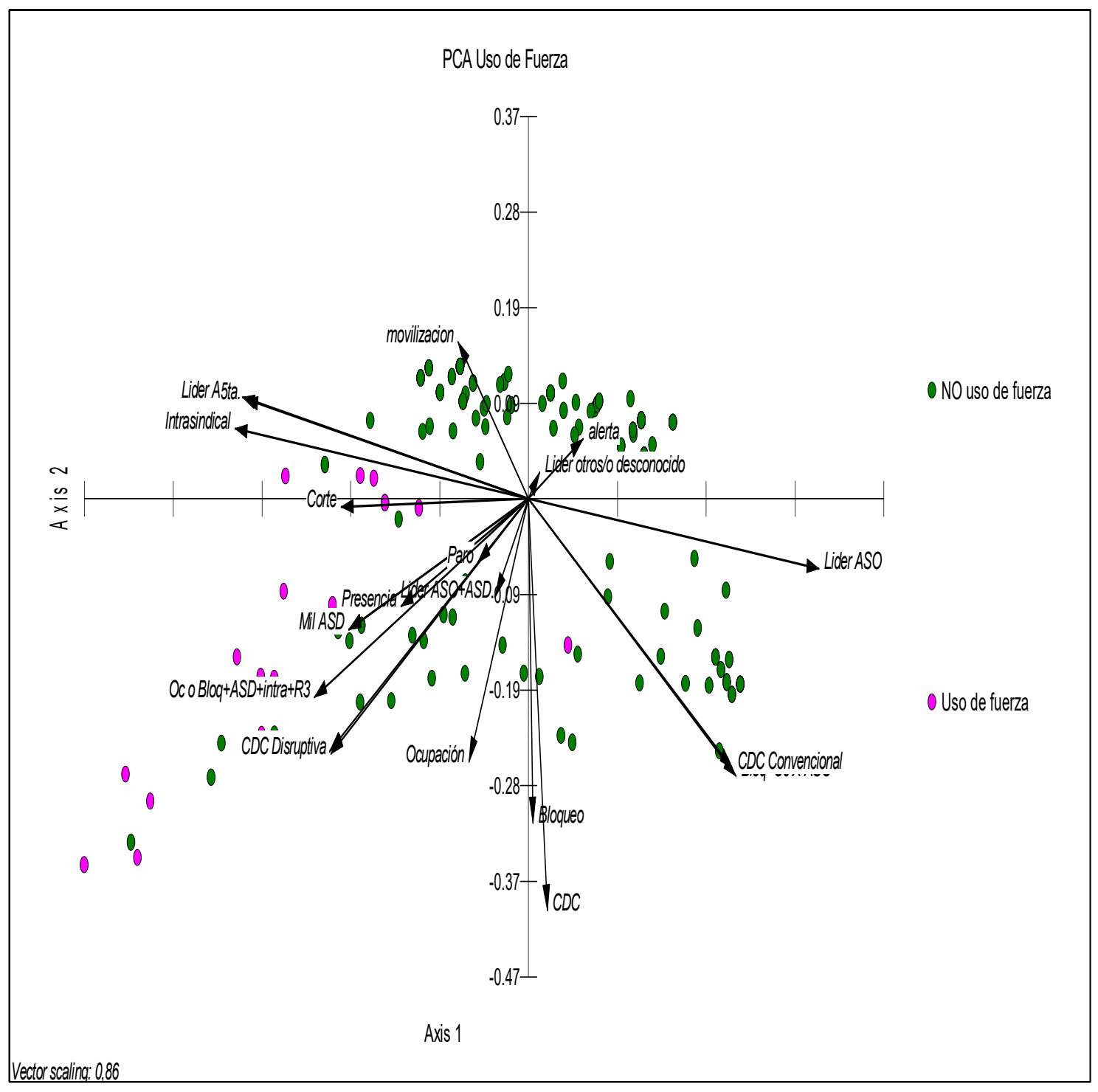


Figura 5

Ploteo de los dos primeros Componentes Principales del ACP

Ocupación/bloqueo grupo intrasindical disidente reprimidas por el uso de la fuerza estatal (Bloq+ASD+intra+R3)

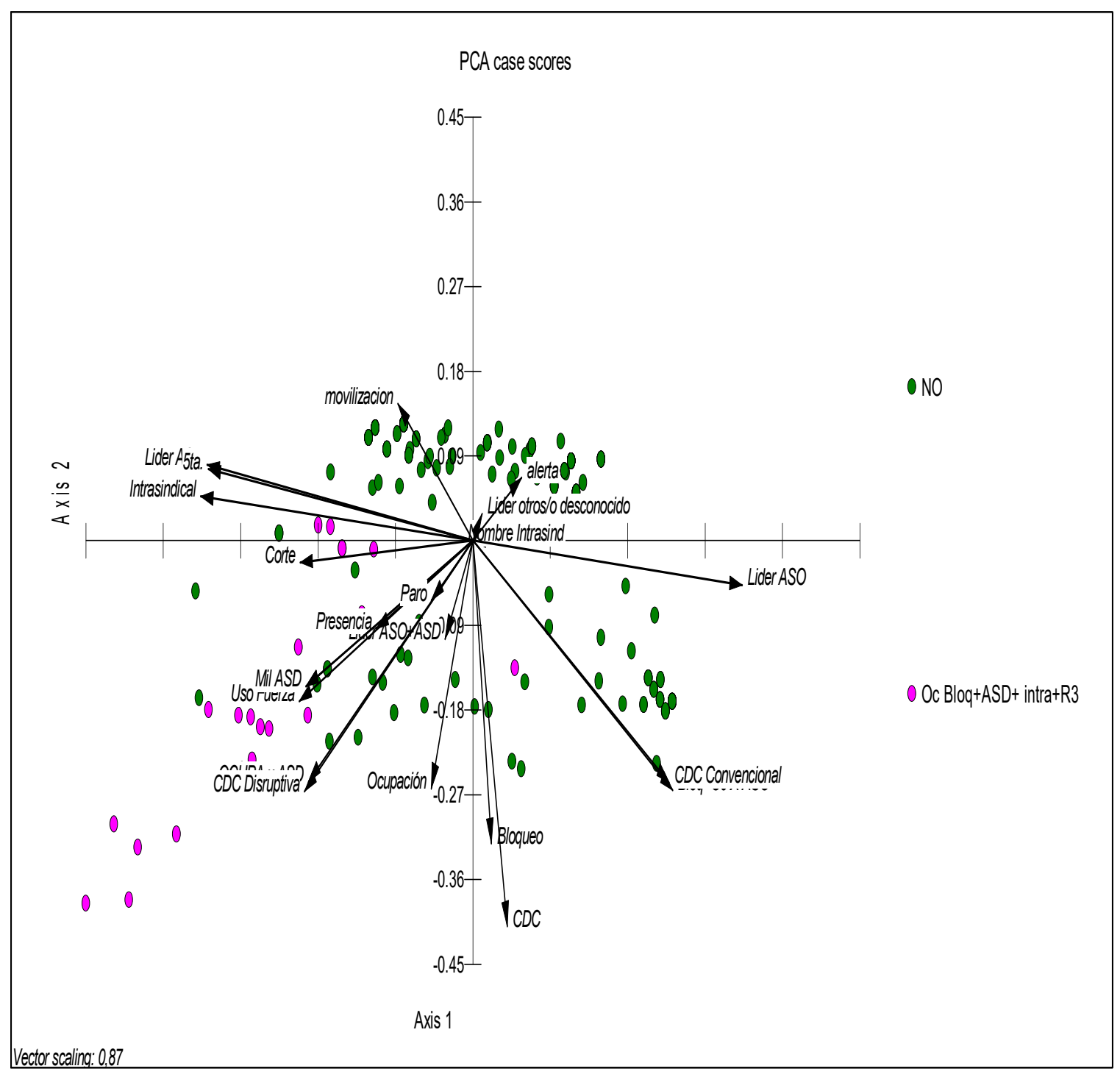


Figura 6

Representación esquemática del sistema de correlaciones de los dos primeros componentes del ACP

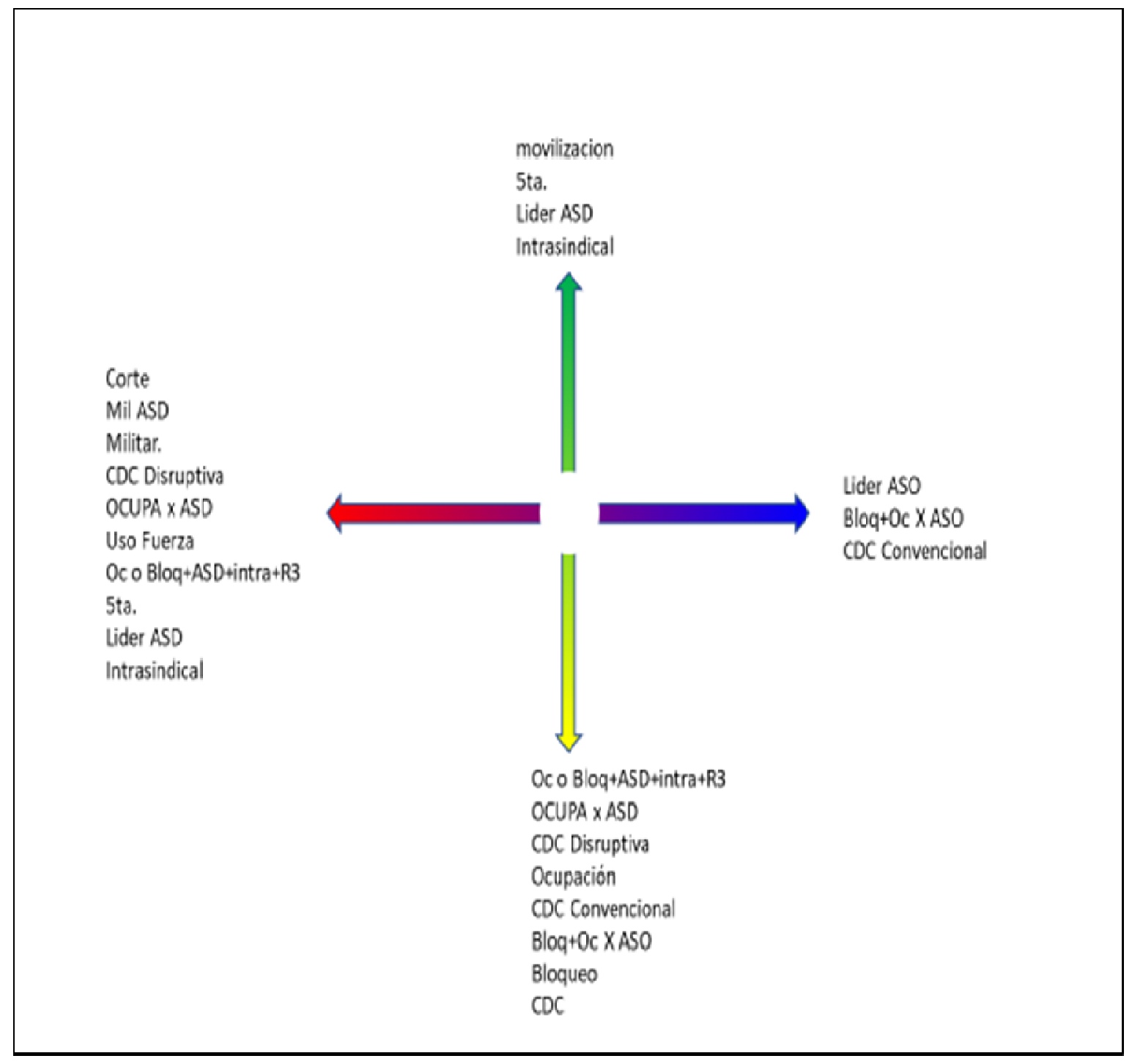


Figura 7

Interpretación del sistema de correlaciones de los dos primeros componentes del ACP
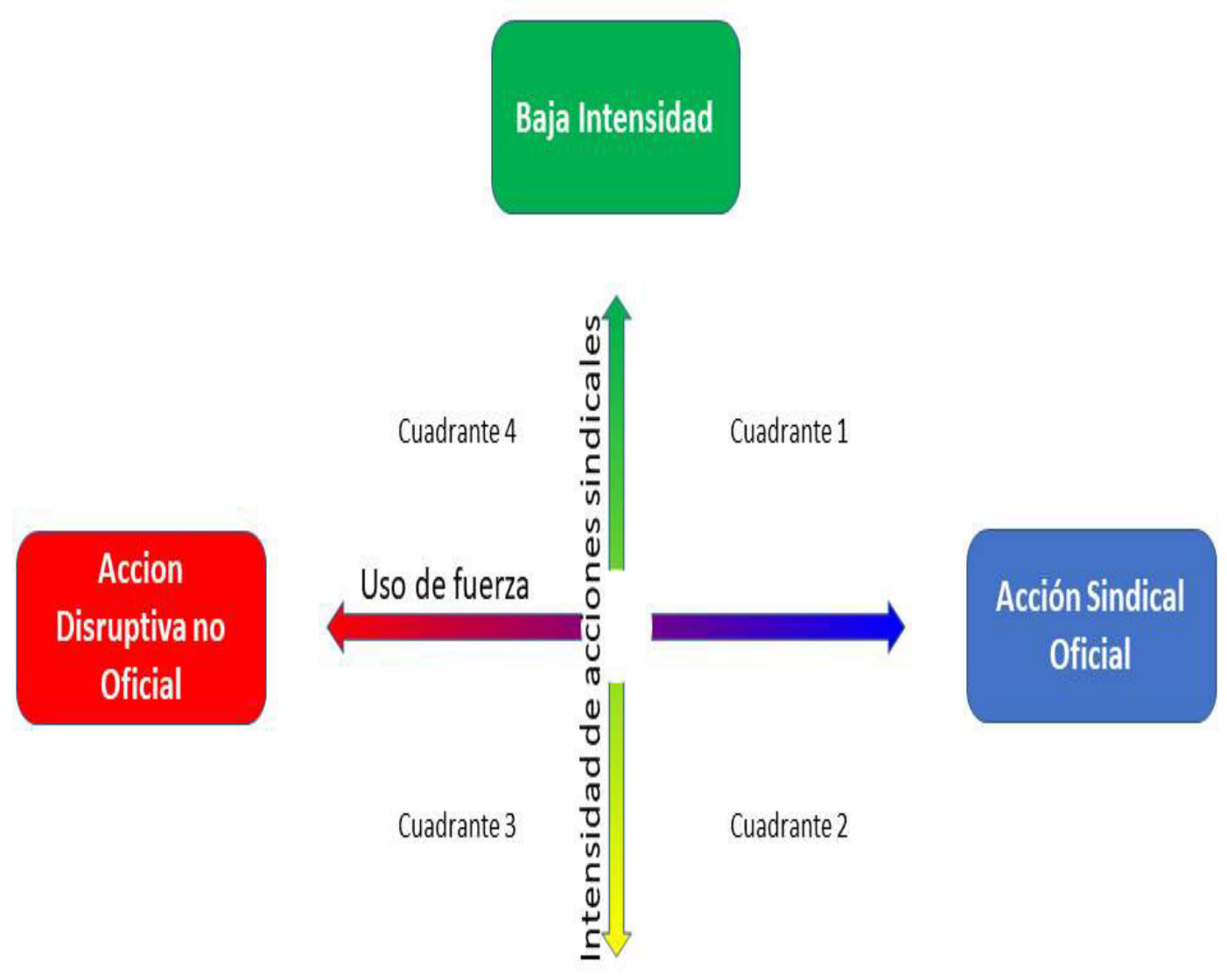

Alta Intensidad 


\section{CONCLUSIONES. PLANO SOCIOLOGICO.}

\section{Relación entre represión e integración o rechazo del actor}

no reconocido. Sobre el recorte tempo-espacial efectuado en nuestro estudio, entendemos que se encuentra constatada la hipótesis inicial de este trabajo ("Cuando agrupamientos de trabajadores no legitimados lideran acciones colectivas de altísima intensidad en sus lugares de trabajo, en momentos de disputa con otros grupos sindicales legitimados, el estado recurre en forma selectiva al uso de la fuerza para evitar (impidiendo) el surgimiento de estos nuevos grupos sindicalesno legitimados por el estado"). Lo que se precisa detalladamente, a través del registro de los datos duros, y obrante en loscapítulos XIV y XV.

No obstante, ¿qué otras conclusiones podemos extraer del análisis del registro efectuado con relación a la represión estatal? Es necesario observar la relación entre el agrupamiento sindical disidente -y las condiciones que favorecen o repelen su consolidación como nuevo actor social- y el estado y su acción represiva-. Este es el nudo de la investigación. Esta relación muestra gran parte de las posibilidades de integración del agrupamiento en su intento por incidir en la sociedad.

En este trabajo, seguimos la propuesta teórica de Della Porta, que toma como variable única para valorar las oportunidades políticas de un grupo, a la represión policial. Ésta, ubica al nivel de represión policial como barómetro adecuado para indicarlas. (Della Porta, D.: 1996, pág.100).Esto es así por muchas razones, pero entre ellas -dijimos- el hecho que esta acción ejerce una influencia limitativa casi excluyente -de entre otras acciones estatales- sobre los repertorios de acción de los agrupamientos insurgentes (Della Porta, D.: 1996, pág.100); y sobre la voluntad de iniciar la acción que los haga emerger como nuevo sujeto social o no,por parte del agrupamiento.

El uso de la fuerza por parte del estado -a pesar de mostrarse como variable única-, tiene un peso específico insoslayable y evidente en el tema de estudio, que la torna científicamente viable para auxiliarnos en este trabajo. "Aunque la represión policial de la protesta no sea la única forma 
que el estado tiene de reaccionar, tiene un efecto relevante sobre los movimientos sociales, y en concreto, sobre la forma de actuar de los movimientos." (Della Porta, D.: 1996, pág.103)."

En primer lugar, la represión policial influye enormemente sobre la percepción que, de sus oportunidades, tienen los activistas. (Della Porta, D.: 1996, pág.104).La represión puede alcanzar tal dureza que impida la visibilidad como grupo, o impedirá que este siquiera intente realizar su acción. La represión estatal es determinante de la oportunidad política del grupo.

A través del registro de esta influencia -del uso de la fuerzapodemos observar la actitud positiva o negativa de integración y respeto por parte del estado, hacia el agrupamiento en vías de consolidación como actor social. La reacción estatal ante los movimientos sociales, está relacionada con las oportunidades y constricciones relevantes; resulta por ello, expresión general del grado de apertura o receptividad del estado.

Del análisis de campo que hemos hecho, surgiría como conclusión la tendencia al rechazo por parte del estado frente la aparición de agrupamientos sindicales disidentes. Esta afirmación, está vinculada en forma directa con la modalidad que tiene la represión sistemática que se señala en este trabajo, y veremos a continuación.

2 . Características de la represión estatal. En este apartado, nos proponemos analizar las características de la represión observada en este trabajo; y a partir de las mismas, señalar las implicancias confirmatorias que tendrían sobre la tesis propuesta. Para poder avanzar sobre estos interrogantes, nos asistiremos de una tipología pertinente que nos permita analizar la represión policial.

La represión ejercida por el estado, es susceptibles de ser identificada, seleccionada y clasificada de conformidad a distintas tipologías que han producido los autores. Muchas de ellas suelen responder a caracterizaciones demasiado amplias, por lo que no resulta de interés su aplicación en este trabajo. ${ }^{35}$

${ }^{35}$ Así Gary Marx, las distingue en razón a los objetivos que buscan (desprestigiar, desmovilizar, crear una mala imagen, etc.); o Charles Tilly, que hace una clasificación que nace de los distintos tipos de regímenes políticos, y su nivel de represión 1. Regímenes represivos, que reprimen muchos grupos e impiden toda acción . 2. Regímenes totalitarios, que reprimen a menos grupos y permiten algún 
Della Porta, de cuyos análisis nos valemos teóricamente en gran parte de esta investigación, intenta una clasificación direccionada a su objeto de estudio: la represión policial. La autora, someterá esta categoría a la clasificación entre distintas (5) tipologías, binarias y antagónicas. De esas combinaciones, surgirá para su interés los siguientes antagonismos "1. Represiva vs. Tolerante, según el número de actividades prohibidas. 2. Selectivo vs. Difuso, según el número de grupos objeto de la represión.3. Preventivo vs. Reactivo, según el momento en que interviene la policía. 4. Duro vs. Blando, según la intensidad de la fuerza utilizada. 5. Sucio vs. Legal, según el grado de respeto mostrado hacia los procedimientos legales y democráticos (Della Porta, D.: 1996,pág.105)".

La aplicación de las categorías de Della Porta al relevamiento efectuado en este trabajo, nos permitiría dar una caracterización de la respuesta represiva en el tramo histórico que se analiza. Bajo aquellos parámetros, la misma puede ser caracterizada como selectiva en cuanto al sujeto;reactiva en cuanto al tiempo del ejercicio;tolerante en cuanto al número de las acciones a que se limita; dura o excesiva en cuanto a la intensidad en el uso de la fuerza; y sucia o ilegal en cuanto al apego a derecho de su ejercicio.

\section{3 .La represión tiene carácter selectivo. En primer lugar, la represión registrada discrimina a un sujeto particular que la} sufre.Por su importancia debemos destacar a ésta, entre todas sus demás notas distintivas. La represión que se estudia luce claramente su carácter selectivo (no difuso o indiscriminado), por ejercerse sobre un acotado grupo de sujetos.

La selectividad, y la carga de discriminación que conlleva, es el carácter primogénito que tiene esta acción estatal. Éste, será el que ordene al resto de sus notas características. Pareciera que el resto de las caracterizaciones -según la tipología antagónica de Della Porta-, vendrían a reforzar esa nota excluyente de selectividad/discriminación que la destaca.

tipo de actividades (las pueden convertir en obligatorias).3. Regímenes tolerantes, que permiten un amplio grupo de actividades, pero merman la acción de los grupos más poderosos. 4.Regímenes débiles. Que son tolerantes a la acción de los grupos Charles Tilly (1978). 
¿Qué se quiere decir con esta afirmación?, que ninguno del resto de sus rasgos binarios relevados, aparecen -siquiera- atenuando esa selectividad, o generando canales de integración institucional que permitan entender que la acción del estado tenga otro objeto, que no sea el de una acción convergente de negación del actor discriminado.

Este carácter de selectividad no debe ser visto de un modo abstracto; por el contrario, debe ser observado en el contexto de la sociedad real donde es aplicada esta tipología, y teniendo en cuenta -además- el sujeto pasivo de la acción represiva.

En Della Porta, la idea de represión selectiva nace como consecuencia de su aplicación frente a una racionalidad impuesta por el estado a los grupos radicalizados, y no en forma indiscriminada sobre la totalidad del universo de sujetos. La represión selectiva y su finalidad de exclusión, alcanzará a los pocos que no acatan las normas convencionales. En ese caso, la acción de los grupos insurgentes no está permitida, y por ese motivo los distingue y selecciona para ser reprimidos.

Esta descripción no se corresponde en el recorte tempoespacial recogido en nuestro estudio.El análisis comparativo de las acciones conflictivas que se relevan en esta muestra, aún en aquellas de alta intensidad, nos muestran que todas las acciones de fuerza son indistintamente ejercidas por los trabajadores y trabajadoras; tanto por parte de ASO como ASD. Lo que denota en estas acciones, un carácter común, convencional y admitido del repertorio de uso; un catálogo que es utilizado de modo universal por la totalidad de trabajadores sindicalizados, y no solo por los agrupamientos sindicales disidentes.

La nota de selectividad en Della Porta, reconoce a sujetos que realizan acciones no admitidas por el estado. En el caso que estudiamos, la selectividad no se origina en función a la realización de acciones diferenciadas del resto del universo de actores. Por el contrario, la selectividad en la represión está dirigida a grupos que cumplen los mismos repertorios convencionales que el resto del universo de sujetos; y no obstante, el estado los selecciona para reprimir. Por eso afirmamos, el propósito y racionalidad diferente con el que se valora aquí a la selectividad.

¿Qué significa represión selectiva en este trabajo? Dicho con Ilaneza, frente a la misma acción conflictiva llevada a cabo por diferentes actores 
sindicales, y ante similares condiciones contextuales, el estado solo ejerce su acción represiva sobre agrupamientos sindicales disidentes. En este trabajo se indicia una práctica institucional oculta, que es la que preselecciona al grupo los ASD (pues los ASO nunca son seleccionados para ser reprimidos), y una vez que están dados el resto del conjunto de condiciones, se termina de activar el mecanismo represivo.

¿Cómo lo acreditamos? El cotejo de la columnas (AG, en MTESS; y $A D$, en APS) que indica la sumatoria de existencia de acciones conflictivas de alta intensidad (bloqueos u ocupaciones), conducidas por ASO más la existencia represión policial, se encuentra vacía. No existe un solo hecho de represión estatal para esos agrupamientos. Por el contrario, el cotejo de la columna (AE en MTESS; y AC, en APS) que indica la sumatoria de existencia de acciones conflictivas de alta intensidad (bloqueos u ocupaciones), más la conducción de esos conflictos por parte de ASD, encuentra periódicamente (reuniendo el resto de las condiciones sistemáticas reconocidas) la respuesta represiva estatal.

Como se expresara con anterioridad, ese mismo agrupamiento disidente sufre también selectivamente la violencia por parte del estado en los casos de represiones preventivas (registro de la columna $U$ en MTESS; y T en APS ), no así las ASO (registro de la columna, T en MTESS; y $S$ en APS). Aparece así, la nota de discriminación y selectividad expulsiva que tiene la represión relevada. Aparece también aquí, el actor social que la sufre. El sostenimiento de la existencia de esta relación, sobre los datos duros registrados en la muestra tienen incidencia para reafirmar parte de la tesis propuesta.

4. La represión tiene carácter ilegal. En segundo lugar, la represión relevada al ser confrontada con los datos que se recogen, luce contraria a derecho. Lo que en la terminología de Della Porta se caracteriza como represión "sucia" (como antagónica a legal). ¿Cómo podemos reconocer ese carácter?

La muestra registra a la totalidad de los actos represivos, en respuesta a acciones conflictivas lícitas llevadas adelante por los trabajadores y trabajadoras. Estas acciones lícitas forman parte de un repertorio de conductas habituales, reconocidas y admitidas, social y 
jurídicamente. Como se señalara precedentemente, la represión se desata en relación al sujeto que la impulsa, y no en respuesta de la naturaleza de la acción. La represión se muestra ilegal, en tanto conducta estatal rompe la regla de oro de igualdad ante la ley.

En la muestra, a lo largo de siete (7) años y sobre el territorio de diez (10) distritos de alta concentración poblacional y actividad fabril y productiva, se registra que en igualdad de condiciones, las acciones colectivas que resultan objeto de represión estatal, solo son las que son lideradas por un agrupamiento disidente.

\section{Legalidad, y acciones de alta intensidad que forman parte de} un repertorio aceptado. Que la medida adoptada por los agrupamientos sea de altísima intensidad, no varía el razonamiento. En el marco teórico de la TMR, se debe entender al bloqueo y a la ocupación de un establecimiento como parte del repertorio aceptado de conductas, entre las diferentes acciones conflictivas que usan los agrupamientos sindicales. Estas conductas son aceptadas dentro de una selección, que el propio estado reconoce como tal y no reprime. Esto es así, y así se releva en el trabajo. Pero, lo que también se registra en la muestra, es que esas conductas del repertorio tienen un solo parámetro de excepción: cuando estas mismas acciones son ejercidas por ASD, las conductas -en ese caso- disparan los mecanismos de represión del estado. Esta discriminación hace de la conducta represiva, una conducta ilegal o sucia (porque reprime a un sujeto predeterminado, y no a la conducta en sí).

Hablamos de inclusión de las acciones colectivas en un repertorio de uso, y su aceptación social. Los trabajadores y trabajadoras no son más que uno, entre la inmensa lista de colectivos que intentan incidir en la sociedad en la que viven. Que lleven adelante una acción conflictiva, es su natural destino; que lleven adelante formas de alta intensidad como una ocupación, será un avatar deseado. Pero que alcance a lograr esa intensidad en la disputa o no; no cambia que ésta acción - un bloqueo de una planta o su ocupación-, no es más que una forma reconocida, prevista y aceptada, por propios y ajenos.

Repetimos, que la medida adoptada sea de altísima intensidad, no varía el razonamiento. La ocupación será entonces lo que se denomina una forma convencional de conflictividad. ¿Por qué convencional? Porque, las 
acciones conflictivas no nacen del aire, nacen de "una práctica aprendida, y aceptada". Lo sintetiza Kertzer"La acción no nace de los cerebros de los organizadores, sino que se inscribe $y$ transmite culturalmente. Las convenciones aprendidas de la acción colectiva forman parte de la cultura pública de una sociedad"(citado por Tarrow, S.: 1997, pág.50)

Los trabajadores y trabajadoras van a una huelga, y saben cómo llevarla adelante, porque generación tras generación de trabajadores las han hecho antes que ellos. Así la han aprendido. Las modalidades con que los colectivos vulnerables suelen enfrentar a sus contendientes, se reiteran y se reconocen a través del tiempo. "Sobre la base de pasados periodos de conflicto con un grupo o grupos determinados o con el gobierno, los individuos construyen un prototipo de protesta o motín que describe lo que hay que hacer en circunstancias concretas, además de explicar la lógica de la acción en cuestión" (Hill y Rostchild, citado por Tarrow, S.: 1997, pág.51).

Los trabajadores y trabajadoras, intuyen y apuestan a que el mayor grado de determinación de su disputa con sus contendientes se evidencia cuando se determina la "toma" del establecimiento. Esta no es desconocida por sus adversarios, ni por el estado que garante el orden; ni por el resto de la sociedad que presencia los hechos. Y más allá del nivel de confrontación y poder que evidencia; es una práctica -aunque resistidaaceptada en el repertorio de utilización del colectivo de trabajadores ${ }^{36}$.

Además de lo ya expresado, se evidencia esta afirmación en nuestro trabajo a través de un dato que no puede ser soslayado; aparece en el relevamiento de la investigación, un número realmente voluminoso de ocupaciones y bloqueos de portones de establecimientos que no han sido "blanco" de la acción represiva del estado.

Por otra parte, el propio MTESS releva sistemáticamente esa acción de alta intensidad, a la que le ha asignado un código específico; muestra

${ }^{36}$ Charles Tilly, explica con naturalidad porque son convencionales este tipo de medidas: "(...) la gente no puede emplear rutinas de acción colectiva que desconoce; cada sociedad tiene una reserva de formas familiares de acción, conocidas tanto por los activistas como por sus oponentes, que se convierten en aspecto habituales de su interacción " (citado por Tarrow, S.: 1997, pág.51). 
clara ésta, de su habitualidad y de la importancia que el estado le asigna a su aparición en el horizonte del mundo de la producción.

\section{Legalidad, y acciones carácter disruptivo que forman parte de} un repertorio aceptado. Debemos recordar, que por más que se reconozca a la ocupación y al bloqueo como acciones convencionales en la tipología del repertorio de uso, no quita que éstas mantengan su carácter disruptivo. El carácter disruptivo, no hace ilegal a una acción.

La acción colectiva, incluso aquellas que hoy lucen un rasgo convencional -aceptadas en sociedad-, han visto la luz como acciones disruptivas. ¿Por qué? ¿Qué se busca con este tipo de acciones? Se busca la fractura, la interrupción brusca. Será la barricada, será el enfrentamiento con las fuerzas de seguridad, etc.. La acción disruptiva en su forma más directa, siempre fue -y será- una amenaza de violencia. La acción disruptiva es indispensable para que un grupo insurgente acopie recursos. Por las características mencionadas, y para romper el "statu quo" que no lo beneficia, es que los grupos insurgentes reunirán recursos para realizar acciones disruptivas.

Una acción para que pueda reunir el carácter disruptivo,debe tener la capacidad de desafiar a las autoridades, fomentar la solidaridad y crear incertidumbre. (Tarrow, S.: 1997, pág.195). No siempre la acción colectiva tiene este efecto. La huelga, en todas sus manifestaciones, desde que cobra identidad -en los albores de la revolución industrial- aparece y se manifiesta inicialmente disruptiva; aunque a través del tiempo suelen llegar a nuestros días, en formas inocuas y convencionales. Esto es natural, la historia de los movimientos sociales es en parte la historia de la incorporación al repertorio convencional de formas nuevas y disruptivas de acción, hasta que son asimiladas por los oponentes y las élites. Ese será el momento en que los movimientos sociales, buscarán nuevas acciones disruptivas.

En el relevamiento de esta investigación, se registra largamente este carácter inocuo de gran parte las medidas de acción. Un carácter adormecido en las acciones que se reportan (no las de mayor intensidad), como si se estuviese frente a un "rito de negociación".

Pero no todas las acciones conflictivas de los trabajadores y trabajadoras, han perdido su carga "genética" de alerta y disrupción. La 
ocupación del establecimiento productivo, en la inmensa mayoría de los casos se mantiene brusca e incólume para sus contendientes. No debemos olvidar aquí, que el establecimiento es el lugar más delicado -y necesariamente de mayor resguardo- para el sostenimiento del sistema capitalista (conforme O'Donnell, G.: 1982). Y el establecimiento -ese espacio también-, es objeto de una disputa política Las clases dominantes no pueden permitir su transformación en un espacio de resistencia (Oeslender, U.: 2002, pág.2.) Por mucho tiempo, la ocupación de un establecimiento productivo será una acción de naturaleza disruptiva.

Las ASD no tiene el tamaño suficiente -aún- para intentar acciones conflictivas de escala. El acopio a través del tiempo, le dará los recursos suficientes para intentar el salto a las grandes lidias. Por todo ello, los trabajadores y trabajadoras disidentes recién cuando han adquirido fuerza, intentarán acciones disruptivas. En la cima de ese esfuerzo, aparecerá la "toma de la fábrica".

En el trabajo de investigación se releva el carácter universal y aceptado dentro del repertorio de acciones disruptivas de uso de los agrupamientos sindicales; la respuesta represiva hacia esa acción respetada- por parte de las fuerzas policiales, se releva ilegal por resultar selectiva y discriminatoria hacia un grupo predeterminado de actores. Un grupo bien delimitado de actores (ASD) realizan la misma acción disruptiva que otros (ASO), pero solo estos últimos resultan amparados por el orden jurídico y la práctica institucional del estado.

5. La pérdida de resguardo constitucional de las acciones represivas del estado. ¿Qué implicancia tiene sobre el sujeto discriminado este carácter de ilegalidad de la represión? La represión tal como la relevamos nos muestra ausencia de resguardo constitucional.-

En el esquema teórico que utilizamos, el resguardo constitucional o el cumplimiento constitucional, es un contexto que podrá incidir favorable sobre las oportunidades políticas de los grupos insurgentes de una sociedad. Por el contrario, la ausencia de ese resguardo, muestra una posición de no integración por parte del estado hacia los sujetos que la sufren. En el caso que se estudia, en relación a los agrupamientos sindicales disidentes. Herbert Kitschelt (citado en Della Porta, D.: 1996, pág.126) 
señaló la importancia de los rasgos constitucionales de un estado para que existan oportunidades para los movimientos sociales.

En el mismo sentido Kriesi, aplicó ese análisis a los conflictos industriales, allí "las estrategias nacionales fijan las reglas de juego, tanto formales como informales, para la resolución del conflicto". Este autor diferencia, entre estrategias nacionales integradoras (de facilitación. cooperación o asimilación); y de exclusión (represivas, de confrontación y polarizadores). En el caso de análisis, se puede inferir la presencia de una conducta estatal de repulsión hacia estos agrupamientos. En realidad, una práctica oculta; una práctica institucional no escrita en ninguna norma estatal, que tiene por finalidad mantener la exclusión grupal en oposición al mandato constitucional.

En el plano del derecho y del deber ser, la respuesta es clara. Nuestro estado tiene como hoja de ruta constitucional (y convencional internacional) estrategias nacionales integradoras (artículos $14^{\circ}$ "bis" y $75^{\circ}$ inc. 22 de la $\mathrm{CN}$ ); las que por otra parte, declaman todos los actores sociales, sean estos agencias estatales o del resto de la sociedad civil. La acción conflictiva reconocida y aceptada de cualquier agrupamiento de la sociedad, que intenta cobrar existencia pública e incidir en la comunidad que vive; tiene en nuestro ordenamiento jurídico el resguardo de integración, que responde a esa estrategia. Las reglas de juego existen, y deben permitir el intento de acceso al grupo mientras cumpla con ellas. Un acceso a incidir que tienen todos colectivos que pertenecen a una sociedad. La muestra más clara de que estas reglas se encuentran vigentes, es el hecho que el estado argentino da cumplimiento institucional para con otros agrupamientos -los ASO - que si son aceptados (Della Porta, D.: 1996, pág.127/8).

Como se puede apreciar en el estudio,lamentablemente el problema de la represión policial como obstáculo para el acceso al reconocimiento societal de grupos minoritarios de la sociedad, no pasa por el marco legal que formalmente es adecuado; por el contrario, en el caso de estudio ese marco no se cumple. El estudio indiciaría que la acción de los agrupamientos sindicales disidentes "se ve limitada por ciertos rasgos institucionales duraderos" que muestran una sistematicidad consistente (Della Porta, D.: 1996, pág.127/8), en incumplimiento a la ley. 
En un plano sociológico y jurídico, si se quiere cumplir el mandato constitucional (de igualdad) y de promoción de integración del grupo en la sociedad, aquella práctica debe ser desactivada. Esa orden ilegal y oculta debe ser removida.

6. La represión dura y reactiva. Por último, siguiendo el cotejo de la represión en el estudio de campo con las categorías binarias de Dallaporta, aparece como nuevas notas su doble carácter,reactivo (en oposición a preventivo frente al conflicto) y brusco (o excesivo en relación al uso de la fuerza pública). Estos caracteres refuerzan -aunque en menor medida- el propósito expulsivo (no integrador) del agrupamiento sindical.

La intervención policial brusca (o con exceso en el uso de la fuerza) y reactiva, frente a una protesta disruptiva de los trabajadores, tiene un efecto ya reconocido en la sociología, que es lograr desencadenar una contradicción cultural. Este efecto, puede responder a un objetivo político. ¿En qué consiste ese desencadenamiento? Cuando dos o mas cuestiones culturalmente importantes y potencialmente contradictorias chocan abiertamente, se produce esta situación (Zald Mayer N. citado en Della Porta, D.: 1996, pág.104). En nuestro caso, en el momento álgido de la movilización colectiva, como es la ocupación de una planta y el derecho de los trabajadores y trabajadoras frente a la acción represiva de la policía -y este hecho ha tenido suficiente difusión-, se convierte en una cuestión controvertida en torno a la cual se generará una posible polarización de la sociedad.

Ante una cuestión que emerge y se torna trascendente para la sociedad, se abre la posibilidad que terceros sean quienes juzguen esas conductas (y los valores que las sustentan). En ese momento se juega gran parte de la suerte de la aceptación de los trabajadores y trabajadoras y sus reclamos frente al resto de la sociedad. Estarán a pasos de su visibilización y reconocimiento; en el mundo sindical, estarán a pasos de lograr su representatividad.

Aparecida una acción conflictiva colectiva, que esta acción "de protesta" puede ser visibilizada o comprendida por el resto de la sociedad como "el ejercicio de un derecho ciudadano o como una disrupción del orden público, tiene consecuencias importantísimas para la legitimación de sus actores." (Della Porta, D.: 1996, pág.104). Que el 
estado reaccione, sin encausar el conflicto y haciéndolo "ostensiblemente" con dureza, tiende a ubicar al tercero ante el segundo de estos escenarios.

En el primero de los casos, auxiliará a la integración del agrupamiento; en el segundo de los casos, se alejará esa posibilidad.

La militarización de las plantas. Las únicas y escasas excepciones a la modalidad represiva reactiva que se registran en el trabajo, confirman lo dicho. La represión preventiva -que es la excepción registrada-, es de mayor intensidad e indiscutiblemente ilegal al resto de las formas de represión relevadas.

Son los casos en que se produce directamente la "militarización" de la planta (su ocupación por fuerzas de seguridad). En estos casos lo que sucede es que el estado ocupa policialmente la totalidad del espacio de trabajo, haciendo desaparecer de raíz lo que Capón Filas denomina las garantías políticas mínima e "indispensable", sin las cuales no puede siquiera- existir el derecho sindical (Capón Filas, R.: 1989, pág.215).

Aparece preventivamente, pero de forma desmesurada una acción represiva que impide de forma absoluta el cumplimiento no solo de una medida de acción sindical, sino que hace desaparecer los "niveles mínimos y esenciales" que el ejercicio de este derecho humano debe tener.

Las consecuencias de la represión policial Sobre el análisis de nuestra observación, deberíamos preguntarnos ¿qué efectos produce esta represión excesiva y reactiva sobre los agrupamientos disidentes?Las consecuencias nocivas, de la represión policial sobre las protestas y sobre los agrupamientos insurgentes ya fueron señalados (Capítulo XII. Represión). Los doy por reproducidos aquí.

La respuesta sobre los efectos negativos de la represión aparecen también sobre el análisis del trabajo de campo ¿Qué posición de fuerza tendrán los agrupamientos sindicales disidentes con posterioridad al ejercicio de la represión en los lugares de trabajo? La observación de los distintos casos, muestra que las ASD desaparecen o atenúan severamente su presencia del radar de conflictividad; se quedan sin recursos. ¿Qué significará en relación a la posibilidad de acceso o acopio del recurso de la representatividad buscado? EL ASD no alcanzará reconocimiento de representatividad. 
La extensión temporal del relevamiento, la observación sobre el mismo territorio y los mismos actores sociales, nos permiten observar, como los ASD, luego de recibir la represión policial excesiva, produce para estos la disminución o eliminación de su actuación en el marco de nuevas luchas. Los agrupamientos disidentes nunca vuelven a alcanzar el mismo nivel de intensidad en sus acciones.

En la observación del caso se puede relevar las consecuencias negativas, desarticulantes de los esfuerzos de los agrupamientos sindicales disidentes que produce la acción represiva del estado.

7. Estrategia predominante del estado a reprimir ASD. ¿Qué es lo que se observa en definitiva? En el marco teórico de la TMR, se releva una tendencia del estado a reprimir ASD ¿Cuándo? y ¿en qué condiciones? El trabajo muestra, que en similares circunstancias, solo se reprime a ASD.

Sobre el recorte en tiempo y espacio que realiza esta investigación, se puede reconocer una cierta tendencia del estado a no recurrir al uso de la fuerza física cuando la acción que impulsan los agrupamientos disidentes son de baja intensidad, o persigue objetivos menores en la disputa.

Por el contrario, cuando la acción conflictiva del agrupamiento disidente resulta altamente crítica y teniendo un resultado favorable a su esfuerzo; en ese caso, el estado hace uso de la fuerza, teniendo como resultado obstaculizar o desactivar el núcleo crítico.

El estado -a través de sus acciones- no permite que este grupo alcance objetivos mayores en sus lidias, como es obtener la representatividad que sus pares reconocerían al triunfar en esas disputas.

En esta aparición de represión discontinua en el tiempo, pero de existencia constante cuando sea resulte necesaria contra las agrupamientos sindicales críticos,podemos ver lo que algunos autores entienden como "estrategia predominante" de un estado (Tarrow citado en Sánchez Estellés, I.: 2004)."En los sistemas representativos -estados no autoritarios-, la protección constitucional de los derechos (...)facilita el acceso uniforme a las políticas populares"(Tarrow, S.: 1997, pág.169). "No obstante, los sistemas representativos pueden dispersar y eliminar los movimientos de oposición. Por una parte, dado que invitan a la crítica y la participación, tales sistemas "procesan" los elementos más desafiantes 
eliminándolos de la política. Por otro lado, pueden ser abiertamente represivos contra aquellos que amenacen -o que pueda hacerse parecer que amenazan- sus preceptos subyacentes". (Tarrow, S.: 1997, pág.169).

Esta noción nos permite interpretar la situación que observamos en el norte del conurbano. La fuerza del estado y esta "estrategia predominante" de "barrer los grupos sindicales díscolos", son elementos estables que condicionan las oportunidades políticas de estos últimos.

No se los elimina, ni se los proscribe. Como en aquellos manómetros de precisión que garantizan que los instrumentos de producción no se rompan por elevamiento del grado de presión; quien debe garantizar la normalidad -dada- del orden social detecta los agentes disociativos, permiten su presencia y acción, pero llevado un grado de riesgo -por posible reproducción por encima de los niveles deseados o posibles de controlar-, se ejerce sobre ellos la dosis necesaria de fuerza como para retrotraer el número y acción del agrupamiento hasta los niveles esperados por el sistema.

Pareciera que la protesta obrera se admite; pero solo si es modesta en sus objetivos. Se admitirá, pero siempre y cuando no sea impulsada por agrupamientos que confronten seriamente $-y$ con posibilidades- al orden político, y a los monopolios sindicales reconocidos. Pasado favorablemente el nivel de acopio "normal y permitido" de recursos por parte de los ocasionales contendientes, se encenderán las alarmas y los dispositivos represivos.

No se estudia aquí, cuales son los factores que sostienen o que hacen variar estrategias predominantes y el uso de la fuerza estatal que condicionan las oportunidades políticas de los grupos insurgentes en la Argentina. Este trabajo pretende demostrar, como elemento existente en nuestra realidad, esa constante represiva. Una constante que es afirmada por los autores (Gilly, A.: 1990; y O'Donnell, G.: 1982), que dan fundamentación teórica a este trabajo.

La valoración de la represión policial como parámetro único para apreciar la permeabilidad o no del estado frente a grupos disidentes, no debe ser apreciada en el vacío, libre de la sociedad que le da sentido. Para poder comprender más acabadamente su importancia, debemos observarla en el escenario concreto de nuestra sociedad. Cuando ese uso de la fuerza 
pública, es interpretada -y auxiliada- por un marco teórico que nos permite reconocer una constante preexistente de estrategias predominantes y un uso de la fuerza estatal, signadas para la aparición de situaciones críticas al orden; entonces, la observación del uso de la fuerza policial se podría comprender como la punta del iceberg, que periódica pero inalterablemente aparece cada vez que se produce la situación crítica que la impulsa. Cada vez que la represión policial aparezca ejercida contra ASD, debemos prestar atención. Solapado detrás de la acción policial, se conserva al sistema y se callan voces. 


\section{CONCLUSIONES. PLANO JURIDICO.}

1. Estado y garantías extra-institucionales. Lo que hoy entendemos como derechos sociales, nacieron de la crítica al modelo liberal clásico, que había creado un régimen de notoria desigualdad legalizando un estatus de dominación. En ese marco,"la represión antisindical y el combate contra la organización de los trabajadores eran presentados como maneras de garantizar las condiciones de "igualdad" entre individuos contratantes" (Abramovich, V. y Courtis, Ch.: 2006, pág.10/2).

A la búsqueda del cambio de la matriz social, para obtener mejores condiciones de vida y de trabajo para los sectores más postergados se la llamó, "la cuestión social" ."En este nuevo derecho (...) se debe partir de una idea de desigualdad material, antes que una igualdad formal; se parte de la existencia de relaciones colectivas de trabajo, antes que relaciones individuales; el estado pasa de garantizar relaciones individuales a legitimar el sistema de producción pero protegiendo a la parte más débil (...)"(Abramovich, V. y Courtis, Ch.: 2006, pág. 13). El derecho social pasó a ser, un derecho de grupos, no de individuos; un derecho que pretende ser un instrumento para equiparar desigualdades. Así se asumirá constitucionalmente por los estados (Abramovich, V. y Courtis, Ch.: 2006, pág. 17/8).

\section{La huelga como garantía extra-institucional. El estado frente a} la garantía del grupo. Dentro de este cúmulo de nuevos derechos en pugna, el derecho de huelga, paso a ser el mecanismo usual de resguardo de estos grupos -vulnerables por cierto- dentro de la sociedad.Lo que técnicamente se denominó posteriormente una garantía .

"Las garantías son mecanismos o técnicas de tutela de los derechos, destinados a asegurar su efectividad". (Abramovich, V. y Courtis, Ch.: 2006, pág.65). Estas garantías pueden ser tipo institucional y extrainstitucional. Las garantías institucionales, son mecanismos confiados a las instituciones o poderes públicos.La huelga no participa de este carácter, la protección no nace de una mediación estatal; será lo que se define como resguardo extra-institucionales. "Las garantías extra institucionales o 
sociales son instrumentos de defensa o tutela de los derechos que dependen directamente de sus titulares. La activación de estos instrumentos de garantía importa por ende la propia iniciativa de los ciudadanos, y no está subordinada a la actuación de los poder públicos." (Abramovich, V. y Courtis, Ch.: 2006, pág.84).

¿Qué importancia devendrá de esta nota? Son formas de control ciudadano En los que no interviene el estado; y al no intervenir, promueven la gestación y consolidación de nuevos poderes dentro de la sociedad. De tal modo, se atenúa $-y$ en algunos casos se impide- la reconducción o apropiación del esfuerzo sectorial de un determinado grupo, ya sea por parte del estado o por parte de otros grupos que ya disponen de una posición social dominante.

"(L)as garantías sociales de mayor notoriedad son las formas de autotutela de los derechos, es decir, aquellas formas de acción en las que los propios titulares emplean vías directas para reclamar o defender un derecho. La historia de los derechos sociales es, en gran medida, la historia del empleo ostensivo de formas de autotutela de derechos, y de su posterior reconocimiento e institucionalización. Algunas formas de autotutela han sido explícitamente incorporadas y reguladas por el ordenamiento jurídico: el ejemplo más típico es el del derecho de huelga".(Abramovich, V. y Courtis, Ch.: 2006, pág.89).

Se debe tener presente que el ejercicio de cualquiera de estas medidas, conlleva inevitablemente la afectación de derechos de terceros. En esencia, toda medida de acción directa busca producir ese daño; un hecho ilícito que el propio ordenamiento autoriza. (Capón Filas, R.: 1989, pág.414). Por ello, la valoración jurídica de estas formas de autotutela exige para su cabal comprensión, tener siempre presente la situación de vulnerabilidad de derechos sociales que enfrentan los grupos sociales que protagonizan estas acciones de protesta. Y esta comprensión debería tener una incidencia central en la respuesta que debe tener el estado frente a una medida, aunque reúna formas radicalizadas.

Por ello, es probable que la situación del grupo, justifique la afectación proporcional de bienes y derechos de terceros;y requerirá por sobre todas las cosas, tolerancia ante esta afectación por parte de la 
autoridad pública y de los demás particulares" (Abramovich, V. y Courtis, Ch.: 2006, pág.91).

Esto implica una consecuencia central para nuestro trabajo: ante las medidas de fuerza debe existir una restricción del uso de la violencia por parte del estado, y de la criminalización como tratamiento oficial del conflicto.

\section{Obligaciones del estado que generan los derechos sociales.}

Esa tolerancia estatal frente a la protesta, se puede observar desde la mirada jurídica. Una vez reconocidos como derechos, aparece la segunda cuestión, ¿si son derechos que obligaciones generan para el estado?

La obligación de respeto.La estructura de los derechos económicos sociales y culturales se caracteriza por un complejo de obligaciones, negativas (de no hacer) y positivas (de dar o hacer) de parte del Estado; obligación de abstenerse de actuar en ciertos ámbitos y de realizar una serie de funciones, a efectos de garantizar el goce de la autonomía individual". (Abramovich, V. y Courtis, Ch.: 1997,p.286).

No obstante lo dicho, debemos destacar previamente, una:"la principal obligación del estado frente al derecho de huelga -junto al derecho a la sindicalización- es una obligación de no hacer". Hay acuerdo en doctrina que la obligación primaria y esencial del estado frente a este derecho es su inacción.

La huelga y la obligación negativa del estado."En cuanto a las obligaciones negativas, se definirían a través de la obligación de abstenerse de realizar cierta actividad por parte del Estado. De ese modo el no intervenir en caso de existir una huelga -o el no impedir a una persona a que se afilie a un sindicato-, tendrán el mismo resguardo que el no impedir la expresión o difusión de ideas, o no violar la correspondencia, o el no detener arbitrariamente, o no impedir a una persona el acceso a la educación" (Abramovich, V. y Courtis, Ch.:1997, p.292/3).

Frente a la más difundida de las clasificaciones, que distingue entre distintos niveles: obligaciones de respeto (el estado no debe vulnerar a través de su acción el ejercicio del derecho), obligaciones de protección (el estado debe evitar que terceros vulneren a través de su acción el ejercicio del derecho), y obligaciones de garantía o satisfacción (el estado debe 
asegurar el derecho cuando el titular no puede hacerlo por sí mismo) (Abramovich, V. y Courtis, Ch.: 2006, pág.26); el incumplimiento estatal encuadra en la primera de las categorías.

Claramente, el estado nacional en el caso de estudio ha incumplido su obligación de respeto frente al ejercicio del derecho de huelga. En este trabajo se logra acreditar las acciones positivas que de modo selectiva, ilegal y discriminatoria realiza el estado incumpliendo así su deber de respeto para con el derecho de huelga ejercido por un agrupamiento colectivo definido que integra nuestra sociedad.

Más allá del incumplimiento de otras obligaciones que debe asumir el estado -que se señalarán a continuación-, las formas represivas estudiadas, muestran de modo palpable la configuración de la vulneración de este derecho (conforme prescriben las cláusulas convencionales señaladas en el Capítulo X, la Constitución Nacional artículos 140 "bis" y $75^{\circ}$ inc. 22, y las disposiciones concordantes del ordenamiento interno establecidas en la ley 23. 551, centralmente en los artículos $1^{\circ}, 4^{\circ}, 5^{\circ}$ y $\left.6^{\circ}\right)$.

\section{Derecho de huelga, y el complejo de obligaciones que} genera. Teniendo presente esta noción, volvemos a lo ya expresado, la estructura de los derechos económicos sociales y culturales -entre ellos la huelga- puede ser caracterizada como un complejo de obligaciones positivas y negativas por parte del Estado. ¿A qué se obligara el estado cuando reconoce un derechos social?

Para hacer un escrutinio más acabado y detallado, tomamos para la determinación de las obligaciones desde otra clasificación -también de generalizada difusión-, que se asienta en un detalle pormenorizado sobre bases en las cláusulas convencionales.

Christian Courtis y Abrahamovich, precisan "sin pretender agotar la enumeración" como Obligaciones genéricas del estado frente a los derechos sociales: 1. Prohibición de toda discriminación; 2. Adoptar medidas inmediatas; 3. Garantizar niveles esenciales de los derechos; 4. Obligación de progresividad y prohibición de regresividad (Abramovich, V. y Courtis, Ch.: 2006, pág.1997, p.48).

Esta clasificación tiene el beneficio de permitir observar con definición las conductas estatales comunes incumplidas. Las mismas se adosan al 
incumplimiento genérico a la obligación de respeto frente al ejercicio del derecho de huelga.

Veamos cual es el grado de incumplimiento que pueda constatarse en el caso de estudio en cada una de ellas.

4. Prohibición de toda discriminación. Los diferentes instrumentos internacionales establecen el deber para los Estado de respetar los derechos reconocidos en los instrumentos suscriptos (en este caso el derecho de huelga) y garantizar su libre y pleno ejercicio a toda persona que esté sujeta a la jurisdicción de aquel, sin discriminación alguna (Salvioli, F.: 2004, pág. 110). Este es un principio rector del derecho internacional de los derechos humanos (Salvioli, F.: 2004, pág. 114).

El Comité de Derechos Humanos de las Naciones Unidas nos da una definición de discriminación como: "[...] toda distinción, exclusión, restricción o preferencia que se basen en determinados motivos, como la raza, el color, el sexo, el idioma, la religión, la opinión política o de otra índole, el origen nacional o social, la posición económica, el nacimiento o cualquier otra condición social, y que tengan por objeto o por resultado anular o menoscabar el reconocimiento, goce o ejercicio, en condiciones de igualdad, de los derechos humanos y libertades fundamentales de todas las personas" 37 .

En forma coincidente, en el primer párrafo de la Observación General n03 del PIDESC, destaca la importancia de esta obligación: "(...)de las obligaciones jurídicas (...)dos resultan particularmente importantes para comprender la índole exacta de las obligaciones contraídas por los Estados Partes. Una de ellas, (...) consiste en que los Estados se "comprometen a garantizar" que los derechos pertinentes se ejercerán "sin discriminación...".

Tal como fuese analizado en capítulo XIV (Resultados. Análisis cualitativo), surge palmariamente acreditado en el relevamiento de campo que existe por parte del estado un incumplimiento a su deber de respeto hacia un colectivo que integra la sociedad.

37 O.N.U., Comité de Derechos Humanos, Observación General 18, No discriminación, 10/11/89, CCPR/C/37, párr. 7. 
Como se afirmara,"la represión relevada es discriminatoria en cuanto al sujeto que la sufre", siendo dirigida a grupos que realiza las mismas acciones que el resto del universo de sujetos; y no obstante, el estado los selecciona para ejercer sobre ellos la represión.

No existe en el caso que se analiza, una distinción objetiva y razonable, que permita interpretar que la conducta lesiva del estado como no violatoria a las obligación que tiene el estado argentino. Estas distinciones no lucen en el estudio de campo. El incumplimiento de estas obligaciones genera la responsabilidad internacional del Estado.En este trabajo se constata la violación por parte del estado argentino en cuanto a su obligación de no discriminar, conforme los artículos Artículos $1^{\circ}$ y $24^{\circ}$ de la Convención Americana; Artículo $2^{\circ}$ del Pacto Internacional de Derechos Civiles y Políticos; Artículos $2^{\circ}$ y $26^{\circ}$ del Pacto Internacional de Derechos Económicos Sociales y Culturales; Artículos $2^{\circ}$ y 70 de la Declaración Universal de Derechos Humanos; y $3^{\circ}$ del Protocolo Adicional de San Salvador de Bahía.

\section{Obligación de adoptar medidas inmediatas.}

Los diferentes instrumentos internacionales establecen una segunda obligación que destacan con similar énfasis a la mencionada en los párrafos precedentes; será el deber para un estado de adoptar medidas inmediatas para que se respete y garantice el derecho afectado (en este caso a ejercer el derecho de huelga).

La misma se encuentra consagrada en los Artículos $2^{\circ}$ de la Convención Americana; Artículo $2^{\circ}$ del Pacto Internacional de Derechos Civiles y Políticos; Artículo $2^{\circ}$ del Pacto Internacional de Derechos Económicos Sociales y Culturales; $1^{\circ}$ y $2^{\circ}$ del Protocolo Adicional de San Salvador de Bahía. Esta obligación internacional, parte de la comprensión de que su efectivización se consagra en el transcurso tiempo; pero no obstante ello, la acción del estado exige su compromiso concreto y la previsión de su logro en un tiempo cercano. "(...)(Si bien la plena realización de los derechos pertinentes puede lograrse de manera paulatina, las medidas tendentes a lograr este objetivo deben adoptarse dentro de un plazo razonablemente breve(...)".Y para ello, se debe recordar que los medios que deben emplearse para dar cumplimiento a esta obligación "de adoptar medidas" incluye a todos los medios apropiados. El estado está 
potencialmente obligado en todos sus poderes, y por todos los medios de que dispone.

Este compromiso genérico, se desmembra en un conjunto de obligaciones que la conforman (Abramovich, V. y Courtis, Ch.: 1997).

5.1.Adecuación del marco legal. Una primer obligación, es la de lograr el inmediato adecuamiento al marco legal. Esta consiste básicamente en derogar toda norma jurídica que resultan manifiestamente contrarias a sus obligaciones convencionales (Abramovich, V. y Courtis, Ch.: 2006, pág.329).En nuestro caso, no sería necesaria tal derogación, porque no existe tal norma en el ordenamiento argentino.

Por el contrario, el ordenamiento argentino -ante la ausencia de norma legal en contrario- no autoriza la intervención estatal para enervar una medida de acción directa. Se sostiene tanto en el ordenamiento administrativo ${ }^{38}$, como en el ordenamiento laboral nacional (Cornaglia, R.:2004, pág.170; Capón Filas, R.: 1989 pág. 422). El poder ejecutivo carece de facultades legales para restringir el ejercicio del derecho de huelga ${ }^{39}$.Aunque obvio, recordamos aquí el principio de legalidad."(...)/a administración sólo puede actuar avanzando sobre la esfera jurídica individual cuando una ley (en forma expresa o razonablemente implícita) la autoriza, en forma reglada o discrecional, a hacerlo. El lector advertirá que esto es precisamente el principio de la legalidad de la administración, generalizado en todas las obras modernas sobre la materia, que expone como técnica jurídica del derecho administrativo el criterio de que la administración no puede actuar sin una fundamentación legal".(Gordillo, A.: 2000; Tomo II, Cap. V, pág.21)

${ }^{38} \mathrm{El}$ estado puede limitar derechos, pero fundado en norma legal. "(...)no afirmamos que el Estado o la administración carezcan en absoluto de facultades para limitar los derechos individuales en pro del bien común, sino que decimos que esas facultades no pueden subsumirse en un concepto común que luego tenga vigencia jurídica autónoma y pueda a su vez fundamentar nuevas facultades y nuevas limitaciones.Por lo tanto, nuestro planteo tiende a demostrar que es errado fundar una limitación a un derecho individual tan sólo en ese concepto, pues él a su vez es inexacto: la limitación deberá, pues, fundarse concretamente en las disposiciones legales o constitucionales y demás principios jurídicos aplicables, pero no en esa "noción" de "poder de policía."(Gordillo, A.: 2000; Tomo II, Cap. V, pág.12)

39 Solo son permitidas muy escasas restricciones, que no forman parte de este trabajo. Una es el límite temporal que le faculta para llamar a conciliación obligatoria (Ley 14.786); y el segundo, es la restricción a su ejercicio acotándolo con servicios mínimos- en servicios esenciales (artículo $24^{\circ}$ ley 25.877). 
Recordemos en este punto también, que cualquier restricción de derechos consagrados en tratados de derechos humanos, podrán someterse únicamente a limitaciones determinadas por ley,en la medida que sean compatibles con la naturaleza del derecho reglamentado,con el exclusivo objeto de promover el bienestar general en una sociedad democrática. (Abramovich, V. y Courtis, Ch.: 2006, pág.341; y Abramovich, V. y Courtis, Ch.:1997, pág.61) Estos lo alcanza de pleno a la protección de este derecho. Conforme Artículos $16^{\circ}$ de la Convención Americana; $4^{\circ}$ del Pacto Internacional de Derechos Económicos Sociales y Culturales; y 50 del Protocolo Adicional de San Salvador de Bahía.

Tal como lo indicáramos, lo que existe son órdenes ocultas y contrarias al ordenamiento.

Pero dentro de esta obligación estatal de adecuación al marco legal, debemos advertir que la misma no se agota en la adecuación normativa interna al respectivo tratado; sino que ésta alcanza a las prácticas estatales relativas a su aplicación, que también deben adecuarse al derecho internacional. Es decir, no basta con que el ordenamiento jurídico interno se adecue formalmente al derecho internacional, sino que es menester que los órganos o funcionarios de cualquier poder estatal, sea ejecutivo, legislativo o judicial, ejerzan sus funciones y realicen o emitan sus actos, resoluciones y sentencias de manera efectivamente acorde con el derecho internacional aplicable.Nace de este alcance, la obligación de eliminar cualquier práctica institucional (incluyendo acciones positivas y acciones por omisión) que afecte el goce de los derechos económicos, sociales y culturales.

En este trabajo se constata esta práctica oculta, que consagra el incumplimiento de adecuación al marco legal.Tal como fuese analizado en el capítulo XIV (Resultados. Análisis cualitativo), la represión que ejerce el estado es contraria al orden constitucional. Su existencia, nace de una práctica institucional que debe ser removida.El incumplimiento de estas obligaciones, que se encuentran constatadas, genera la responsabilidad internacional del Estado,

5.2. Relevamiento de información, vigilancia efectiva y formulación de plan. (Abramovich, V. y Courtis, Ch.: 1997, pág.52), integran a esta obligación de adoptar medidas inmediatas, que el estado frente al derecho en reguardo, realice un relevamiento de información, la 
vigilancia efectiva, y confeccione un plan para alcanzar progresivamente la efectividad de esos derechos (en nuestro caso el derecho de huelga).

En relación a este aspecto, debemos señalar que el MTESS realiza un relevamiento pormenorizado del ejercicio de este derecho. La producción de información es un presupuesto para la vigilancia del grado de efectividad del derecho. Lo que no está cumplido es la vigilancia efectiva sobre las situaciones en conflicto con el propósito, ya que se evidencia el incumplimiento en relación al grupo discriminado. Y también se evidencia la ausencia de un plan para lograr en el tiempo la efectividad del derecho.-

5.3. Proveer de recursos efectivos. Complementa esta obligación de adoptar medidas inmediatas, la obligación de proveer recursos (presupuestarios, materiales y legales) para la plena efectividad de los derechos. No existiría incumplimiento de esta obligación en el caso de estudio, salvo aquellos de muy bajo costo que se ocasiones para la instrumentación de la obligación de vigilancia efectiva, ya citada.

6. Obligación de garantizar niveles esenciales. Como tercer obligación genérica de los estados frente a derechos económicos sociales y culturales, aparece la obligación mínima de asegurar la satisfacción por lo menos de los niveles esenciales de cada uno de los derechos sociales.

Esto implica adoptar medidas que conlleven algún tipo de acción positiva, cuando el grado de satisfacción del derecho se encuentre en niveles que no alcancen los mínimos exigibles (Abramovich, V. y Courtis, Ch.: 1997, pág.55). Pero también conlleva la obligación de inacción para garantizar esos mismos niveles. Este es el caso de estudio.-

Para poder apreciar la importancia del cumplimiento de esta obligación por parte del estado,debemos destacar que estos niveles se deben mantener aún en tiempos de graves limitaciones de recursos causadas por procesos de ajuste (OG n 3 ). En los peores momentos, se debe proteger con más intensidad a los más vulnerables. "No solo existe un mínimo esencial de protección de cada uno de los derechos, sino un sector de la población que representa el mínimo de ciudadanos que debe recibir, aún durante la crisis, la protección del estado en relación a sus derechos sociales" (Abramovich, V. y Courtis, Ch.: 1997, pág.55). 
En este trabajo se releva una forma particular de represión por parte del estado, es una forma preventiva y extremadamente dura del uso de la fuerza pública, y que consiste en la "ocupación" por parte de las fuerzas de seguridad de la planta o establecimiento. Popularmente ha recibido el nombre de "militarización" de la planta o establecimiento, lo que condice con las fuertes imágenes que dejan la presencia de centenares de integrantes de las distintas fuerzas de seguridad detrás de los cercos enrejados de las empresas. Imágenes que pueden transportar en el imaginario, a otros tiempos; tiempos de enfrentamientos bélicos o de "estados de excepción" sobre parte de la población de un país.

Desde el punto de vista legal, la administración carece de fundamentos legales para disponer de estos actos jurídicos. Aunque no forma parte de este estudio, cabe aclarar en la observación, que salvo en alguna escasísima excepción, la casi absoluta mayoría de las ocupaciones policiales preventivas que se relevan en este período, no existió orden judicial alguna que lo sustente.

La ocupación policial preventiva, además de ilegal, es un acto de la administración que impide de modo total el ejercicio de medidas de acción directa en el lugar de trabajo. De tal modo que su existencia, constata el incumplimiento a la obligación de garantizar el nivel mínimo del derecho a resguardar.

En este trabajo se constata estas manifestaciones represivas, tal como fuese analizado en el capítulo XIV (Resultados. Análisis cualitativo), la misma aparece en los casos allí relevados. La falta a estas obligaciones -que se encuentra constatada el registro- importan la violación a ese nivel esencial mínimo, generado así la responsabilidad internacional del Estado por tal incumplimiento.

\section{Obligación de progresividad y prohibición de regresividad.}

Por último se establece en lareferida clasificación de obligaciones genéricas para los estados, la Obligación de progresividad y prohibición de regresividad en materia de derechos económicos, sociales $y$ culturales.

La misma se encuentra consagrada en los Artículos $26^{\circ}$ de la Convención Americana; Artículos 20 del Pacto Internacional de Derechos 
Económicos Sociales y Culturales; y $1^{0}$ del Protocolo Adicional de San Salvador de Bahía.

Por ésta los Estados Partes se comprometen a adoptar medidas para lograr progresivamente, y por todos los medios apropiados, la plena efectividad de los derechos incluidos en los instrumentos internacionales. La noción de progresividad abarca dos sentidos complementarios: por un lado, el reconocimiento de que la satisfacción plena de los derechos supone una cierta gradualidad (aunque no debe ser malinterpretada en el sentido de privar a la obligación de todo contenido significativo.) (Abramovich, V. y Courtis, Ch.: 2006, pág.334); y por otro lado, (...) impone la obligación de moverse tan rápida y efectivamente como sea posible hacia la meta" (punto 9 del OG n³) .) (Abramovich, V. y Courtis, Ch.: 2006, pág.334) .

De esta obligación estatal, también surge otra de naturaleza muy concreta, la obligación de no regresividad, (Abramovich, V. y Courtis, Ch.: 2006, pág.335); conforme Artículos $26^{\circ}$ de la Convención Americana; Artículo $4^{\circ}$ del Pacto Internacional de Derechos Civiles y Políticos; Artículos 20 y 40 del Pacto Internacional de Derechos Económicos Sociales y Culturales; y $1^{\circ}$ del Protocolo Adicional de San Salvador de Bahía.

En relación a estas, y a la constatación en el relevamiento de un modus operandi oculto por parte del estado para restringir el ejercicio del derecho de huelga para un sector de la población, quisiera detenernos en un aspecto de esta obligación común de progresividad.

Tal como nos orienta en la interpretación de la obligación del estado,"la plena efectividad de todos los derechos económicos, sociales y culturales en general no podrá lograrse en un breve período de tiempo.(...) . Este impone así una obligación de proceder lo más expedita y eficazmente posible con miras a lograr ese objetivo" (párrafo 9 de la O.G. n³). De allí que se impone para el estado, la obligación a implementar en un plazo razonablemente breve medidas que tiendan a ese objetivo. Dar pasos concretos hacia la satisfacción total. "En esta línea, puede establecerse que un estado viola el pacto, por ejemplo cuando no logra remover a la mayor brevedad posible todos los obstáculos que impidan la realización inmediata de un derecho.(...)"(Abramovich, V. y Courtis, Ch.: 1997, pág.50/1)."Los Estados están obligados a adoptar medidas positivas para revertir o cambiar situaciones discriminatorias existentes en sus sociedades, en perjuicio de 
determinado grupo de personas. Esto implica el deber especial de protección que el Estado debe ejercer con respecto a actuaciones y prácticas de terceros que, bajo su tolerancia o aquiescencia, creen, mantengan o favorezcan las situaciones discriminatorias (OG n 18Párrafo 104).

La constatación efectuada por este trabajo, impone al estado de la realización de medidas a su alcance que resulten una respuesta jurídica adecuada para garantizar el respeto al ejercicio del derecho de huelga para los ASD.- 


\section{ANALISIS DEL CASO ORELLANO. SU PROYECCION SOBRE EL TEMA DE TESIS.}

Durante el mismo período que corresponde al tiempo evaluado en el trabajo de investigación, se desencadenó un conflicto colectivo en la planta que la empresa Correo Oficial de la República Argentina S.A. posee en la localidad de Monte Grande, en el partido bonaerense de Esteban Echeverría. El conflicto se extendió desde mayo a los primeros días de agosto del año 2009. El conflicto en sí, no tuvo ninguna peculiaridad que lo destaque por sobre otros de su tipo, sin embargo tendrá la suerte de trascender a partir de su judicialización. Las actuaciones concluirán en la CSJN ("Recurso de hecho deducido por la demandada en la causa Orellano, Francisco Daniel c./ Correo Oficial de la República Argentina S.A. S./ juicio sumarísimo").-

¿Por qué integrar al estudio un capítulo que analice el caso "Orellano"? El interés del caso está dado, en razón al destacado actor institucional que la origina y las enormes consecuencias que sus posicionamientos produce sobre el mundo del trabajo. En segundo término, porque en este fallo la CSJN estableció doctrina sobre la titularidad para el ejercicio del derecho de huelga, la que arrastrará importantes secuelas sobre el mecanismo represivo sistemático que se investiga en este trabajo.

En primer término, analizaremos pormenorizadamente el conflicto, las circunstancias de hecho que constituyen el caso que llegó a la Corte. Y lo haremos destacando el mismo desagregado de elementos que realizamos en la investigación. El objetivo aquí será evaluar si existe o no un emparentamiento entre el conflicto postal y nuestro estudio. ¿Existió actividad represiva por parte del estado?, y en su caso ¿se puede reconocer la misma sistematicidad (matriz) represiva que se pudo relevar en la investigación?

En segundo término, analizaremos el caso de la CSJN relacionándolo para observar la respuesta del más alto tribunal de la república, sus consecuencias y su funcionalidad en relación del análisis que proponemos. 


\section{Registro del conflicto colectivo del Correo Oficial de la}

\section{República Argentina S.A. ${ }^{40}$}

Conflicto localizado. El conflicto laboral que motivara el fallo de la CSJN fue un conflicto localizado. En su principio fue un conflicto de actividad (englobaba a la totalidad de los gremios postales, y tuvo una extensión territorial nacional.) que se originó en un reclamo de naturaleza salarial. Pero con el acuerdo alcanzado entre sindicatos y la empresa, se desactiva su conflictividad y se dispara un conflicto particular acotado estrictamente a la planta Monte Grande.-

El Correo Oficial de la República Argentina S.A. es una de las cinco (5) empresas más grandes del estado nacional. No solo se encarga de garantizar el servicio postal en todo el territorio; también realiza la logística del proceso electoral y es responsable de pagar cientos de miles de jubilaciones y pensiones, además de los planes sociales, en todo el país. Tiene un plantel de aproximadamente dieciséis mil setecientos (16.700) trabajadores y mil seiscientos (1.600) sucursales.

Dentro de ese esquema de producción, el establecimiento más importante que posee la empresa, por sus dimensiones y su función estratégica, es la planta que tiene instalada en la localidad de Monte Grande. El establecimiento está destinado a la distribución postal y logística. Su paralización, virtualmente paraliza al servicio postal argentino. Si bien el trabajo fuerte "de la carta" ha caído (quizás irremediablemente por razones tecnológicas), el establecimiento se ha reconvertido en un operador logístico de dimensiones (comercialización a través de internet). El conflicto laboral que motivará el fallo de la CSJN ("Orellano"), tuvo lugar en este establecimiento.-

Ubicación temporal. El conflicto se extendió aproximadamente por tres (3) meses y medio; que transcurren desde principios de mayo del año 2009 hasta los primeros días de agosto del mismo año.

Las causas de las medidas de fuerza. Tanto este conflicto de mayo del 2009, como su antecedente inmediato ocurrido durante el año

40 Para la elaboración de este capítulo, se realizó relevamiento periodístico del conflicto, de artículos de doctrina que originaron, de la audiencia realizada ante la CSJN y se efectuaron entrevistas al actor y su abogado patrocinante en autos. 
2007, se originan en un reclamo salarial. Los sindicatos tenían la pretensión de obtener un aumento salarial del treinta por ciento (30\%).

Además de éste, existían otros dos (2) reclamos que solo se manifestaron en la planta Monte Grande. El primero, era lograr pasar el setenta por ciento $(70 \%)$ del sueldo a sumas bonificables (ya que no lo eran). Este pedido ya había sido reclamado en el conflicto de 2007, sin obtener respuesta favorable.

El otro reclamo que impulsaban los trabajadores en Monte Grande era la regularización de un enorme número de personal precarizado. Éste era un viejo conflicto del sector por los denominados "contratos basura". Con ese nombre se refieren los trabajadores postales a los contratos que se realizan a través de agencias de colocaciones o empresas de servicios eventuales; personal que es contratado por un plazo determinado de tiempo.

La inmensa mayoría de los trabajadores son conscientes que esas agencias someten sus decisiones sobre el ingreso y desvinculación del personal a la empresa de correo, solo a partir de la autorización o visado previo de la organizaciones sindicales y/o funcionarios de alto rango de la empresa postal. Si un trabajador falta mucho, o si es díscolo, o hace una huelga no dirigida por ASO, en el corto plazo quedará desvinculado de la empresa o no podrá ser recontratado. Las agencias de empleo que proveen trabajadores al Correo Argentino S.A. , operarían en la realidad a demanda de los intereses de empleadores y de los sindicatos del sector. Una buena parte de los trabajadores vinculan además, a estas agencias con las propias estructuras sindicales.-

La condición de precariedad en la que se encuentran los trabajadores contratados por estas agencias es notoria, aunque estos no participen en ninguna actividad gremial o política. Son trabajadores de segunda en la misma empresa. Desde el inicio del conflicto, los trabajadores en Monte Grande querían que ese personal contratado temporalmente, pase a planta.

A mediados de mayo del 2009 , la empresa y los sindicatos del sector llegan a un acuerdo, otorgando el aumento del treinta por ciento (30\%) peticionado, pero sin integrarlo el básico. Tampoco se resuelve favorablemente el pase a planta del personal contratado. A partir de este 
incordio, el conflicto se desactivará en el país y solo continuara en la planta de logística del sur bonaerense.

Representación sindical en el lugar de trabajo. En la actividad postason cuatro (4) las grandes organizaciones sindicales del sector (FOECOP Federación de Obreros y Empleados de Correo Oficial y Privados , AATRAC Asociación Argentina de Trabajadores de la Comunicación-, FEJEPROC-AJEPROC Asociación del Personal Jerárquico, Profesional y Técnico de la Secretaría de Estado de Comunicaciones, y FOECYT-SITRACYT Sindicato de Trabajadores de Correos y Telecomunicaciones). Conforman algunas de estas entidades un número importante de sindicatos de base que tienen personería gremial repartidos por todo el país. En la actualidad son ochenta y una (81) las asociaciones sindicales con representación. Las referidas organizaciones actúan coordinadamente a través un mismo ámbito (la "intersindical" del Correo Oficial de la República Argentina).

Los sindicatos son tan fuertes y monolíticos, y las estructuras oficialistas tan expandidas y celosamente reactivas a la aparición de nuevos actores gremiales que no permiten el crecimiento de ninguna fuerza sindical de oposición. Ni dentro, ni fuera de sus estructuras. En Monte Grande también se da esa realidad. Desde siempre todos los sindicatos de base en la planta van a elecciones con lista de unidad.

En cuanto a la representación sindical en el establecimiento, se conforma con delegados de dos (2) sindicatos (AATRAC y SITRACYT). Ambas organizaciones no tienen entre ellas disputa de representación ni confrontación alguna; ambas representaciones en el lugar de trabajo "caminan juntas"41.

Aparición de la disputa intrasindical. A principio de mayo de 2009 -momento del conflicto en todo el país- no había lista de oposición en la planta Monte Grande, ni siquiera en germen. A partir del descontento -de enormes dimensiones- que motivaba el reclamo y la disconformidad con el acuerdo alcanzado en la paritaria por el aumento salarial, se generó allí un brote de confrontación. El acuerdo alcanzado no desactivó el descontento (inusitado para el sector). La efervescencia no amainó, lo que configuró un

41 Daniel Orellano -el actor en autos- al momento del inicio del conflicto, estaba agremiado a ambas organizaciones sindicales, SITRACYT y ATRAC (a esta organización por los servicios de su Obra Social). 
estado asambleario creciente. Este estado despierta conscientemente en un grupo de trabajadores la decisión de intentar canalizarlo y conformar una organización que dispute la representación en la planta.

No será la primera vez que sucedía este intento. Se debe recordar que durante el conflicto del año 2007, se avizoró espasmódicamente un grupo de trabajadores que intentó amalgamar una suerte de oposición. El despido dispuesto por la empresa sobre algunos de estos trabajadores, más la presencia de la Gendarmería Nacional en ese conflicto antecedente, desarmó el intento en ciernes.

En mediados mayo de 2009 -cuando termina el conflicto para los sindicatos oficialistas- los trabajadores que decidirán la continuidad saben que no pueden construir esa organización dentro sus organizaciones. Por eso deciden buscar resguardo sindical en ATE (Asociación Trabajadores del Estado) y construir desde allí una oposición. Deciden ver si ATE puede entrar en la planta. Ésta es una asociación sindical que agrupa a trabajadores del estado, y siendo el Correo Oficial de la República Argentina una empresa estatal podía afiliarlos. No obstante, ATE no tiene personería gremial para el sector postal. ¿Por qué van a ATE?, porque ya han pensado y decidido armar un núcleo que les permitiera conformar una oposición; se evalúan las dificultades y entienden que tienen su única oportunidad de disputa "real" con ese encuadramiento ${ }^{42}$.

Decididos los trabajadores, se arma una comisión interna paralela y estos son los que llevan adelante medidas de fuerza (de creciente adhesión) para lograr las reivindicaciones no alcanzadas por los sindicatos postales en la negociación. Saben que junto a la suerte de esa lucha, correrá la suerte de lograr una organización en la planta.

\footnotetext{
${ }^{42}$ Generación de poder autónomo. Es importante señalar -y eso se constató en las entrevistas que se realizaron-, que se registra la existencia de lo que en estudio se individualizó como función de generación de poder autónomo en las representaciones sindicales en los lugares de trabajo. Esta tiene por objeto construir poder autónomo frente a la conducción de la organización sindical que integra. Claramente lo explicitaron los entrevistados. Los trabajadores vieron esa posibilidad, e intentaron construir ese poder. Son identificadas con las conductas independientes de la agrupación sindical paralela en el establecimiento. Allí liderará y confrontará con SITRACYT. Y coincidente con ello, -como en el estudio- solo ante la presencia de esta funcionalidad de las representación sindical en los lugares de trabajo, se evidencia la represión por parte del estado.
} 
La empresa y las ASO toman conciencia de la actuación de una organización en las sombra y a partir de ese momento se irá confeccionando una lista negra con los trabajadores que impulsan la oposición en la planta.

Medidas de acción directa. Intensidad. Liderazgos en el conflicto. Durante todo el tiempo de confrontación con la empresa, desde principios de mayo hasta mediados de junio, las medidas de fuerza llevadas a cabo por los trabajadores consistieron en la realización de asambleas durante cada turno de trabajo y la realización de trabajo a desgano. Como se puede observar, se registró el mismo repertorio de medidas de fuerzas, tanto cuando el conflicto es liderado por las ASO, como cuando es conducido por la incipiente ASD.

En el momento que la ASO desactiva la confrontación (con el acuerdo salarial) y pasa a ser conducido por la ASD, se profundizarán las medidas. El número de asambleas y su numerosidad, logran virtualmente la paralización de la planta. Se produce la saturación del predio, quedando en espera de distribución 6.000 .000 de piezas, que además perdieron el estándar de entrega y el consecuente perjuicio económico a la empresa. Los organización sindical paralela toma conciencia del poder de daño que puede generar solo en diez (10) días de confrontación limitando el ritmo de trabajo.

Ante este estado asambleario creciente, la empresa decide desactivar el movimiento de fuerza y abrupta y temporalmente lo logra. La empresa dirige una circular a los trabajadores por intermedio de los supervisores en la que se les recuerda a los trabajadores que estas asambleas están prohibidas por reglamentos internos de la empresa. En ese momento la empresa envía telegramas de desvinculación a personal que se encontraba contratado por agencia. $Y$ se registra además el primer momento de militarización de la planta para el 23 de mayo con la ocupación por parte de la Gendarmería Nacional. Los trabajadores, conscientes de las represalias y la ausencia del acompañamiento de las ASO, pulsan sus fuerzas, y como consecuencia de esa evaluación las MAD se dejan de hacer.

Este hecho de la represión de mediados de mayo es muy importante para tener en cuenta su similitud con el estudio. Aquí se observa con absoluta claridad como ante idénticas medidas de fuerza llevadas adelante 
por diferentes actores, la represión de las fuerzas de seguridad solo aparece cuando quién conduce el conflicto es una ASD.-

Para poder darle continuidad a la disputa, y ante las posibilidad cierta de nuevas represalias, la organización en las sombras decide formalizar el resguardo legal y sindical de ATE. Para ello deciden oficializar la representación sindical en la empresa llevando adelante la elección de delegados por esta entidad.

El 15 de Julio, contra viento y marea, se realiza la elección de los delegados de ATE. Una vez que cobra estado público esta decisión, el 15 de julio la empresa despide a las diez (10) personas de la planta que conformaban el núcleo impulsor de la agrupación disidente. Además, no dejará ingresar a los trabajadores y representantes sindicales al establecimiento. La elección se lleva a cabo igual en la puerta principal de acceso, en un colectivo parado frente al mismo. Con los despidos recibidos y la elección de Delegados, la organización sindical alcanza su mayor adhesión y fuerza. En ese momento se decide por parte de los trabajadores el bloqueo de la planta. Coincidente con este momento, como dos años antes y hacía más de un mes atrás, la gendarmería nacional ocupa con los integrantes de su fuerza la planta.

Durante un tiempo se mantuvo fuerte el movimiento de lucha, con bloqueos por parte de trabajadores del portón y manifestaciones de acompañamiento. Pero transcurridos 15 días (el 31 de Julio), concluirá la empresa su propósito y aprovechando la finalización periódica de los contratos por agencia y escusados en esa circunstancia formal, no le es renovado sus contratos a otros cincuenta (50) trabajadores. Se marcan y despiden a los trabajadores rebeldes y a estos se le suman empleados "carpeteros" y algunos pocos trabajadores excelentes que la empresa quería desvincular por razones de costos. Con esta barrida se da el golpe de gracia para desmantelar al grupo sindical disidente.

La organización de oposición tuvo su máxima fortaleza en el momento de los despidos. Con posterioridad a las desvinculaciones del 31/7 hubo manifestaciones periódicas, pero fue amenguando el acompañamiento en los portones, hasta perder su vitalidad. Con esa derrota y vencido ese tiempo, desaparece la organización opositora en ciernes. 
Los trabajadores recurrirán al poder judicial para restablecer el orden jurídico. Las actuaciones judiciales que se motivarán, no tendrán mayor incidencia en la protección del agrupamiento. La primer reinstalación de un trabajador despedido se obtendrá recién después de pasados dos (2) años de ocurridos los hechos. El actor de la demanda que llegará a la CSJN (Daniel Francisco Orellano), será reinstalado recién después de pasados cuatro (4) años de producido el conflicto (el 13 de julio del 2013). Una trabajadora recién fue reinstalada judicialmente durante el último trimestre del año 2018; y todavía queda una última trabajadora despedida que a la fecha de esta presentación no fue aún reinstalada.

Con las reinstalaciones no se recuperó la organización,ni mucho menos. Solo once (11) sobre sesenta (60) trabajadores despedidos intentaron judicialmente la reinstalación. La inmensa mayoría de los despedidos buscaron el pago de la indemnización y desvincularse de la empresa. Los pocos que, tardía y progresivamente volvieron, una vez reincorporados no pudieron reconstituir ningún tejido gremial. Los compañeros de trabajo los vieron a partir de su regreso como un ejemplo, y son respetados. Los jefes de los trabajadores -inclusive- los reconocen también como personas íntegras y buenos trabajadores (algunos de ellos se manifestaron de ese modo como testigos en los juicios). Pero de la organización que intentaron construir no quedó nada en pie.

\section{Constatación de la tesis en el caso "Orellano". Del} relevamiento efectuado se constatan las mismas características del caso tratado por la CSJN, que aquellas que sustenta la hipótesis de la tesis. Como guionadas se calcan en el conflicto postal las respuestas represivas de las fuerzas de seguridad hacia los trabajadores cuando son liderados por grupos díscolos de sus organizaciones. $Y$ en este sentido debemos destacar particularmente que en el conflicto del caso "Orellano" se pueden constatar la casi totalidad de las conclusiones a las que se arriba en el estudio teórico.

En primer término, y para despejar toda duda, diremos que en el caso se registra represión policial hacia un agrupamiento sindical disidente bajo las mismas y pormenorizadas condiciones que son individualizadas en el estudio. 
En el conflicto postal se constató que la represión policial estatal (RPE) hacia los agrupamientos sindicales solo se manifiesta cuando se reúne ese número cerrado de condiciones, a saber: se debe estar en presencia de conflicto localizado, debe existir una disputa intrasindical, debe encontrarse liderando el conflicto laboral la ASD, y por último debe manifestarse una alta intensidad de las medidas de acción llevadas a cabo.

Observando el caso "Orellano" se registra además el doble análisis que propone el estudio. Por un lado, se confirma la represión policial hacia el ASD solo bajo esas determinadas condiciones; y por otra parte, se confirmar que ante idénticas condiciones, si quien lidera el conflicto es una ASO, la represión no se produce.

Coincidentemente con la investigación se constata en el conflicto del Correo Argentino que, ante la ausencia de cualquiera de los elementos que conforman ese número cerrado de condiciones, no se produce la represión estatal.

Y complementariamente se constata también en el conflicto que, cuando el liderazgo del movimiento gremial lo lleva adelante el agrupamiento sindical oficialista (SITRACYT), el colectivo laboral no sufre la represión policial del estado en ningún caso.

Constatación de la caracterización de la represión analizada en la tesis, en el caso. En el caso del conflicto postal se releva un nivel elevadísimo -aunque selectivo y acotado en el tiempo- de acción represiva por parte de las fuerzas de seguridad. La planta Monte Grande fue literalmente ocupada en dos (2) oportunidades por fuerzas de la Gendarmería Nacional (casos de represión policial estatal disuasiva). La militarización siempre durará el tiempo que lleve desactivar la acción del grupo sindical disidente.

Se reitera en relación a estas dos (2) intervenciones de la fuerza estatal lo ya dicho; aquí se registra como,ante idénticas medidas de acción directa (asambleas informativas y trabajo a desgano) que son llevadas adelante por sucesivos y diferentes actores sindicales, la represión de las fuerzas de seguridad solo se manifiesta cuando quién conduce el conflicto es una ASD.

Como se afirma en la hipótesis, el uso de la fuerza policial se desembolsa en el momento de mayor intensidad de la acción sindical de los 
grupos disidentes. En el caso del conflicto postal, su propósito era evitar el aumento en la intensidad de medidas de acción directa (a través de una inminente toma del establecimiento).

La acción represiva el 23 de mayo y días subsiguientes se desata en el momento en el que las medidas de fuerza tienen una altísima adhesión y son elevadamente efectivas. Las asambleas y el trabajo a desgano (aunque aparentemente leves) producen en un breve tiempo un daño importante al empleador, resultando por ello altamente efectivas. Pero por otra parte las mismas tuvieron una adhesión creciente hasta su desactivación. La acción represiva en mayo se produce cuando las MAD han producido la sobresaturación de la planta (se acumula un número inconmensurable de envíos postales) y ante la inminente escalada de intensidad que se derivaría del conocimiento en el establecimiento logístico de los despidos dispuestos a parte de los operarios.

La acción represiva del 15 de julio y días subsiguiente, también se adoptará preventiva y coordinadamente con la empresa para garantizar la acción disuasiva y evitar la elevación del conflicto. La planta amanecerá nuevamente militarizada. En esa fecha, la Gendarmería Nacional ocupa el establecimiento en forma preventiva y coordinando con una decisión empresaria en vías de ejecución que elevará el nivel de agitación. Ese día la empresa dispone -y comunica- los diez (10) despidos de los trabajadores que conforman el núcleo básico de representantes no formales que impulsan las medidas de fuerza en la planta. Ese día además, la ocupación de GN pretende impedir que se lleve adelante la elección de delegados, que se termina efectivizando en un ómnibus en el portón principal. Los trabajadores bloquearán los portones de acceso desde ese día y por el breve tiempo que les permitió su precaria organización.

Características de la represión. La represión que aparece en el conflicto del establecimiento postal reúne también las mismas notas que se tipifican en el estudio (que son resumidas en el capítulo XVI). La misma tiene un grosero carácter selectivo (no difuso o indiscriminado), que se ejercerse sobre una agrupación sindical disidente ( $y$ en abierta lucha); un carácter duro o excesivo, por la tremenda intensidad de la medida (RDPE) ; un carácter doblemente sucio o ilegal, por el propósito discriminatorio que lo impulsa y por la naturaleza de su acción (ocupación militar de un 
establecimiento); y responde por su intensidad preventiva a los únicos casos de excepcionalidad del carácter reactivo expuestos en el Capítulo XVI.

3. El caso en la CSJN. Crítica. ¿Qué resuelve la CSJN en el caso Orellano? El máximo Tribunal resuelve un aspecto central sobre la titularidad del derecho a promover una huelga, restringiendo su ejercicio exclusivamente en favor de las asociaciones sindicales ("Que de todo 10 expuesto se sigue que la normativa federal examinada solamente confiere el derecho de declarar una huelga a las asociaciones profesionales"; conforme 15to. considerando).

Compartimos aquí las sólidas críticas que se le han realizado (Cornaglia, Ricardo: año 2016; Capón Filas, Rodolfo E. : 2016; García, Héctor Omar : 2016). El decisorio restringe grosera e inconstitucionalmente el derecho de huelga. En primer lugar, de su lectura se destaca la negación del derecho de huelga a los trabajadores como derecho individual de incidencia colectiva del que son titulares. La corte lo reconocerá como derecho colectivo exclusivo en cabeza de los sindicatos.-

Los sindicatos ya tienen reconocido este derecho colectivo, la doctrina y la jurisprudencia especializada son uniformes en ello. Pero esta aceptación no debe excluir del ejercicio de esta garantía vital a los trabajadores por sí mismos, como decide expresamente la CSJN.

Desde el momento de la asunción constitucional en nuestro país del derecho de huelga, se sostuvo este múltiple reconocimiento de titulares. Así lo plantearon distintos convencionales en 1957. Y dentro de la doctrina especializada laboral, se mantiene hasta hoy férreamente esta noción (Cornaglia, Ricardo J. : año 2006 , pág.122. ; Capón Filas, Rodolfo Ernesto: año 1989; pág. 417).

Con la reforma constitucional del año 1994, y el reconocimiento de los derechos de incidencia colectiva (arts. $42^{\circ}$ y $43^{\circ} \mathrm{CN}$ ), se refuerza conceptual y positivamente esta titularidad fuera de la estructura formal sindical. El derecho de huelga será -sin duda- un derecho de incidencia colectiva que podrá ser ejercido por los trabajadores (Gordillo, Agustín: año 2.000, pág. 23 ; Cornaglia, Ricardo J.: año 2006, pág.123 y siguientes).

Paradójicamente el fallo niega a los trabajadores ese ejercicio en forma directa, desconociendo que en su origen lo parieron los propios 
trabajadores antes que fueran reconocidos por el estado. Capón Filas recordaba irónicamente la esterilidad de este debate: "los niños siempre nacieron, con o sin comadrona, partera, ginecóloga: el Derecho del Trabajo nació porque la huelga lo generó. Todo lo demás, las largas discusiones, son meros juegos de abalorios"(Capón Filas ,Rodolfo: año 2016).

Son varias las razones que impiden excluir del ejercicio de este derecho a los trabajadores, con independencia de lo dispuesto por una organización formal que la declare. Entre ellas destacamos una cuestión de naturaleza óntica que así lo impone, son solo los trabajadores quienes a través de sus conductas los que plasman en la realidad una huelga (Cornaglia , Ricardo: año 2016).

La CSJN entiende inconstitucionalmente además que sin la existencia de una declaración formal de un sindicato (el titular legitimado), no puede ejercerse el derecho. En su lógica, la exigencia de esa declaración formal resulta previa y necesaria para que un colectivo de trabajadores decida una medida de fuerza.

No solo la realidad concreta le da la espalda a ese razonamiento; lo que resulta de gravedad para viciar al decisorio, es que esta restricción que exige la declaración formal de la huelga, se dispone sin que exista una norma positiva que la justifique. El fallo violenta así el principio de razonabilidad que nos ordena el artículo $28^{\circ}$ de la CN ("La Corte con su decisorio se constituyó en un legislador irrazonable. Además de burlar el principio republicano de la división de los poderes" (Cornaglia, Ricardo: año 2016).

Ya desarrollamos en otra parte de este trabajo, que nos encontramos frente a un instrumento de autotutela que el estado reconoce. Y esta es la garantía última que un trabajador tiene para defender su alimento y el de su familia. La exigencia de declaración por parte de un tercero resulta a todas luces arbitraria, tanto "como reglamentar la defensa propia en el derecho penal"(Cornaglia, Ricardo: año 2016).

4. Incidencia del fallo sobre el tema de tesis. La CSJN establece una doctrina que aspira a impedir el ejercicio del derecho de huelga a cualquier otro colectivo de trabajadores que no ostente la representación formal de una AS. 
Aunque debe advertirse que queda "mucha tela por cortar" detrás de este fallo, de la lectura de su texto no caben dudas de una cuestión central: todo agrupamiento de trabajadores que no responda a esta organicidad se encuentra vedado del derecho de declarar una huelga; y como consecuencia de ello, a ejercer ese derecho por sí.

En el caso que llega a la CSJN la restricción se refiere, particular y expresamente, a los "grupos informales de trabajadores". Sin embargo, los colectivos de trabajadores afectados con la limitación serán muchos más, reforzando así el carácter ya refractario de las monolíticas organizaciones sindicales en la Argentina.

Una digresión. En este punto debemos detenernos en una obligada digresión. ¿Sobre qué realidad se pretende aplicar el fallo? Palpablemente esta doctrina no puede aplicarse a la inmensa realidad que presupone nombrar. Sobre un universo de trabajadores con escasísima sindicalización, surge implícita la exigencia de sindicalización previa -que legitime- para ejercer el derecho de huelga.

A poco de analizar sus elementos concretos, se puede comprender que esta directriz del fallo solo puede proyectarse de un modo inevitablemente nocivo sobre la inmensa mayoría del universo de los trabajadores. Esta doctrina de la CSJN al aplicarse, terminaría negando el derecho de huelga a una porción enorme -ampliamente mayoritaria- del mundo sindical argentino.

El análisis de los datos concretos muestran esta inconsistencia. Para el período en que se desarrolla el estudio y en el que se desató el conflicto en el Correo Argentino S.A., la tasa de afiliación en la República Argentina que difundía el MTESS era escasamente del treinta y siete por ciento $(37 \%)$. Pero a poco que se analizan los parámetros que se utilizan para llegar a esa cifra, se corre el velo y podemos comprender la disminución del mismo llegando a niveles inimaginables. Algunos autores hablan de una tasa real de sindicalización que no superan el diez por ciento (10\%) de los trabajadores argentinos ${ }^{43}$.

${ }^{43}$ De acuerdo a los estudios que difunde el MTESS, la tasa media de sindicalización al 14.05.2013 era del 37\%. Pero el cruce de ésta afirmación con otros datos que genera el propio MTESS, nos encontraremos la falacia de esa afirmación. Según la cartera laboral el empleo no registrado, era del $34,60 \%$ en el último trimestre de 2012. Siendo así, ese $37 \%$ original al calcularse sobre el 
El universo de trabajadores sin sindicalización en Argentina es de tal magnitud, que no nos deja mayores dudas que los trabajadores no esperarán a que existan las organizaciones sindicales legitimadas para ejercer su derecho a huelga.

Efecto sobre las disputas internas gremiales. ¿Y qué efectos tiene la doctrina de la CSJN sobre las organizaciones sindicales existentes y la disputa intrasindical? Volviendo nuestro análisis al tema de tesis, debemos señalar que como consecuencia de esta doctrina jurisprudencial, carece de derecho a huelga la forma de organización primaria, natural y casi excluyente a la que recurren los trabajadores para instrumentar su libertad asociacional. Hablamos de los núcleos disidentes que se forman en el propio seno de la organización sindical que integran. En la práctica, la gran destinataria del chaleco de fuerza jurídico confeccionado por la CSJN será toda agrupación interna en disidencia con la conducción de las conducciones oficiales de las organizaciones, en tanto y en cuanto resulte minoritaria y estutariamente impedida para tal ejercicio (agregamos nosotros).

La incidencia sobre el tema de tesis es enorme. La CSJN deslegitima toda huelga "lanzada" en una disputa intrasindical, esas disputas en las que existe oposición a las conducciones y sin su acompañamiento. A partir de esta doctrina ¿quiénes serán aquellos que se arriesguen a impulsar o

$65,40 \%$ del total del universo, reduce la tasa real de sindicalización a un índice que no supera el $24,19 \%$. Y si a esto se añade que el cálculo se efectúa no sobre el $100 \%$ de las empresas sino apenas sobre un $40 \%$ de las mismas, ya que quedan afuera de la operación matemática las que empleen menos de 10 trabajadores (pues la encuesta de Indicadores Laborales (EIL), del MTESS estudia la sindicalización en empresas que empleen más de 10 trabajadores) y las ubicadas fuera de la zonas que releva.Los informes refieren solamente a parte del país : Gran Buenos Aires, Gran Córdoba, Gran Rosario, Gran Mendoza, Gran Tucumán, Gran Resistencia, Gran Santa Fe y Gran Paraná, no tomando en cuenta la Ciudad Autónoma de Buenos Aires, los Parques Industriales diseminados por el país entero y el resto del territorio nacional, incluidas las Islas Malvinas. Es decir, solo toman en cuenta apenas el $40 \%$ del mismo, ubicando a las restantes localidades y provincias en una verdadera zona de exclusión. La tasa de sindicalización media real es cercana al 09,67\%. La estadística no toma en cuenta además, a los trabajadores rurales (2.400.000, según el Censo de 2012) ni al personal de casas particulares (1.000.000, de acuerdo a registro relevado en esa época por la CTA).(Capón Filas, Rodolfo E. ; año 2016). 
acompañar un movimiento de lucha por afuera de las decisiones de las estructuras oficiales?

¿Qué función tiene entonces el fallo de la CSJN? Éste en la práctica, habilitará la persecución de aquellos trabajadores que se desvíen de ese sendero. La trascendencia que tiene sobre el mundo del trabajo y la producción, está dada por la importancia del actor institucional que la origina. El caso Orellano aspira a ser el ejemplo a seguir con los trabajadores desviados.

Bien se advierte que reducir el reconocimiento de la titularidad del derecho de huelga, exclusivamente a las asociaciones sindicales, "encubre una forma represora de la huelga" (RC). El fallo que se estudia, viene a perfeccionar el mecanismo represivo que se describe en la tesis, reforzando la estrategia predominante del estado (conforme Capítulo XIV , punto 7.) en expulsar las voces críticas del propio sistema. La voz sindical disidente deberá crecer, sabiendo que deberá sortear no solo la acción lesiva de autodefensa de los empleadores, la inacción lesiva de sus propias organizaciones, y la respuesta represiva de las fuerzas de seguridad del estado; sino que deberá saber que los acompañará y el silencio cómplice y expulsivo del poder judicial. 


\section{TRADICIONES EN QUE SE FUNDAMENTA EL ESTUDIO.}

Este estudio analiza los efectos negativos de la represión estatal, que obstaculizan la emersión como nuevo actor social a un agrupamiento sindical que disputa en conflictos desarrollados en el acotado ámbito de su lugar de trabajo.

1. Originalidad del estudio. En nuestro país, el estudio de los conflictos localizados, y la emersión de las nuevas representaciones sindicales solo ha sido objeto de tratamiento en estudios de caso. ${ }^{44}$ No se relevan estudios generalizados que permitan avanzar en una mayor comprensión sobre este tema.

Existen también trabajos que avanzan en el conocimiento de los conflictos localizados en la Argentina, pero dirigidos a saber cuáles son las causas que determinan la conflictividad en esta desagregación (Spaltemberg, Ricardo: 2012, p.105).

Este trabajo -entendemos-, tiene TRES (3) notas originales a considerar. En primer lugar, se analiza el universo total de casos posibles (no estudios de caso), observando los conflictos localizados, la represión estatal y su relación con la aparición de nuevos agrupamientos de representación de los trabajadores y trabajadoras;y haciéndolosobre una muestra de entidad.

Concordante con lo dicho en el párrafo anterior, y destacando la investigación, la segunda originalidad es que la muestra es sometida a un doble análisis; en primer término un examen cualitativo, y en segundo término, lo que no se han observado antecedentes en la materia de estudio, se somete la muestra a un análisis estadístico.-

44 Lotito, Diego y Ros Jonatan; "La lucha de KraftFoods. La emergencia del movimiento obrero argentino y la izquierda revolucionaria." Disponible en http://www.ft-ci.org/La-lucha-de-Kraft-Foods. Varela, Paula; "Rebeldía Fabril. Disponible en http://www.ips.org.ar/wpcontent/uploads/2011/03/Rebeld\%C3\%ADa-fabril.pdf Lenguita, Paula y Juan Montes Cató (2009), Resistencias laborales. Experiencias de repolitización del trabajo en Argentina, Insumisos, Buenos Aires.Lenguita, Paula (2011), "Revitalización desde lasbases del sindicalismo argentino", Revista Nueva Sociedad No 232, marzo-abril. 
Y la tercer originalidad se encuentra, en que el tema se aborda desde una perspectiva no explorada en un estudio de campo de este tipo, como es analizar la incidencia de la acción represiva del estado sobre los conflictos localizados, y su influencia en la aparición o no de nuevos liderazgos sindicales.

2. Tradiciones en que se sostiene el estudio. Podríamos tratar de ubicar el estudio en cualquiera del amplio margen de temas con los que se relaciona ${ }^{45}$, sin embargo el objeto central de nuestra mirada está puesta en la funcionalidad represiva de la acción del estado.

Esta investigación se ubica en la discusión sobre la función y naturaleza del estado, y su relación integradora o excluyente, con los diferentes grupos humanos que habitan su territorio. $Y$ en particular, la funcionalidad que construye con las voces críticas -los actores que impulsan su transformación-. Frente a esta funcionalidad, uno debe ubicar qué "rol" tienen los derechos humanos.-

3. Estado burocrático autoritario. En primer lugar, entendemos que se haya presente en esta observación, la actuación de una organización estatal particular dentro del orden capitalista, lo que O'Donnell ha caracterizado para nuestra historia política como estado burocrático autoritario (O'Donnell, G.: 1982).

"El estado burocrático autoritario, es un tipo de estado de una sociedad capitalista.(...) El estado capitalista es garante y organizador de las relaciones sociales capitalistas y, por lo tanto, de la dominación que ellas concretan. Esto implica que el Estado no es garante de la burguesía, sino del conjunto de la relación que establece a esta clase como clase dominante. No es, por lo tanto, un Estado de la burguesía: es un estado capitalista, lo cual no es exactamente lo mismo. Esto entraña que, en tanto

45 Es objeto de este estudio, conocer el resultado relacionando un número importante de variables, tales como la conflictividad laboral exclusivamente en los establecimientos productivos, la existencia de disputas intrasindicales, el liderazgo diferenciado entre distintos agrupamientos que intervienen en esos conflictos, la exteriorización de conductas autónomas de las organizaciones sindicales a las que pertenecen, la manifestación de conductas críticas al orden que debe conservar el estado, y el ejercicio de la represión por parte del estado. 
el Estado garantiza y organiza la vigencia de -principalmente- las relaciones sociales capitalistas, es garante y organizador de las clases que se enlazan en esa relación. Esto incluye a las clases dominadas, aunque su garantía de éstas sea en el sentido de reponerlas, o reproducirlas, como tales clases dominadas. Esto tiene algunas consecuencias importantes. Una de ellas es que, no pocas veces, el interés general de reproducción de dichas relaciones ( $y$, por lo tanto de las clases por ellas vinculadas) lleva al aparato estatal a desempeñar un papel custodial respecto de las clases dominadas, incluso en contra de demandas de la burguesía" (O 'Donnell, G.: 1982, pág.15/16).

4. Proceso de alienación y uniformidad social. $Y$ respondiendo a esta forma de organización social,nuestra observación coincide con lo afirmado por Enrique Dussel, en cuanto a la constatación de una matriz de conservación y reproducción del modelo socioeconómico sostenida sobre la base de la exclusión de los elementos críticos del sistema. El sistema, y el orden socioeconómico que lo instrumenta, solo permite la supervivencia de aquellos que le sirven, y de aquellos que lo reverencian. (Dussel, E.: 1985,pág. 114/5.).-

Esta constatación, exhibe la funcionalidad estatal que deben enfrentar los agrupamientos críticos del sistema. Dentro de esa funcionalidad, aparece un carácter selectivo -discriminatorio y excluyentehacia todo lo que no impulse sus modos de construcción. Todo agrupamiento crítico confronta con un sistema que tiende a seleccionar a sus propios herederos. (Bourdieu, P. y Passeron, J., 2003). Una selección, que además, excede la fuerza de voluntad de los propios seres humanos (Levinas, E.: 1993, pág.41-3) ${ }^{46}$. El capitalismo en este proceso

${ }^{46}$ Levinas explica por qué, esta circunstancia de reproducción se desarrolla aún sobre la propia voluntad de las personas que viven dentro del sistema. Emmanuel Levinas ha sostenido y descripto con dramática solidez desde una ontología deudora de Buber e inclusiva del otro, la imposibilidad que tiene el hombre arrojado a las fuerzas que juegan en nuestra sociedad, para torcer el rumbo que le impone al individuo la violencia y el dinero hasta lograr su sometimiento.: "El desacuerdo absoluto con una voluntad extraña no excluye el cumplimiento de sus designios.(...)La voluntad no contiene, entonces, toda la significación de su propio querer. En cuanto sujeto libre de este querer, existe como juguete de un destino que lo desborda.(...)Se trata de una alienación que nada debe a la historia sino que antes bien instituye la historia, es una alienación ontológica. $Y$ es al mismo tiempo la primer injusticia.(...)La limitación de la voluntad no es interior (la voluntad es en el hombre tan infinita como en dios), no reside en el 
de construcción mundial de su poder, ha ido afirmando de modo creciente un modelo de reproducción social de naturaleza excluyente.

Esta afirmación no es libresca, por el contrario es muy concreta. Aparece omnipresente tras las necesidades que nos acosan a diario, y en casi todos los ámbitos de nuestra vida. Los seres humanos nacemos a la vida severamente condicionados -en un tiempo y un espacio concreto- por el ordenamiento socioeconómico; condicionamientos que rondarán toda nuestra existencia. Y la inmensa mayoría de nuestros esfuerzos, serán casi exclusivamente destinados a servir y acrecentar al propio orden que lo condiciona. Un proceso en el que las necesidades y deseos de las personas para sobrevivir, son inhibidas y sustituidas por otras necesidades; aquellas necesidades -que permiten la supervivencia- del sistema. "Lo que acontece en el sistema capitalista es que existe una política de producción del deseo, que se funda en el proyecto del sistema, y que crea por la publicidad un deseo o necesidad colectiva: el mercado."(Dussel, E.: 1985,pág.150 ; Marcuse, H.: 1983, pág.29 y 92).Constituyendo así en ese esfuerzo, un proceso de alienación que es la matriz de su conservación. La necesidad de recrear al infinito la ganancia, los objetos que la producen y las instituciones que las sostiene, demandan y traccionan el devenir de la inmensa mayoría de la vida en sociedad.

Las razones que desnudan esta mecánica de sustitución de las necesidades y deseos de las personas por las necesidades del sistema que obligan a la supervivencia de quienes no acaten sus mandatos, son descriptas por GyörgyMárkus. El sistema va seleccionando a las conductas que lo reproducen. Aun cuando el argumento se presente a primera vista como simple, no pierde validez la sentenciosa verdad que cobija . "Mediante el trabajo nos apropiamos del mundo que nos rodea (...).Desde su

querer de la voluntad sino en su situación. En esta situación, en la que la voluntad sin abdicar en absoluto, recibe no obstante un sentido que le es ajeno (...).)La injusticia no se reduce a la ofensa a la voluntad que hiere su dignidad. La voluntad resulta maltratada, violentada, forzada hasta hacerle olvidar su para-sí, hasta hacerle sentir la potencia de la fuerza que la doblega.(...)Pero la violencia del acero deja escapar a la voluntad que pretende dominar. La verdadera violencia es la que conserva la voluntad que ha forzado. Su instrumento es el oro, y la violencia es la corrupción. Sin recurrir siquiera a la justicia, la vía de la violencia pacífica, de la explotación, de la muerte lenta, sustituye a la pasión de la guerra."(Levinas, E.: 1993, pág.41-43) 
naturaleza podemos ver la importancia de la base económica en la conformación del comportamiento social e individual.(...) Como afirma GyörgyMárkus, "cada acto singular de actividad humana supone la preexistencia de una necesidad determinante de la actividad. Pero en el proceso histórico total la relación se invierte (...) es el objeto producido por el hombre lo que origina la necesidad humana colectiva del mismo" (Herrera Flores, J.: 1989 pág.62).

5. Encrucijada para las voces críticas. Para los distintos sujetos y agrupamientos que viven en esta forma particular de organización de la sociedad, se les ofrece de modo perpetuo la opción del acatamiento o la exclusión.En ese lugar dificultoso, y frente a esa funcionalidad, se encontrarán los agrupamientos sindicales críticos, que portan el mandato transgeneracional de transformar la sociedad hacia formas más justas de acuerdo al interés de trabajadores y trabajadoras.

¿Qué pasará con las voces críticas?, las voces que no resulten dóciles o no acompañen este proceso. Dussel explicitará esta funcionalidad represiva del poder -desde su mirada filosófica-, ejercida dentro de un espacio concreto donde se desarrolla el modelo capitalista. Dentro de esa funcionalidad, aparece la imposibilidad de diálogo del modelo imperante. El orden dominante se autopercibe y actúa como único camino. "La lógica de la totalidad establece su discurso desde la identidad o fundamento hacia la diferencia. Es una lógica de la naturaleza o del totalitarismo. Es la lógica de la alienación de la exterioridad o de la cosificación de la alteridad, del otro hombre.(Dussel, E.: 1985, pág.54)

Aparecerá la imposibilidad de diálogo para quien es diferente, el otro. Pues el diálogo abre a la posibilidad del encuentro con lo otro, y ese encuentro es percibido como crisis o riesgo

¿Qué es el otro? Lo otro que el sistema ("El otro es la noción precisa con la que denominaremos la exterioridad en cuanto tal(...). El otro es alteridad de todo sistema posible, más allá de "lo mismo"(...)" (Dussel, E.: 1985 pág.55). Esa presencia del otro no reproduce el orden, por ello las dificultades para construir en el diálogo y en la pluralidad que tiene el sistema socioeconómico en el que vivimos. 
Aparece aquí la importancia de la otra voz, como punto de partida para la construcción de la realidad a partir de otros parámetros, que resultará inclusiva. Es el momento en que uno puede ver más allá de su propio horizonte de vida. Lo que se denomina como momento analéctico,indican el hecho real humano por el que todo hombre, todo grupo o pueblo, se sitúa siempre "más allá" (anó-) del horizonte que le impone su totalidad cerrada (Dussel, E.: 1985 pág.180).

La tendencia a la exclusión. Esta fuerza excluyente de lo crítico, también es explicitada desde el campo de la sociología. En este trabajo se constata lo planteado por SydneyTarrow en cuanto a la existencia de "estrategias predominantes" para desactivar o fagocitar grupos no complacientes (Tarrow, S.: 1997, pág.169) y repicado por Della Porta, particularizándolo en la actividad represiva del estado (Della Porta, D.: 1996, pág.131) ${ }^{47}$.

Estaríamos frente a lo que se podría denominar una tendencia predominante del estado hacia la exclusión, y que en esta investigación se particulariza sobre agrupamientos críticos en el mundo sindical. Reafirmando desde este plano, la exclusión que responde a las funcionalidades del EBA (O 'Donnell, G.: 1982).

6. El rol de los derechos humanos. Pero, ¿dónde aparecerán en lo concreto las posibilidades de su transformación hacia condiciones más valiosas? En respuesta a esta pregunta, debemos señalar que paralelamente a esta funcionalidad expulsiva y con tendencia a la uniformidad totalitaria, existe otra que responde a la necesidad de emersión de los agrupamientos críticos del sistema capitalista. Aparecerán aquí los derechos humanos y su por qué, y la confrontación con esa lógica.

En orden a esa directriz, compartimos el naturaleza intrínseca, que en los derechos humanos reconoce AgnesHeller.La autora, entiende a los derechos humanos como "necesidades radicales";"necesidades que el

\footnotetext{
47"Resumiendo, tanto las instituciones como la cultura política crean un conjunto de oportunidades y de límites bastantes estables, en el que se encuadra la represión policial. (...) lo que nuestra descripción parece sugerir es que las tradiciones históricas o las estrategias nacionales ejercen una gran influencia sobre la represión policial de la protesta". (Della Porta, D.: 1996, pág.131).
} 
sistema capitalista no tiene más remedio que reconocer para su reproducción, pero de imposible satisfacción dentro de sus esquemas" (Herrera Flores, J.: 1989 . pág.87).

Como afirma esta autora "(...) nacen en la sociedad capitalista como consecuencia del desarrollo de la sociedad civil, pero que no pueden ser satisfechas dentro de los límites de la misma. Por lo tanto, las necesidades radicales son factores de superación de la sociedad capitalista. (...)"(Heller, A.: 1996, pág.28).

Los derechos humanos, y el estado de conciencia ética universal que -conllevan y- los impulsa; los han tornado elementos indigeribles, pero además inmanejables. Un caballo de Troya abandonado en la playa. En esa calidad, y en ese estado de conciencia deben ser tutelados. Las voces no deben ser calladas. En el caso de observación, el derecho humano a la protesta que portan los agrupamientos disidentes debe ser protegido.

Que la exigencia de derechos surja de aquellos que se encuentran bajo condiciones de debilidad, no hace más que confirmar -teóricamentela necesidad de protección. Bien lo enseña LuiggiFerrajoli,"Los derechos fundamentales se afirman siempre como leyes del más débil en alternativa a la ley del más fuerte que regía y regiría en su ausencia .La historia del constitucionalismo es la historia de esta progresiva ampliación de la esfera pública de los derechos. Una historia no teórica, sino social y política, dado que ninguno de estos derechos cayó del cielo sino que todos fueron conquistados mediante rupturas institucionales: las grandes revoluciones americana y francesa, los movimientos decimonónicos por los estatutos, y, en fin, las luchas obreras, feministas, pacifistas y ecologistas de este siglo" (Ferrajoli, L.: 1997, pág.54). En similar parecer, Michael Ignatieff, lo sostiene cuando afirma que "...la prueba de la legitimidad de los derechos humanos es su aceptación por parte de los que están abajo, por lo débiles" (Ignatieff, M.: 2003, pág.92).

La trascendencia del diálogo para la transformación del sistema. Frente al riesgo que el orden socioeconómico imperante, en su tendencia hacia la uniformidad, impulse la desaparición de la pluralidad de voces críticas; el diálogo y la diversidad (el otro y la potencialidad de sus derechos en ciernes), aparecen como arma transformadora del orden creado en la sociedad capitalista. 
No debemos perder -ni naturalizar- la pérdida de ninguna voz. En una sociedad democrática, todas las voces deben ser oídas. Nos sustentamos en ese encuentro, porque ese es un espacio irreductible de existencia humana. Nuestra existencia como seres humanos no es aislada, la experiencia fundacional de la existencia humana es de modo inevitable una coexistencia. Sobre esta construcción dialéctica nos descubrimos seres humanos.

Debemos aportar esfuerzos en la construcción de una sociedad que respete ese encuentro, lo que categorizaba Buber como "humanidad real". "En todos los niveles de la sociedad humana, en cambio, en alguna medida las personas se confirman unas a otras y de manera práctica en sus cualidades y capacidades, y se puede llamar humana a una sociedad en tanto sus miembros se confirman recíprocamente.(...)El hombre, en cuanto tal, distancia e independiza al hombre, deja que otros hombres como él vivan a su alrededor, y así puede, él y solo él, entrar en relación con sus semejantes siendo quien es. El fundamento de la coexistencia entre hombres es doble y uno a la vez: el deseo que cada uno tiene de ser confirmado por otros hombres como lo que es y como lo que puede llegar a ser, y la capacidad innata que posee de confirmar precisamente así a sus congéneres. Que esta capacidad sea tan inconmensurablemente improductiva hace a la auténtica debilidad y cuestionabilidad del género humano: solo hay humanidad real cuando se desarrolla dicha capacidad" (Buber, M.: 2004, pág.139).

De la defensa irrestricta de esta coexistencia y la semilla de humanidad que encierra surge el imperativo ético con el que podamos construir una sociedad mejor. La COIDH en varias oportunidades ha destacado el carácter inseparable de los derechos sindicales, de su condición de expresión de voces de la sociedad. ${ }^{48}$

${ }^{48}$ Caso Baena: El artículo 16.1 de la Convención comprende el "derecho a asociarse libremente con fines ideológicos, religiosos, políticos, económicos, laborales, sociales, culturales, deportivos o de cualquier otra índole". Estos términos establecen literalmente que quienes están bajo la protección de la Convención tienen no sólo el derecho y la libertad de asociarse libremente con otras personas, sin intervención de las autoridades públicas que limiten o entorpezcan el ejercicio del respectivo derecho, lo que representa, por lo tanto, un derecho de cada individuo. Además, gozan del derecho y la libertad de buscar la realización común de un fin lícito, sin presiones o intromisiones que puedan alterar o desnaturalizar su 
7. El derecho a huelga y el respeto de la otra voz. Se destaca en el cuidado de esas voces, el respeto hacia el derecho de huelga como forma de garantizar los derechos en conflicto. Frente al enfrentamiento y disputa que exhibe un conflicto laboral, se debe superar la trampa de comprender al ejercicio de un derecho que resulta fundamental para la conservación y plena vigencia de una democracia, con una manifestación anormal. Bien enseña Capón Filas en relación la necesidad de expulsar a este prejuicio y sus consecuencias nefastas de la sociedad civil . "(...)Se enerva el derecho de huelga y se penaliza su ejercicio, sin resolver las injusticias estructurales que funcionan como causa eficiente." (Capón Filas, R.: 1989, pág. 415).

La respuesta debe ser otra.Compartimos la mirada de Ricardo Cornaglia: "El derecho de huelga es un derecho natural del hombre en el campo del trabajo, como lo es el de resistencia a la opresión en el campo político, (...) es evidente que la huelga implica el rompimiento con el orden establecido, que como tal, tiene la pretensión de ser un orden justo, y no olvidemos que la exclusión del recurso a la fuerza es el fin de toda organización social(...)." (Cornaglia, R.: 2006, pág.91). La respuesta podría ser vista como la oportunidad que da toda crisis.

Roberto Gargarela, aporta una observación que refuerza esta afirmación. Un punto de vista trascendental para observar las manifestaciones de un conflicto social, es la "intersección de derecho y

finalidad (Cfr. CasoBaena Ricardo y otros. Sentencia de 2 de febrero de 2001. Serie C. No. 72 , párrs. 156 y 159.).

Caso HuilcaTecse:"70. En su dimensión individual, la libertad de asociación, en materia laboral, no se agota con el reconocimiento teórico del derecho a formar sindicatos, sino que comprende además, inseparablemente, el derecho a utilizar cualquier medio apropiado para ejercer esa libertad. Cuando la Convención proclama que la libertad de asociación comprende el derecho de asociarse libremente con fines "de cualquier [...] índole", está subrayando que la libertad para asociarse y la persecución de ciertos fines colectivos son indivisibles, de modo que una restricción de las posibilidades de asociarse representa directamente, y en la misma medida, un límite al derecho de la colectividad de alcanzar los fines que se proponga. De ahí la importancia de la adecuación con la Convención del régimen legal aplicable a los sindicatos y de las acciones del Estado, o que ocurran con tolerancia de éste, que pudieran hacer inoperante este derecho en la práctica. 71. En su dimensión social la libertad de asociación es un medio que permite a los integrantes de un grupo o colectividad laboral alcanzar determinados fines en conjunto y beneficiarse de los mismos. 72. Las dos dimensiones mencionadas (supra párrs. 69, 70 y 71) de la libertad de asociación deben ser garantizadas simultáneamente, sin perjuicio de las restricciones permitidas en el inciso 2 del artículo 16 de la Convención" 
democracia". De cómo pensamos la democracia, dependerá la reacción frente a una protesta; en nuestro caso la huelga, una forma de protesta al fin.

A poco que se reflexione, se puede comprender el valor destacado que tiene una huelga como instrumento que potencie miradas críticas al sistema. Vivimos en una democracia representativa, y en este sistema "/a única alternativa con la que cuentan los ciudadanos para cambiar el rumbo de las cosas es la de protestar y quejarse frente a las autoridades. Si se socava dicha posibilidad, la democracia representativa se convierte en una oligarquía o una plutocracia, es decir la democracia llega a su fin." (Gargarella, R.: 2005, pág.60). "De allí que una democracia, aún modesta, no solo no puede darse el lujo de perder ciertas voces críticas, sino que más bien, y por el contrario, debe hacer todo lo posible para potenciar a cada una de ellas". (Gargarella, R.: 2005, pág.60). No estamos en una democracia directa, sino representativa. Debemos dotar a esta última de sentido.

Aparece así la importancia que porta el derecho de huelga en una sociedad democrática. "(S)i los derechos, en general, merecen una protección especial frente a otro tipo de intereses generales, ciertos derechos en particular -como la libertad de expresión- merecen una sobreprotección, aún dentro del área especialmente protegida en la que se encuentran (el área de los derechos). Este tipo de derechos o "superderechos" resultan merecedores de la máxima protección judicial, fundamentalmente, dada su proximidad con el nervio democrático. De allí que en lugar de ser vistos -como a veces ocurre en nuestra justicia- como "otros" derechos en juego, los últimos a recortar o desplazar en el balance de derechos e intereses que se realice" (Gargarella, R.: 2005, pág.74).La huelga reviste ostensiblemente su cercanía a ese "nervio democrático" del que habla el autor. La libertad sindical es protegida y promovida universalmente, porque sus manifestaciones son elementos democratizadores de la sociedad y socializadores del poder.

El Tribunal Europeo de Derechos Humanos tiene similar mirada en esta cuestión: "El Estado debe garantizar que las personas puedan ejercer libremente su libertad sindical sin temor de que serán sujetos a violencia alguna, de lo contrario, se podría disminuir la capacidad de las agrupaciones 
de organizarse para la protección de sus intereses". ${ }^{49} \mathrm{Y}$ con esas voces, los derechos por nacer. Lo que Mauricio Birgin enseñaba hace 30 años: "Puede decirse que existe un uso arraigado de la práctica de ocupación del lugar de trabajo y otras formas, que puede llevar a preguntarnos si no hay en ellas un uso creador de derechos y por lo tanto también puede decirse "un derecho de ocupación de los lugares de trabajo en trance de nacer" (Birgin, M.: 1988,pág.272).

${ }^{49}$ Cfr. Eur. Court H.R.Plattform "Ärztefür das Leben" v Austria, supra nota 17, párr. 32. 


\section{PROPUESTA JURIDICA. CONDUCTA TRANSFORMADORA.}

1 .Trascendencia del lugar de trabajo.O 'Donnell en su libro -ya clásico-, exhibe como uno de los particulares sustratos de la tipología del estado capitalista que estudia, "la actitud vigilante de las clases dominantes y la acción determinada del estado para impedir la autonomía de los sectores populares, sus organizaciones y su expresión política" (O 'Donnell, G.: 1982). Esta nota y esta funcionalidad del estado, no debe escapar de nuestro pensamiento al momento de evaluar, el control y el uso de la fuerza que aquel ejerce sobre conductas "críticas" de los trabajadores y trabajadoras en el espacio que se sabe vulnerable para el sistema capitalista, como es hoy un establecimiento de producción.-

Si solo a través de la constancia y la decisión política de un agrupamiento crítico de trabajadores y trabajadoras, se generan las condiciones para hacerse oír, y de ese modo hacer que ese espacio deje de ser volátil por un tiempo y permita la expresión grupal. Si la aparición de esa voz diferente, es valorada positivamente por el orden jurídico (casos Baena, HuilcaTecse).Entonces, el estado debe llevar adelante las acciones y omisiones necesarias que permitan esa aparición. El lugar del nacimiento de derechos (el lugar de trabajo), no debe ser entendido por los funcionarios estatales como un ámbito contaminado que debe ser sanado. Por el contrario, por aquel preciso motivo, ese ámbito debe ser percibido por el estado con mayor respeto hacia la aparición de conductas críticas al orden constituido.

La sociedad civil y los estamentos estatales, deben ser concientes que la intervención de la fuerza del estado en un establecimiento en el que se está llevando adelante un conflicto, es un lugar para prestar mayor atención y respeto hacia las conductas y los sujetos que las portan. Allí están naciendo los nuevos derechos.

El objeto de este trabajo analiza un recorte a la realidad desde el plano sociológico; pero además analiza ese recorte desde una perspectiva jurídica. En orden a esta perspectiva, dado el análisis efectuado en el 
recorte tempo-espacial de este trabajo, la constatación de los incumplimientos convencionales por parte del estado nacional, y lo disvalioso de su vigencia, cabe proponer una respuesta jurídica apegada a derecho, lo que -repitiendo a autores- mencionamos como una conducta transformadora del sistema.

¿Qué sería una conducta transformadora? (Capón Filas, R.: 1992, pág.48) Una respuesta valiosa de los operadores del sistema; una respuesta que se adecue al control constitucional y convencional. Esta conducta, deberá implementar la idea fuerza que nace de esta investigación; en la que se respete el ejercicio del derecho de huelga en los lugares de trabajo, sin discriminación, para la totalidad de los trabajadores.

La conducta transformadora, debe tener por norte impedir esta acción lesiva y discriminadora del estado.

2. Propuesta jurídica.La conducta transformadora a proponer, debe ser conducente a dar cumplimiento a las obligaciones que el estado ha asumido y resultan derivadas de los instrumentos suscriptos en el marco del sistema universal y regional de derechos humanos.

Sin perjuicio de entender que las formas de solución de este conflicto jurídico pueden ser vastísimas, se proponen las siguientes respuestas, que no reportan gastos para el erario público, y se concretan a través de un mínimo redireccionamiento de los recursos que ya se emplean.

1. Una iniciativa legislativa que garantice el deber de respeto por parte del estado en relación al ejercicio del derecho de huelga para los trabajadores y trabajadoras en su lugar de trabajo. El mismo debe ser inclusivo de la prohibición expresa de acciones represivas de orden preventivo que impidan de modo total el ejercicio del derecho de huelga (obra como Anexo).

2. Implementación en el ámbito del MTESS de la Nación, de medidas que hagan efectiva la obligación de vigilancia efectiva. Para ello se propone un protocolo de actuación para la detección y seguimiento de conflictos laborales localizados, que tome intervención e impida la concreción y mantenimiento de conductas discriminatorias -entre ellas represivas- por parte del estado. 
3. En forma complementaria se recuerda la obligación de confeccionar un plan de acción que garantice la erradicación de esta práctica institucional ilegal que se mantiene oculta. 


\section{BIBLIOGRAFIA.}

Abramovich, Víctor y Courtis, Christian; "Hacia la exigibilidad de los derechos económicos, sociales y culturales. Estándares internacionales y criterios de aplicación ante los tribunales locales; en "Curso Básico Autoformativo sobre Derechos Económicos, Sociales y Culturales", del Instituto Interamericano de Derechos Humanos. Original en Ediciones del Puerto, Buenos Aires, 1997.-

Abramovich, Víctor y Courtis, Christian; "El umbral de la ciudadanía. Significado de los derechos sociales en el estado social constitucional"; Editores del Puerto S.R.L., Buenos Aires, año 2006.

Basualdo, Victoria; "Los delegados y las comisiones internas en la historia argentina: 1943-2007", en "La industria y el sindicalismo de base en la Argentina", Editorial Atuel, Buenos Aires, año 2010.

Basualdo, Victoria; "Los delegados y las comisiones internas en la historia argentina. Una mirada de largo plazo, desde sus orígenes hasta la actualidad" .Ebert-Dgd-Cta-Fetia, Buenos Aires, Año 2008.Disponible en https://lostrabajadoresenargentina.files.wordpress.com/2013/09/basualdovictoria-sobre-ci.pdf

Birgin, Mauricio: "El derecho de huelga. Otras medidas de acción directa. Citando a Maurice Cohen. Ed. Sociales, París, 1980. Separata de la Revista Derecho Laboral no 11, año 1988.

Bourdieu, Pierre y Passeron, Jean-Claude; Editorial Siglo XXI,
México,
2003. https://socioeducacion.files.wordpress.com/2011/05/bourdieu-pierr-losherederos.pdf

Brunette, Ignasi y Pizzi, Alejandro. La acción colectiva desde la Teoría de la movilización de recursos. Sociedad y Utopía. Revista de Ciencias Sociales no 36. Noviembre de 2010 (pp.27-38). Disponible en http://www.sociedadyutopia.es/index.php/temas/article/69-la-accioncolectiva-desde-la-teoria-de-la-movilizacion-de-recursos

Buber, Martín; "El camino del hombre"; Editorial Altamira, Serie Pensamiento Judaico, año 2004.

Capón Filas, Rodolfo Ernesto; "Derecho Laboral", Librería Editora Platense, Primera edición, La Plata, año 1979.

Capón Filas, Rodolfo Ernesto; "Tratado del derecho del trabajo", Librería Editora Platense, Primera edición, La Plata, 2014 
Capón Filas, Rodolfo Ernesto; "El nuevo derecho sindical argentino", Librería Editora Platense, Primera edición, La Plata, 1989.

Capón Filas, Rodolfo Ernesto; "El nuevo derecho sindical argentino", Librería Editora Platense, Tercera edición, La Plata, 2008.

Capón Filas ,Rodolfo ; "Titularidad del derecho de huelga. Comentario al caso CS Recurso de Hecho "Orellano, Francisco Daniel c/ Correo Oficial de la República Argentina S.A. S/ juicio sumarísimo"; Publicación Digital, EFT, Buenos Aires, Año 2016).

Capón Filas, Rodolfo Ernesto; "Síntesis de la Concepción Sistémica del Derecho Laboral", Editorial LEUKA, Buenos Aires, año 1992.

Ceruso, Diego; "La izquierda y la organización sindical en el lugar de trabajo, 1920-1940"; en "ARCHIVOS de historia del movimiento obrero y la izquierda, no 1", Buenos Aires, Año 2013. Disponible en PDF http://www.archivosrevista.com.ar.ca1.toservers.com/contenido/wpcontent/uploads/2013/07/Ceruso.pdf

Colina, C. L., \& Roldán, P. L. (1991). El análisis de componentes principales: aplicación al análisis de datos secundarios. Papers: revista de sociologia, (37) $31-63$.

Cornaglia, Ricardo J.; Derecho de huelga. Derecho colectivo de trabajo"; Editorial La Ley, 1ra. Edición, Buenos Aires, año 2006.-

Cornaglia, Ricardo J.; Derecho Sindical. Derecho colectivo de trabajo"; Editorial La Ley, 1ra. Edición, Buenos Aires, año 2004.-

Cornaglia , Ricardo "La titularidad del derecho de Huelga. Las incoherencias de la Corte en la doctrina sentada en el fallo "Orellano" ; Publicado en Doctrina Laboral y Previsional. Errepar. No. 371, julio del 2016.

Corte, Néstor; "El modelo sindical argentino. Régimen legal de las asociaciones sindicales.", RubinzalCulzoni . Editores, Segunda edición actualizada ; año 1994

Corte Interamericana de Derechos Humanos. Caso Baena Ricardo y otros vs. Panamá; y Caso HuilcaTecse vs. Perú.

Corte Suprema de Justicia de la Nación ;"ATE c. Ministerio de Trabajo Empleo y Seguridad Social de la Nación", A. No 201, L. XL.

Corte Suprema de Justicia de la Nación ; "Recurso de hecho deducido por la demandada en la causa Orellano, Francisco Daniel c./ Correo Oficial de la República Argentina S.A. s./ juicio sumarísimo".

Corte Suprema de Justicia de la Nación ; Audiencia pública https://www.youtube.com/watch?v=x2PE34a8p6s 
CENDA - Centro de Estudios para el Desarrollo Argentino (2010) "La anatomía del nuevo patrón de crecimiento y la encrucijada actual. La economía argentina en el período 2002 - 2010", Editorial Atuel, Buenos Aires.

Central de Trabajadores Argentinos (CTA) 2010: "Informes anuales de conflictividad laboral" (2005-2010). Disponibles en: http://www.cta.org.ar/base/rubrique214.html

Cremonte , Matías (2015 ) ; "La titularidad del derecho de huelga" , publicado en temas de derecho laboral , Noviembre de 2015 , ERREPAR , Buenos Aires , pág. 23/34. Disponible en http://palabrade.cl/latitularidaddelderechodehuelga.html

Crisci, J. V., \& Armengol, M. F. L. (1983). Introducción a la teoría y práctica de la taxonomía numérica (No. 57.06 CRI). Washington: OEA

Della Porta, Donnatella (1996); "Movimientos sociales y Estado: algunas ideas en torno a la represión policial de la protesta"; en "Movimientos sociales. Perspectivas comparadas. Oportunidades políticas, estructuras de movilización y marcos interpretativos culturales". Editorial Istmo. Disponible en http://books.google.com.ar/books?id=erRNPI8WwwC\&pg =PA100\&lpg=PA100\&dq=della +porta +movilizaciones +soci ales+estado+represion\&source =bl\&ots =F08KWYURVU\&sig=RAoOM6pTOkS Kegb2pLpxFunbgbY\&hl=es\&sa $=$ X\&ei $=$ nUtOVKSnMM7FggSwmYKICA\&ved $=0$ CB0Q6AEwAA\#v=onepage \&q=della\%20porta\%20movilizaciones $\% 20$ sociale s\%20estado\%20represion $\& f=$ false

Dobarro, Viviana M., en "La huelga en los servicios esenciales", en Revista Doctrina Laboral,t. XV, nro. 193, ps.776 y siguientes, Ed. Errepar, Buenos Aires, Septiembre de 2001, año XVII.

Dussel, Enrique; "Filosofía de la Liberación", Ediciones La Aurora, Tercera Edición Buenos Aires 1985.

Etchemendy, Sebastián. (2011); "El sindicalismo argentino: la complejidad de un actor clave" en El modelo sindical en debate. Disponible en: http://library.fes.de/pdffiles/bueros/argentinien/08423.pdf

Etzioni, Amitai; "La sociedad activa. Una Teoría de los procesos societales y políticos"; Editorial Aguilar; Madrid, año 1980, pág. 257.

Fernández Madrid, Juan Carlos; "Tratado Práctico de Derecho del Trabajo", Terceras edición, Editorial La Ley . Buenos Aires, 2007

Ferrajoli, Luigi; "Derechos y Garantías", Ed.Trotta, Madrid 1997.-

Frenkel, Roberto y Damill, Mario; "La economía argentina bajo los Kirchner: una historia de dos lustros" (Trabajo preparado en diciembre de 2013 como capítulo del libro Peruzzotti E. y C. Gervasoni (editores.): "La Década Kirchnerista", Buenos Aires, Editorial Sudamericana). Disponible en PDF FRENKEL Economía Kirchnerista 91_2013 
García , Héctor Omar: "¿Quiénes son titulares del derecho de huelga?" (Sobre la doctrina sentada por la Corte Suprema en la causa "Orellano c. Correo Oficial de la República Argentina" y las inconsistencias de sus fundamentos). ; Publicado en DT, Año LXXVI, Nº 07, julio 2016, pp. 1532/154 Buenos Aires.

Gargarella, Roberto; "El derecho a la protesta.El primer derecho"; 1ra. Edición; Editorial Ad-Hoc; Buenos Aires, año 2005.-

Gilly, Adolfo; "La anormalidad Argentina. Estado, Corporaciones, Trabajadores"; en "El estado en América Latina. Teoría y práctica" (Pablo González Casanova. Coordinador); Editorial Siglo XXI - Universidad de las Naciones Unidas, México, año 1990. https://books.google.com.ar/books?id=Np1LkHW290YC\&pg=PA187\&lpg=PA $187 \& d q=$ la + anomal\%C3\%ADa +argentina + gilly\&source =bl\&ots =zAdfKn3yk M\&sig=JgdMpGHGb7Hyv3WRxLsOvIZe9s\&hl=es\&sa =X\&ved=0ahUKEwjBtamf6P7JAhVGGZAKHXY9ByUQ6A EIGzAA\#v=onepage\&q=la\%20anomal\%C3\%ADa\%20argentina\%20gilly\&f=t $\underline{\text { rue }}$

González Callejas, Eduardo; "La represión estatal como proceso de violencia política". HISPANIA NOVA. Revista de Historia Contemporánea. $\begin{array}{llll}\text { Número } & 10 & \text { (2012). } & \text { Disponible }\end{array}$ hispanianova.rediris.es/10/dossier/10d001.pdf .

Gordillo, Agustín; "Tratado de Derecho Administrativo. Tomo 2 , La defensa del usuário y del administrado", Cuarta Edición; Fundación de Derecho Administrativo, Buenos Aires, año 2.000.

Hair, J. F., Anderson, R. E., Tatham, R. L., \& Black, W. C. (1999). Análisis multivariante (Vol. 491). Madrid: Prentice Hall.

Heller, Agnes, "Una revisión de la teoría de las necesidades", Editorial Paidós, Barcelona, año 1996.

Herrera Flores, Joaquín; "Los derechos humanos desde la Escuela de Budapest", Fundación Cultural Enrique Luño Peña, 1989.

Ignatieff, Michael ; "Los derechos humanos como política e idolatría", Editorial Paidos Ibérica, año 2003.

Izquierdo, Roberto; "Los antecedentes norteamericanos de nuestro régimen de "Prácticas desleales", Revista Trabajo y Seguridad Social

Organización Internacional del Trabajo; "Libertad Sindical . Recopilación de decisiones y principios del Comité de Libertad Sindical del Consejo de Administración de la OIT". Quinta edición. Oficina Internacional del trabajo. Ginebra, 2006 
La Nación (2009); "Acuerdo salarial para trabajadores del Correo Argentino, HYPERLINK "https://www.lanacion.com.ar/1156233-por-unconflicto-gremial-empleados-del-correo-argentino-cortaron-la-riccheri Copyright (c) LA NACION

lacolectiva.org.ar (2009); "Sin respuestas para los despedidos de Correo Argentino" , HYPERLINK "http://lacolectiva.org.ar/panoramacolectivo-25-07-

2009/index.php?option=com_docman\&task=doc_download\&gid=277" It "_self" \o "Panorama Colectivo - 25-07-2009"

La izquierda diario (2016) ; Lecturas del fallo de la Corte Suprema contra el derecho a huelgahttps://www.laizquierdadiario.com.ve/Lecturasdel-fallo-de-la-Corte-Suprema-contra-el-derecho-a-huelga

La izquierda diario (2016) ; "El fallo de la Corte es un claro golpe contra los trabajadores"

La izquierda diario (2016) (2016) ; "Los titulares del derecho de huelga son los trabajadores"

Lenguita, Paula y Juan Montes Cató (2009), Resistencias laborales. Experiencias de repolitización del trabajo en Argentina, Insumisos, Buenos Aires.

Lenguita, Paula (2011), "Revitalización desde lasbases del sindicalismo argentino", Revista Nueva SociedadNo 232, marzo-abril.

Levinas, Emmanuel; "El yo y la totalidad", compilado en "Entre Nosotros.Ensayos para pensar en otros.", Ed.Pre-Textos, 1993, Valencia.-

Lotito, Diego y Ros Jonatan; "La lucha de KraftFoods. La emergencia del movimiento obrero argentino y la izquierda revolucionaria." Disponible en http://www.ft-ci.org/La-lucha-de-Kraft-Foods.

Longo, Julieta (2011); "Conflictos laborales en la posconvertibilidad: una aproximación a partir de fuentes periodísticas". Disponible en PDF http://www.ungs.edu.ar/ms ici/wp-content/uploads/2012/11/gt2 mesa2 Longo.pdf 1983.

Marcuse, Herbert, "Eros y civilización", Ed. SARPE, Madris, año

Ministerio de Trabajo Empleo y Seguridad Social de la Nación (2008) "Un nuevo indicador del Ministerio de Trabajo Empleo y Seguridad Social. Los conflictos laborales en la Argentina 2006-2007" Disponible en PDF http://www.trabajo.gob.ar/left/estadisticas/descargas/conlab/NuevoIndicad ordeConflictividadLaboral2007.pdf

Monzón, Máximo D., "El régimen de las asociaciones profesionales de trabajadores según la ley 20.615", Revista Derecho del Trabajo, 1974. 
O'Donnell, Guillermo; "El estado burocrático autoritario. Triunfos, derrotas y crisis"; Editorial Belgrano, Buenos Aires, 1982.

Oslender, Ulrico; "Espacio, lugar y movimientos sociales: Hacia una espacialidad de resistencia"; Scripta Nova, Revista Electrónica de Geografía y ciencias sociales, Universidad de Barcelona. Vol. VI, núm. 115, 1 de Junio de 2002.

Palomino, Héctor (2011); "¿Está preparado el sindicalismo argentino para un mundo global?" en El modelo sindical en debate. Disponible en: http://library.fes.de/pdffiles/bueros/argentinien/08423.pdf

Paredes, Juan-Pablo (2013); Movilizarse tiene sentido: Análisis cultural en el estudio de movilizaciones sociales". Publicado en ICSOUniversidad Diego Portales, Chile. Disponible en http://www.scielo.cl/scielo.php?script $=$ sci arttext\&pid $=$ S0718$\underline{69242013000200003}$

Pearson K. 1901. On lines and planes of closest fit to systems of points in space. The London, Edinburgh, and Dublin Philosophical Magazine and Journal of Science, 2(11): 559-572.

PTS Zona Norte GBA. Disponible en http://www.pts.org.ar/PTSZona-Norte-GBA

Página 12 (2009) , "Con el discurso de los patrones" ; disponible en HYPERLINK "https://www.pagina12.com.ar/diario/elpais/index-2016-0612.html"

Roldán, P. L. (1996). La construcción de tipologías: metodología de análisis. Papers: Revista de sociología, (48), 9-29. Disponible en https://www.researchgate.net/profile/Pedro Lopez-

Roldan/publication/39081335 La Construccion de Tipologias Metodologia de Analisis/links/00b4951b106ce16951000000/La-Construccion-de-

Tipologias-Metodologia-de-Analisis.pdf

Salvioli, Fabián: "La protección de los derechos económicos, sociales y culturales en el sistema interamericano de derechos humanos"; En Revista N 40; ed. Instituto Interamericano de Derechos Humanos; San José de Costa Rica, 2004.

Sampieri H. Metodología de la Investigación. sexta edición. Edit. Mc Graw Hill, 2014.

Sánchez Estellés, Isis; "La estructura de oportunidad política y su impacto en el movimiento español contra la guerra (2003-2004)". Publicado por University of Essex / Universidad de Castilla - La Mancha. Dsponible en www.fes-sociologia.com/files/congress/10/grupos-trabajo/.../109.pdf.

Santela, Agustín; "La representación sindical en la empresa. ¿Un concepto desactualizado?; en "El modelo sindical en debate", ASET Friedrich Ebert Stiftung Argentina, año 2011, P.13 
http://biblioteca.clacso.edu.ar/Argentina/iigg-

uba/20161115105144/Sindical.pdf

Spaltemberg, Ricardo (2012); "La diversidad de los conflictos laborales: dispersión y centralización en las lógicas de acción de los asalariados privados"; Publicación del Ministerio de Trabajo Empleo y Seguridad Social de la Nación.

Svampa, Marianela (2007); "Los avatares del sindicalismo argentino" en Le Monde Diplomatique, número 91

Tarrow, Sidney; "El poder en movimiento. Los movimientos sociales, la acción colectiva y la política". Editorial Alianza Universidad, Madrid, 1997. Disponible en PDF https://derechoalaciudadflacso.files.wordpress.com/2014/01/sidey-tarrowel-poder-en-movimiento-los-movimientos-sociales-la-accion-colectiva-y-lapolitica.pdf

Trajtemberg, David "Representación sindical en los lugares de trabajo: un análisis del Módulo de Relaciones Laborales; Ponencia en Jornadas de Sociología de la Universidad Nacional de La Plata, del 5 al 7 de Diciembre del 2012, y Publicado en Trabajo, Ocupación y Empleo, editada por el Ministerio de Trabajo, Empleo y Seguridad Social.

Triola, M. F. (2004). Probabilidad y estadística. Pearson educación.

Varela, Paula; "Rebeldía Fabril. Disponible en http://www.ips.org.ar/wp-content/uploads/2011/03/Rebeld\%C3\%ADafabril.pdf

Von Ihering, Rodolfo; "La lucha por el derecho", Biblioteca Virtual Universal, Año2002. Jersey.

Zar JH. 2010. Biostatistical Analysis. $5^{a}$ ed. Prentice Hall, New 


\section{INDICE.}

\begin{tabular}{|c|c|}
\hline I. Introducción. & Pág.1 \\
\hline $\begin{array}{l}\text { II. Escenario económico y conflictividad laboral en el período } \\
2007-2013 \text {. }\end{array}$ & Pág.5 \\
\hline 1.La economía durante el período 2007-2013. & Pág.5 \\
\hline 2.La conflictividad laboral durante el período (2007-2013). & Pág.7 \\
\hline III. Plan de Trabajo. & Pág.11 \\
\hline IV. Características del enfoque adoptado. & Pág.15 \\
\hline 1.Objeto de la investigación. & Pág.15 \\
\hline 2.La teoría de movilización de recursos. & Pág.16 \\
\hline 3.Las oportunidades políticas. & Pág.18 \\
\hline 4.La represión. & Pág.19 \\
\hline 5.Los repertorios de acción colectiva. & Pág.21 \\
\hline V. La representatividad. & Pág.23 \\
\hline 1.La disputa por la representatividad & Pág.23 \\
\hline 2.Representatividad y representación & Pág.24 \\
\hline $\begin{array}{l}\text { 3.El valor de la representatividad como paso insoslayable hacia el } \\
\text { reconocimiento del estado }\end{array}$ & Pág.25 \\
\hline 4.Disputas intersindicales e intrasindicales & Pág.26 \\
\hline 5.El estado mete la cola. & Pág.27 \\
\hline VI. La representación sindical en los lugares de trabajo. & Pág.30 \\
\hline 1.El interés por las Comisiones Internas. & Pág.30 \\
\hline $\begin{array}{l}\text { 2.La representación en los lugares de trabajo, rasgo propio del modelo } \\
\text { sindical argentino. }\end{array}$ & Pág.31 \\
\hline 3.Funciones de las representaciones en los lugares de trabajo & Pág.33 \\
\hline $\begin{array}{l}\text { 4.Tensión entre Sindicatos y representación sindical en los lugares de } \\
\text { trabajo. Un actor diferente en el movimiento obrero. }\end{array}$ & Pág.35 \\
\hline 5.Las comisiones internas como poder autónomo. & Pág.37 \\
\hline $\begin{array}{l}\text { VII. La incidencia del espacio en una disputa. La lucha sindical en } \\
\text { los establecimientos. }\end{array}$ & Pág.40 \\
\hline 1.El lugar de trabajo, la fragua de sueños. & Pág.40 \\
\hline 2.El lugar de trabajo como espacio político. & Pág.41 \\
\hline 3.El lugar de trabajo, como arena inexorable & Pág.44 \\
\hline 4.El lugar de la crisis de dominación celular & Pág.45 \\
\hline VIII. Los conflictos localizados. & Pág.49 \\
\hline 1.Conflicto Laboral y espacio. Clasificación de los conflictos. & Pág.49 \\
\hline 2.Conflictos industriales y localizados & Pág.49 \\
\hline 3.Conflictos localizados & Pág.51 \\
\hline IX. La trascendencia del der & Pág.53 \\
\hline
\end{tabular}




\begin{tabular}{|c|c|}
\hline y trabajadoras. & \\
\hline 1.La lucha & Pág.53 \\
\hline 2.La hiposuficiencia y su respuesta, la autonomía sectorial. & Pág.55 \\
\hline X. EI derecho de huelga. & Pág.57 \\
\hline 1. Libertad sindical. & Pág.57 \\
\hline 2.El derecho de huelga, su reconocimiento en el derecho positivo. & Pág.59 \\
\hline XI.Las medidas de fuerza como recursos. & Pág.61 \\
\hline 1.Los conflictos laborales en la teoría de movilización de recursos & Pág.61 \\
\hline 2.Complementación metodológica con fuente principal. & Pág.62 \\
\hline 3.Los conflictos laborales y la teoría de movilización de recursos. & Pág.63 \\
\hline $\begin{array}{l}\text { XII.La represión. La lucha por el poder, estado y contendientes no } \\
\text { reconocidos. }\end{array}$ & Pág.64 \\
\hline 1.La represión y los grupos insurgentes. & Pág.64 \\
\hline 2.Noción de represión. & Pág.65 \\
\hline 3. Factores que determinan las movilizaciones. & Pág.66 \\
\hline $\begin{array}{l}\text { 4.La acción represiva del estado como factor determinante de la acción } \\
\text { del grupo. }\end{array}$ & Pág.67 \\
\hline 5.Las consecuencias de la represión policial sobre las protestas. & Pág.68 \\
\hline XIII. Metodología de trabajo & Pág.70 \\
\hline 1.Esquema. & Pág.70 \\
\hline 2.Fuente del MTESS, y metodología de trabajo. & Pág.70 \\
\hline 3.La Matriz utilizada. & Pág.72 \\
\hline 4.La Fuente del Agrupamiento político sindical. & Pág.75 \\
\hline XIV. Resultados. Análisis cualitativo. & Pág.77 \\
\hline XV. Resultados. Análisis estadístico. & Pág.84 \\
\hline 1.Correlación entre variables. & Pág.84 \\
\hline $\begin{array}{l}\text { 2.Estructura de asociación entre variables: Análisis de Componentes } \\
\text { Principales (ACP) }\end{array}$ & Pág.85 \\
\hline 3. Resultados estadísticos .Análisis de correlación entre variables. & Pág.88 \\
\hline 4. Análisis de componentes principales sobre matriz de correlación. & Pág.88 \\
\hline XVI. Conclusiones. Plano sociológico. & Pág.101 \\
\hline $\begin{array}{l}\text { 1.Relación entre represión e integración o rechazo del actor no } \\
\text { reconocido. }\end{array}$ & Pág.101 \\
\hline 2. Características de la represión estatal. & Pág.102 \\
\hline 3.La represión tiene carácter selectivo. & Pág.103 \\
\hline 4.La represión tiene carácter ilegal. & Pág.105 \\
\hline $\begin{array}{l}\text { 5.La pérdida de resguardo constitucional de las acciones represivas del } \\
\text { estado. }\end{array}$ & Pág.109 \\
\hline 6.La represión dura y reactiva. & Pág.111 \\
\hline 7.Estrategia predominante del estado a reprimir agrupaciones sinc & Pág.113 \\
\hline
\end{tabular}




\begin{tabular}{|c|c|}
\hline disidentes. & \\
\hline XVII. Conclusiones. Plano jurídico. & Pág.116 \\
\hline 1.Estado y garantías extra-institucionales. & Pág.116 \\
\hline 2.Obligaciones del estado que generan los derechos sociales. & Pág.118 \\
\hline 3.Derecho de huelga, y el complejo de obligaciones que genera. & Pág.119 \\
\hline 4.Prohibición de toda discriminación. & Pág.120 \\
\hline 5.Obligación de adoptar medidas inmediatas. & Pág.121 \\
\hline 6.Obligación de garantizar niveles esenciales. & Pág.124 \\
\hline 7.Obligación de progresividad y prohibición de regresividad & Pág.125 \\
\hline $\begin{array}{l}\text { XVIII. Análisis del caso Orellano. Su proyección sobre el tema de } \\
\text { tesis. }\end{array}$ & Pág.127 \\
\hline $\begin{array}{l}\text { 1.Registro del conflicto colectivo del Correo Oficial de la República } \\
\text { Argentina S.A }\end{array}$ & Pág.129 \\
\hline 2. Constatación de la tesis en el caso "Orellano". & Pág.135 \\
\hline 3. El caso en la CSJN. Crítica. & Pág.138 \\
\hline 4. Incidencia del fallo sobre el tema de tesis. & Pág.140 \\
\hline XIX. Tradiciones en que se fundamenta el estudio. & Pág.142 \\
\hline 1.Originalidad del estudio. & Pág.142 \\
\hline 2.Tradiciones que lo sostienen. & Pág.144 \\
\hline 3.Estado burocrático autoritario. & Pág.144 \\
\hline 4.Proceso de alienación y uniformidad social. & Pág.145 \\
\hline 5.Encrucijada para las voces críticas. & Pág.147 \\
\hline 6.El rol de los derechos humanos. & Pág.148 \\
\hline 7.El derecho a huelga y el respeto de la otra voz. & Pág.150 \\
\hline XX.Propuesta jurídica. Conducta Transformadora. & Pág.154 \\
\hline 1.Trascendencia del lugar de trabajo. & Pág.154 \\
\hline 2.Propuesta jurídica & Pág.155 \\
\hline XXI. Bibliografía. & Pág.157 \\
\hline XXII. Índice. & Pág.165 \\
\hline Siglas. & Pág.168 \\
\hline ANEXOS & Pág.170 \\
\hline
\end{tabular}




\section{SIGLAS}

AATRAC:Asociación Argentina de Trabajadores de la Comunicación.APG: Asociación sindical con personería gremial.

APS: Agrupación Político Sindical.

AS: Asociación Sindical

ASD: Agrupamiento sindical disidente.

ASI: Asociación sindical simplemente inscripta.

ASO: Agrupamiento sindical oficialista.

ATE: Asociación Trabajadores del Estado.

CADH: Convención Americana de Derechos Humanos.

CDC: Crisis de dominación celular.

CSJN: Corte Suprema de Justicia de la Nación.

DADDH: Declaración Americana de los Derechos y Deberes del Hombre.

DUDH: Declaración Universal de Derechos Humanos.

EOP: Escuela de oportunidades políticas.

FEJEPROC-AJEPROC: Asociación del Personal Jerárquico, Profesional y Técnico de la Secretaría de Estado de Comunicaciones.

FOECOP:Federación de Obreros y Empleados de Correo Oficial y Privados.

FOECYT-SITRACYT:Sindicato de Trabajadores de Correos y

Telecomunicaciones

GN: Gendarmería Nacional.

MAD: Medidas de acción directa.

MSA: Modelo sindical argentino.

MTESS: Ministerio de Trabajo, Empleo, y Seguridad Social de la Nación.

O.G.: Observación General del Comité de DESC.

OIT: Organización Internacional del Trabajo.

PIDCP: Pacto Internacional de Derechos Civiles y Políticos.

PIDESC: Pacto Internacional de Derechos Económicos Sociales y Culturales.

RPE: Represión policial del estado.

RPED: Represión oficial estatal disuasiva.

TMR: Teoría de movilización de recursos. 


\section{ANEXOS}

\section{A) Proyecto de Ley.}

Artículo $1^{0}$ : Queda prohibida la intervención de miembros de las Fuerzas de Seguridad, tanto nacionales, provinciales, como de la Ciudad Autónoma de Buenos Aires, en todo conflicto colectivo laboral que se manifieste en un lugar de trabajo, con la sola excepción que se prescribe en el artículo $3^{\circ}$ de la presente ley.-

Artículo 20: Se entenderán como lugares de trabajo a los efectos de la presente ley, a todos los establecimientos o dependencias laborales, y sus accesos, donde los trabajadores y trabajadoras desempeñan sus tareas cualquiera sea la función o denominación que le asigne el empleador, y sea este un sujeto de naturaleza pública o privada.-

Artículo 30: Solo se podrá ordenar la intervención de miembros de las fuerzas de seguridad mencionadas en el artículo $1^{\circ}$ en el lugar de trabajo, por resolución dictada por Juez competente, en los siguientes casos:

1)en el supuesto en que exista riesgo de vida o salud de las personas, debidamente constatado y por el tiempo que se mantenga esa situación de riesgo; y

2) cuando la medida tenga por objeto, remover al personal de seguridad privada, que a instancia del empleador, obstaculice o impida el ejercicio del derecho de huelga o de los derechos derivados del principio de la libertad sindical. -

ARTICUlO 40: El Poder Ejecutivo determinará quien resulta autoridad aplicación a los efectos del cumplimiento de la presente ley.- 
Artículo 5: La reglamentación deberá determinar las atribuciones y competencias, para la aplicación y control en el cumplimiento de la presente ley.-

La reglamentación deberá establecer el protocolo de actuación de las fuerzas de seguridad referidas en el artículo $2^{\circ}$, de tal modo que se garantice la no afectación del ejercicio de la libertad sindical en el lugar de trabajo garantizada por la presente ley.-

Artículo $6^{\circ}$. Invítese a las provincias y a la ciudad Autónoma de Buenos Aires a adherirse a la presente ley.

Artículo 70. Comuníquese.-

\section{B) Soporte magnético.}

Obran en soporte magnético: 1) DOS (2) planillas excels que contienenlas matrices de entrecruzamiento de datos; 2) CIENTO SESENTA Y CUATRO (164) archivos word que detallan las características de cada conflicto analizado; 3) DIECIOCHO (18) archivos Word que contiene cada uno de ellos los link que registran la fuente del registración de datos de la APS.

\section{C) Planillas Excels (soporte papel)}

DOS (2) planillas excels en papel, que contienenlas matrices de entrecruzamiento de datos 